\title{
Promoting Success
}

\section{A Getting To Outcomes ${ }^{\circledast}$ Guide to Implementing Continuous Quality Improvement for Community Service Organizations}

Sarah B. Hunter, Patricia A. Ebener, Matthew Chinman, Allison J. Ober, Christina Y. Huang 
For more information on this publication, visit www.rand.org/t/tl179

Published by the RAND Corporation, Santa Monica, Calif.

(C) Copyright 2015 RAND Corporation

RAND $^{\circledR}$ is a registered trademark.

\section{Limited Print and Electronic Distribution Rights}

This document and trademark(s) contained herein are protected by law. This representation of RAND intellectual property is provided for noncommercial use only. Unauthorized posting of this publication online is prohibited. Permission is given to duplicate this document for personal use only, as long as it is unaltered and complete. Permission is required from RAND to reproduce, or reuse in another form, any of its research documents for commercial use. For information on reprint and linking permissions, please visit www.rand.org/pubs/permissions.html.

The RAND Corporation is a research organization that develops solutions to public policy challenges to help make communities throughout the world safer and more secure, healthier and more prosperous. RAND is nonprofit, nonpartisan, and committed to the public interest.

RAND's publications do not necessarily reflect the opinions of its research clients and sponsors.

Support RAND

Make a tax-deductible charitable contribution at www.rand.org/giving/contribute

www.rand.org 


\section{Preface}

Promoting Success: A Getting To Outcomes ${ }^{\circledR}$ Guide to Implementing Continuous Quality Improvement for Community Service Organizations offers practical steps for conducting continuous quality improvement (CQI) in community service organizations (CSOs). CQI is a performance improvement process that prescribes planned, formal, systematic, and ongoing changes to improve program delivery and outcomes.

Many traditional CQI practices may be challenging to undertake in CSOs, such as the use of easily accessible data. This guide, created in collaboration with a CSO addressing substance use with additional input from a number of other CSOs that provide different types of services, provides tools that are of specific relevance to CSOs, such as for addressing outreach and referrals, admissions, service delivery, and outcomes aspects of a CSO program. This guide is suitable for executives, managers, and supervisory staff of CSOs interested in program improvement and for others who support the work of CSOs (e.g., policymakers, funders, evaluators, and program consultants).

This guide is in a "do-it-yourself" format. After a brief overview, (Chapter 1), the guide presents the historical context of the CQI movement and its application to CSOs (Chapter 2). Each chapter that follows contains steps for implementing CQI, along with tips and practical examples. Some chapters provide checklists to facilitate the CQI process and the appendixes contain blank, pull-out worksheets. A detailed glossary provides definitions of CQI terms used throughout the guide.

The CQI process detailed in this guide is based on a broader program management tool called Getting To Outcomes $®$ (GTO). GTO is designed to help practitioners better plan, implement, evaluate, improve, and sustain programs (see Appendix A). CQI is the improvement aspect of the GTO tool. Several GTO publications can be downloaded for free from the RAND website:

http://www.rand.org/health/projects/getting-to-outcomes.html. The GTO model has been applied to many community service programs, including teenage pregnancy prevention programs, services for homeless veterans, and early childhood social services. 


\section{CONTENTS}

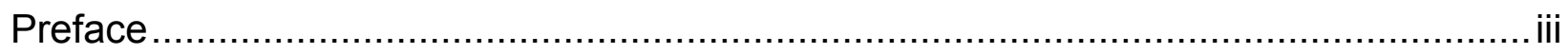

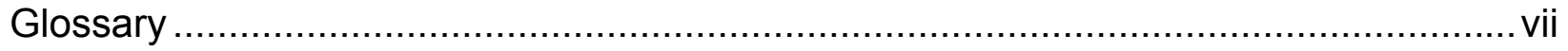

Summary

Chapter 1: Introduction: Why Use This Guide? ................................................... 1

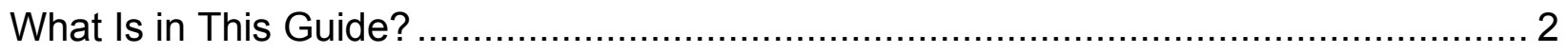

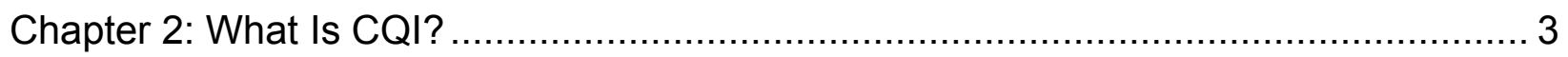

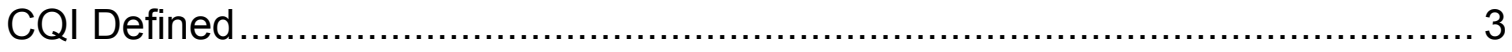

The Historical Origins of CQI .............................................................. 3

Applying CQI to Community Service Organizations ……............................ 5

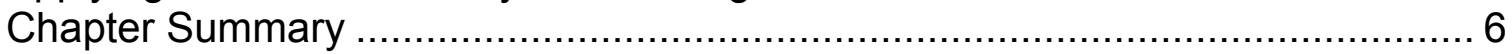

Chapter 3: CQI Step 1: Preparing to Conduct CQI..................................................... 7

The Importance of Practicing CQI for Community Service Organizations ............ 7

Build Support for Quality Improvement in Your Organization ........................... 8

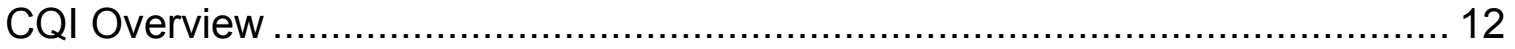

Chapter Summary …............................................................................ 13

Chapter 4: CQI Step 2: Plan: Gather Data to Inform CQI Efforts ............................... 14

Who Should Be Involved? .................................................................. 14

Which Worksheet to Use? ..................................................................... 14

The Delivery Worksheet (DW)—Worksheet 1: Overview ................................ 17

Delivery Worksheet (DW) Summary ……............................................... 26

The Outcomes Worksheet (OW) —Worksheet 2: Overview ............................. 27

Outcomes Worksheet (OW) Summary ………........................................ 35

The Component Worksheet (CW)—Worksheet 3: Overview........................... 37

Component Worksheet (CW) Summary ………......................................... 49

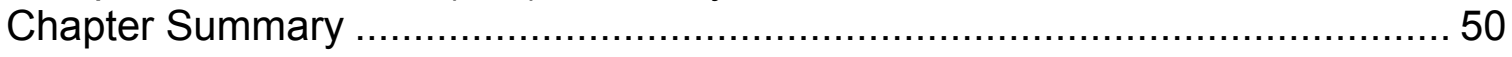

Chapter 5: CQI Step 3: Plan: Identifying a CQI Action .............................................. 51

Who Should Be Involved? ............................................................... 51

The CQI Action Identification Worksheet (CQI-AIW)-

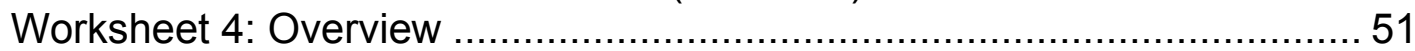

CQI-Action Identification Worksheet (CQI-AIW) Summary .............................. 57

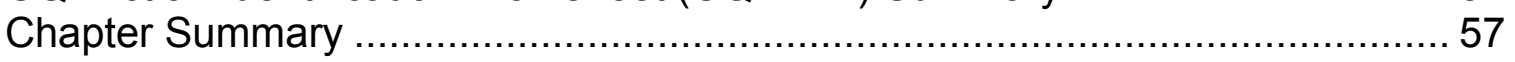

Chapter 6: CQI Step 4: Do and Study: Launching and Studying CQl's Effects on

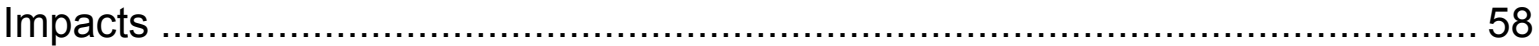

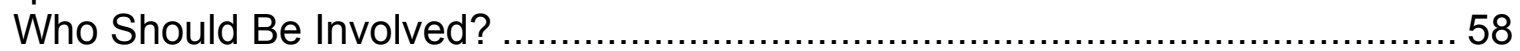

Launching CQI Worksheet-Worksheet 5: Overview ................................... 58

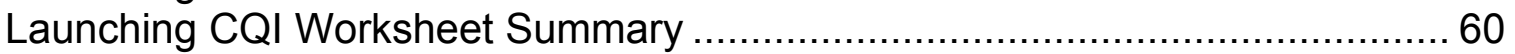

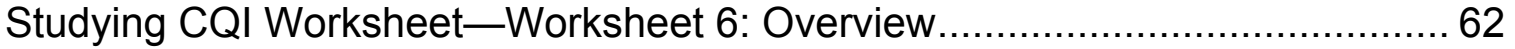

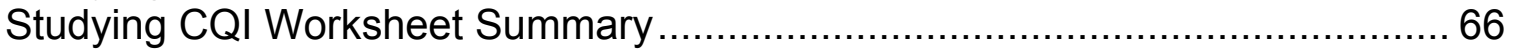

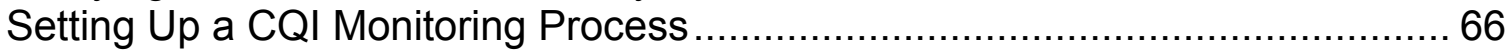

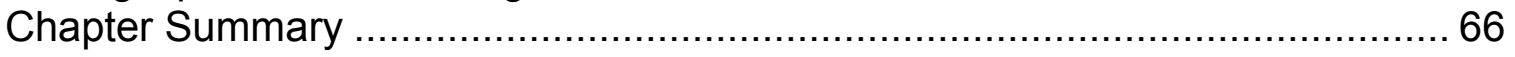




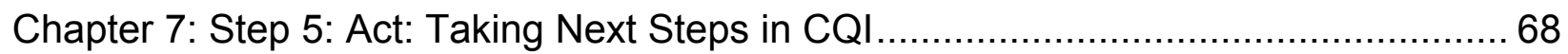

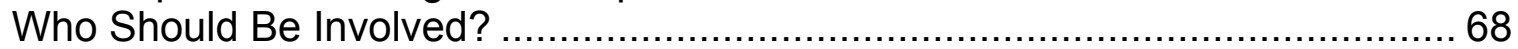

The Next Steps in CQI Worksheet—Worksheet 7: Overview ..........................68 68

Next Steps in CQI Worksheet Summary ................................................... 73

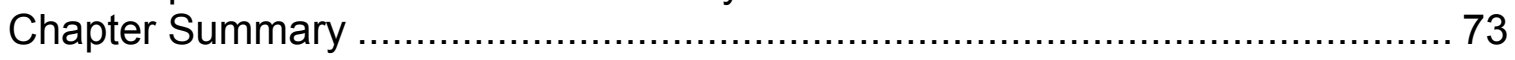

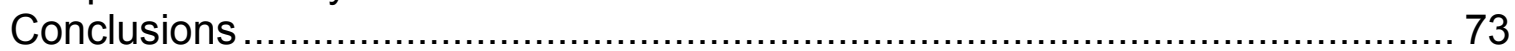

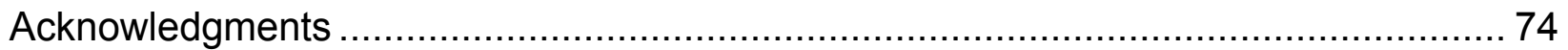

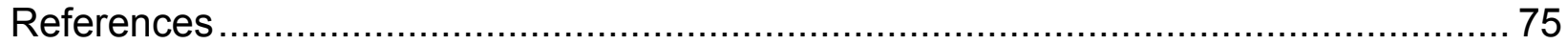

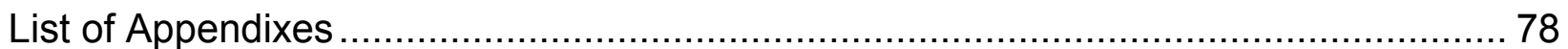

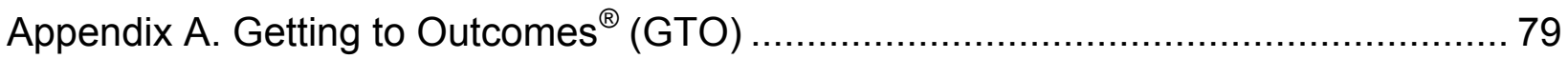

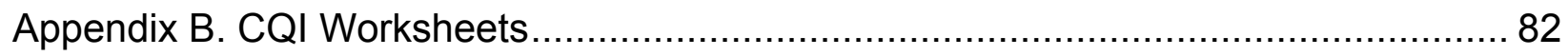

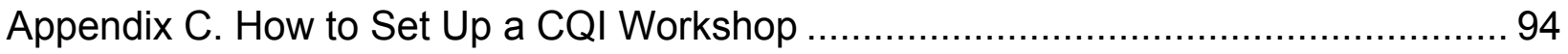

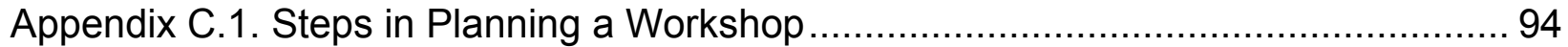

Appendix C.2. Example Presentation Materials for Workshop

Welcome/Introduction by the CSO Leader ................................................... 100

Appendix C.3. Example Presentation Materials for the GTO and CQI Descriptions ... 107

Appendix C.4. Example Presentation Materials and Handouts for

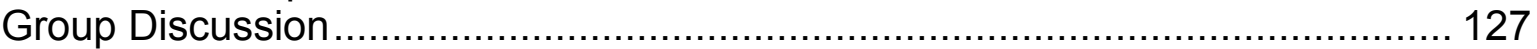

Appendix C.5. Example Event Feedback Form ................................................. 131

Appendix C.6. Post-Workshop CQI Activities ....................................................... 133 


\section{Examples}

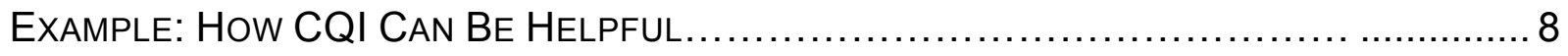

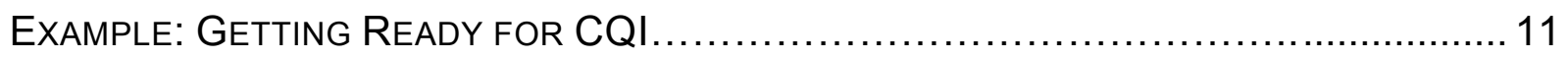

EXAmple: Program Delivery ObJective............................................... 17

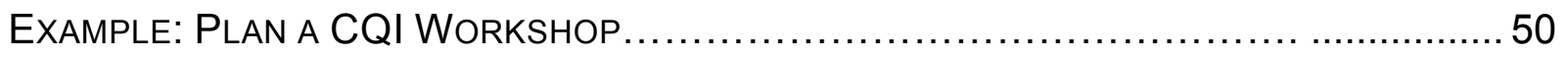

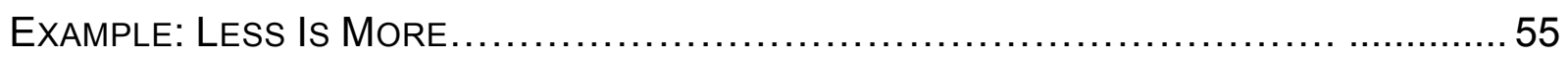

EXAMPLE: FIgURING OUT WHAT ACCOUNTED FOR YOUR CQI IMPACT ...................... 70

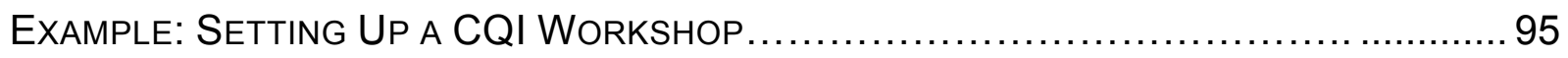

EXAMPLE: RUNNING THE CQI WORKSHOP............................................. 97

\section{Tips}

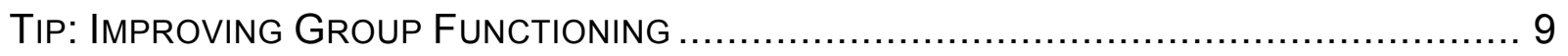

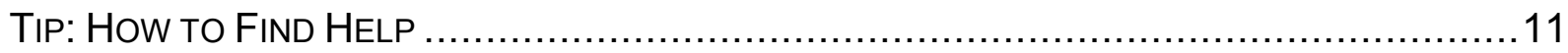

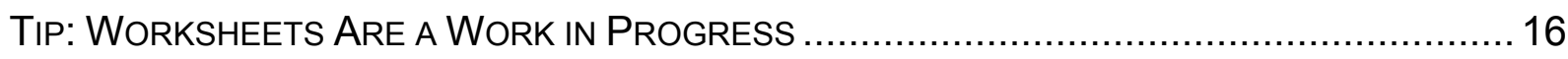

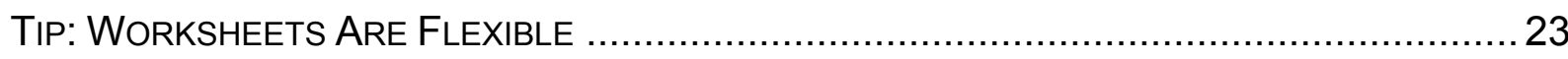

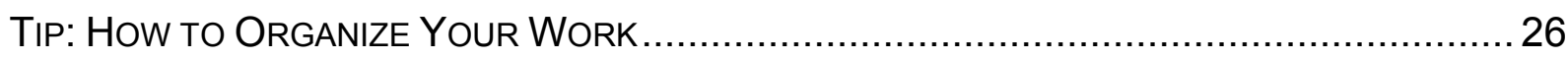

TIP: How to Document Your Program OUtCome OBJECTIVES ................................. 28

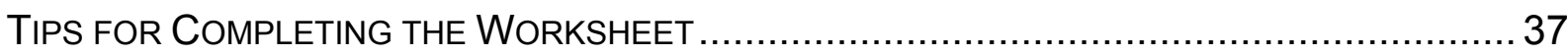

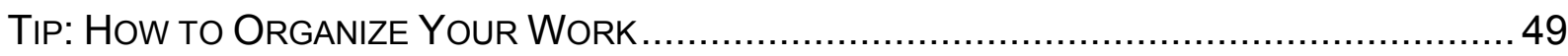

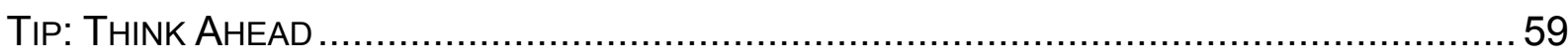

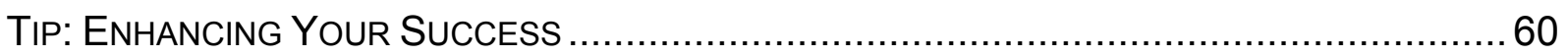




\section{Glossary}

Capacity: The capability or resources to perform a service may include such things as staffing, skills, training, and facilities.

Community service organizations (CSOs): Community-based entities that provide social services, such as health, mental health, substance abuse, education, and employment assistance.

Continuous quality improvement (CQI): A planned, systematic, and ongoing process of initiating, monitoring, and evaluating changes with the goal to improve outcomes (Shortell, Bennett \& Byck, 1998; see also Total Quality Management).

CQI Action: A quality improvement initiative that an organization decides to undertake to improve its program.

Empowerment evaluation: An approach to gathering, analyzing, and using data about a program that involves key stakeholders and promotes evaluation as a strategy for empowering communities to engage in system changes (Fetterman, Kaftarian, \& Wandersman, 2015).

Evidence-based program: A program that is supported by documentation showing that it has been effectively implemented in the past, and multiple times, in a manner attentive to scientific standards of evidence and with results that show a consistent pattern or credible and positive effects.

Evidence-based practices and principles: Practices and principles that have been demonstrated to achieve the desired outcomes. Such guidelines may be determined through peer-reviewed research, professional associations, regulatory mandates, or expert panel reviews.

Fidelity: The degree to which a program or service is delivered in line with the developer's intentions, such that "high" fidelity refers to strong adherence to the developer's version of the program or service.

Getting To Outcomes ${ }^{\circledR}$ (GTO): A user-friendly, 10-step, logically organized process for planning, implementing, evaluating, and continuously improving community-based programs and community initiatives.

Government Performance and Results Act of 1993 (Pub.L. 103-62): Governmental mandate to shift accountability efforts from measuring the process (e.g., activities undertaken) to focus more on the results (e.g., gains in employability, safety, responsiveness, or program quality). The act requires federal agencies to develop strategic plans, performance measures, annual performance plans, and performance reporting.

Institute for Healthcare Improvement (IHI): A nonprofit organization that works to motivate improvement in health care organizations like hospitals and medical clinics (Kenney, 2008). 
Ishikawa diagram (also known as fishbone diagram or cause-and-effect diagram): Used to show the relationship between factors in an organization that influence processes and outcomes. It is a tool designed to help quality circles in quality improvement. Ishikawa thought it was critical that these diagrams be constructed using an open group communication format. The diagrams are useful as tools for finding, sorting, and documenting causes in variation in quality and the mutual relationships between them.

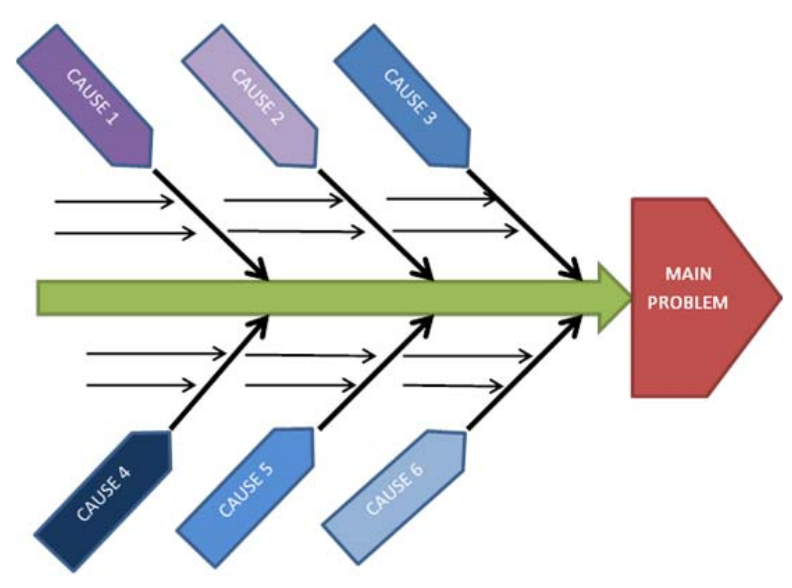

Multifunctional, multidivisional teams: A group formed from individuals that work in different departments of an organization, e.g., a group consisting of staff from upper management, finance, admissions, and the clinical service departments.

Outcomes: The results from program service delivery. It may be conveyed by changes in individual knowledge, attitudes, or behaviors or community-level changes, such as changes in community awareness, policies, or actions (e.g., collaboration among agencies). For example, program outcomes may be pregnancy rates among teenage girls in a given county or among girls receiving a given set of services.

Plan-Do-Study-Act or PDSA: A structured, cyclical process for developing and implementing change. Plan means to collect and analyze data and develop solutions; do means to implement one of the proposed solutions; study is to measure any changes as the result of the proposed solution that was implemented; act is to adopt the solution or standard practice, or start over.

Performance indicators: Also known among many variations as benchmarks, quality measures, and performance measures. Performance indicators refer to measures that tell one about the quality of the process or output (in the case of CSOs, service) being delivered.

Process and outcome indicators: Process indicators measure various aspects of the services delivered in an organization-including outputs. Outcome indicators measure the result of the process, such as severity of symptoms or mortality rates.

Program accountability: The systemic inclusion of critical elements of planning, implementation, and evaluation into a program in order to achieve results.

Program delivery objectives: The service goals of a program. For example, program delivery objectives may be the number served by a program or the amount of program delivered. (See also Outputs.)

Program funding: The source of support for the program. For example, a program may be supported through funding from a local, regional, state, or national organization or through client-generated fees. A funder may specify for whom the program should serve (e.g., Medicaid-eligible clients).

Program outcome objectives: The expected results or outcomes of a program. 
Quality: The extent to which health services increase the likelihood of desired health outcomes and are consistent with current professional knowledge (evidence-based practices) (Institute of Medicine, 2001).

Quality circles: Groups composed of workers and supervisors who meet regularly to study quality improvement within an organization.

Results-based accountability: Expected results (also known as goals) are clearly articulated, and data are regularly collected and reported to address questions of whether results have been achieved.

Target population: The population or clients intended to be served by a program.

Total Quality Management: A philosophy, a set of principles, and tools and procedures/practices that provide guidelines for maximizing achievement in an organization by meeting the expectations of customers and clients (McKinney \& Howard, 1998). TQM has been described as having four basic aspects: customer focus, continuous improvement, structured problem-solving processes for identifying and solving problems, and employee empowerment (see also Continuous Quality Improvement). 


\section{Summary}

Continuous quality improvement (CQI) was first used in the manufacturing industry and more recently applied to health care to improve service delivery and outcomes. Based on the successes in those areas, $\mathrm{CQI}$ is now being applied to community service organizations (CSOs). However, these organizations may lack many of the resources used in these other settings, such as a clearly defined set of outputs and data sources, to help inform their CQI efforts. The purpose of this guide is to help CSOs to adopt a CQI process to help improve service delivery and outcomes. This CQI guide was created as part of a broader program management tool called Getting To Outcomes (GTO). GTO specifies CQI as part of its 10-step process. In this CQI guide, a series of worksheets are provided to assist community service organizations through a systematic CQI process called Plan-Do-Study-Act cycles. The worksheets are designed to be customized to meet the needs of the programs and/or organizations using them. Information on how to establish CQI as an ongoing process within an organization is also provided. All of the worksheets and processes described in this guide were developed collaboratively and piloted with CSO staff from adolescent substance abuse prevention and treatment programs. The experiences from that project are described throughout this guide as illustrations. We incorporated input from a number of other CSOs that provide different types of services. In summary, we hope that the information and experiences that are conveyed herein help CSOs adopt and sustain CQI practices in order to continuously improve service delivery and outcomes. 


\section{Chapter 1 \\ Introduction: Why Use This Guide?}

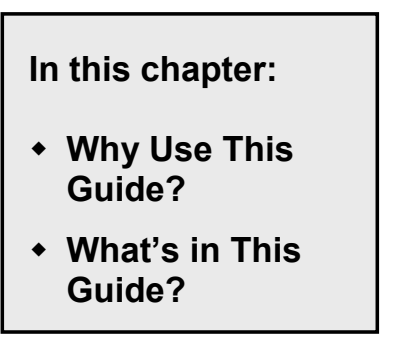

- Have you wanted to improve your programming but were not sure how? - Do you want to know how to use data to improve your organization's programs?

- Would you like tools to engage program staff in making systematic changes and assessing their impact?

If you have answered "yes" to any of these questions, then this guide may be helpful to you. It outlines a practical approach to putting data to work to make systematic changes, with the ultimate goal of improving programming in community service organizations (CSOs). ${ }^{1}$ CSOs are non-profit entities based in the community that provide social services, such as health and mental health care, substance use treatment, educational or vocational services, and employment assistance. Though this guide was written based on collaboration with a CSO that delivers substance abuse prevention and treatment services, we received input from a number of CSOs that provide different types of services. We believe that this guide can also meet the needs of both public and private, for-profit organizations that provide a variety of different social services to the community.

This guide focuses on continuous quality improvement (CQI) conducted by in-house CSO staff. We have taken this approach because many CSOs do not have the resources to hire someone outside their organization to support such work. In addition, we believe that the best program improvements are often those executed by people most familiar with the program. That said, organizational leadership support is needed to carry out many of the recommendations provided in this guide. You will need to consider involving others in your organization who are involved with programmatic decisionmaking when undertaking a CQI effort. The CQI process is most powerful when many different people within an organization are involved in and committed to it. You will find more information in later chapters to help you determine who in your organization needs to participate in CQI.

Here are some assumptions we made when writing this guide:

- You want to improve your organization's programming.

- You have some experience with operating the program targeted for improvement and have authority to make changes to it.

- You have access to some data about the program to be improved, such as who is served, referral sources, wait times, services provided, and/or outcomes (or can work to obtain this kind of data).

- Your organization is committed to using data to inform decisionmaking and program quality improvement.

As noted earlier, this guide grew out of a Getting To Outcomes ${ }^{\circledR}$ (GTO) demonstration project with a CSO. GTO is designed to help practitioners to better plan, implement, evaluate, improve, and sustain programs. Program staff had some experience with data and their value and were interested in gaining expertise in applying the data gathered to improve their programs' and organization's outcomes. The GTO model is briefly described on pages $79-81$. You may find it useful to more thoroughly review the GTO model before using this guide. In the GTO model, CQI is considered after a program has been planned and implemented. Free downloadable GTO materials are available at: http://www.rand.org/health/projects/getting-to-outcomes.html.

${ }^{1}$ Words appearing in boldface italics are defined in the glossary found at the front of this guide. 


\section{What Is in This Guide?}

The next chapter-"What Is CQI?"-provides an overview of continuous quality improvement, or CQI for short. Anyone who picks up this guide can read this chapter to gain some background information about the development and application of CQI in different settings. We describe some of the innovations in the field we applied to meet the needs of CSOs. We also discuss the challenges of conducting CQI in CSOs and our attempts to make CQI relevant to this setting.

"Preparing to Conduct CQI" describes how CQI can be applied to CSOs. This chapter also provides more details about planning for CQI, including the recommended groundwork for launching a CQI effort.

"Gathering Data to Inform CQI Efforts" provides three tools (the Delivery Worksheet, the Outcomes Worksheet, and the Component Worksheet) to help CSOs gather existing information about programs than can later be used to plan a CQI effort. Instructions for how to complete the worksheets are given along with accompanying examples of completed worksheets. Blank worksheets to use for your own program are available in the Worksheet Appendix.

"Identifying a CQI Action" provides tips, practical examples, and a worksheet to undertake a CQI initiative in a CSO. The chapter includes ways to select a CQI initiative, which we term a CQI Action.

"Launching and Studying CQl" offers a planning tool—the Launching CQI Worksheet—to help start a CQI Action within a program and organization after it has been selected. In addition, the chapter provides a guide as to how to study the impact of the CQI Action.

"Taking Next Steps in CQI" offers a tool to help assist in decisionmaking once a CQI Action has been launched and studied. The worksheet offers guidance as to how to decide whether the CQI Action should be continued, modified, or discontinued and where to go next for additional assistance.

Useful features incorporated throughout this guide include:

- important terms indicated in boldface italics and defined in the glossary

- ideas for how to build and support a CQI effort in your organization

- instructions on how to use all worksheets, written in a step-by-step format

- tips and examples taken from actual CQI experiences of CSOs and other organizations

- short summaries and checklists at the end of each chapter to help you review what you have learned and prepare you to move onto the next chapter.

All of the worksheets presented in this guide were developed and tested during the course of our own CQI work. The worksheets can be used as they are or they can be modified as needed to fit your own program, initiative, or organization. You can download and make paper copies of the worksheets to write on, or you can fill out the writable PDFs provided with this document and then print them once completed. 


\section{chaners \\ What Is CQI?}

"Quality does not come from inspection but from improvement of the process."

W. Edward Deming

\begin{tabular}{|l|}
\hline In this chapter: \\
- CQI Defined \\
The Historical \\
Origins of CQI \\
Applying CQI to \\
Community \\
Service \\
Organizations \\
\hline
\end{tabular}

\section{CQI Defined}

Continuous quality improvement or CQI refers to a planned, formal, systematic, and ongoing process intended to improve outcomes. By planned, we mean that the process is strategic rather than opportunistic and based on review of current practices. Decisions are made based on objective, measured data. These data may be collected through process and outcome monitoring. Formal means that the work is intentional, using a team to work through a systematic process such that the effects of any changes are observed and compared with planned expectations. Information is then used to help decide whether the changes led to improvements. Because the most effective quality improvement efforts are done in repeated cycles to build on past performance, the efforts are ongoing or "continuous" quality improvements. Also, the ongoing nature of CQI reflects how it should be incorporated within an organization so that it is viewed as "part of the work" rather than an "added on" or "once and awhile" activity.

\section{The Historical Origins of CQI}

Monitoring quality is a long-standing tradition in the manufacturing and other industrial fields. Going as far back as 300-600 AD, arts and craft guilds monitored quality. In these settings, master craftsmen created standards, provided training, and reviewed products before distribution.

\section{The Industrial Revolution and World War II Inspired the Need for New Approaches to Quality Improvement}

The modern quality improvement movement has its beginnings in the 1920 s, following the Industrial Revolution and subsequent gains in manufacturing efficiency. Foreseeing the need to check consistency and diagnose problems in the manufacturing process, Walter Shewhart at Bell Laboratories created the idea of continuous improvement cycles, or "Shewhart" cycles (Deming, 2000). Shewhart cycles involve using the scientific method of testing and evaluating a hypothesis-that is, an educated guess about what is happening in the production cycle. W. Edwards Deming helped the defense industry adopt these methods around the time of World War II and later renamed the process Plan-Do-Study-Act or PDSA to better describe it. PDSA cycles are systematic approaches to problem solving and are used for testing change on a small scale. This involves iteration, meaning that PDSA is done in repeated cycles, improving knowledge about the process each time.

\section{As the Quality Improvement Movement Developed, the Focus Shifted from Production Output to Management and Production Processes}

Following World War II, Deming and, later, Joseph Juran were invited to work with Japanese companies interested in improving product design and quality. Deming and Juran recognized that leadership was critical to improving quality and developed quality improvement training courses for managers. Deming 
argued that leadership must understand the system to improve quality and avoid problems. System problems include poor or nonexistent plans, procedures, performance criteria, and work processes. Juran argued that 80 percent of all organizational problems are inherent in the system (McKinney and Howard, 1998). According to Juran, these systematic problems could be solved by management. Juran's managerial lectures emphasized planning and organizational issues and the need for management to set goals and targets for improvement. Rather than spending time, effort, and money recognizing defects at the end of the production line, Deming emphasized that attention should be paid to the production process (Kenney, 2008). This approach required management to work in collaboration with front-line workers to improve the process or system.

Kauro Ishikawa, a Japanese engineer and manager, expanded on Deming and Juran's quality movement approach by engaging small teams of managers, supervisors, and front-line workers in the quality improvement process in groups known as quality circles (Bauer, Duffy, and Westcott, 2002). Quality circles are groups of workers and their supervisors who meet on a regular basis to work on quality improvement issues. Ishikawa also developed tools such as the Ishikawa diagram (sometimes called the fishbone diagram or cause-and-effect diagram) to help teams diagnose system problems. In later chapters of this guide, we provide a worksheet that is based on Ishikawa's fishbone diagram for use in CSOs. Improvements in Japan's economic situation following the war were attributed to these industrial quality improvement efforts. By the 1970s, products manufactured in Japan started receiving a first-rate reputation. Japanese success led many U.S. companies to adopt quality improvement approaches in the 1980s.

\section{During the 1980s, Early Industrial Quality Improvement Work Was Consolidated into a Single Movement-Total Quality Management (TQM)}

During the 1980s, the ideas and practices advocated by Deming, Juran, Ishikawa, and others began to coalesce into a broad-based industrial movement called Total Quality Management (TQM), representing a philosophy, set of principles, and tools and practices (McKinney and Howard, 1998). TQM has been described as having four basic aspects: customer focus, continuous improvement, structured problemsolving processes for identifying and solving problems, and employee empowerment (Westphal, Gulati, and Shortell, 1997). First, TQM emphasizes identifying and attempting to exceed the needs of both internal customers (i.e., fellow workers) and external customers. For example, in a school system, the internal customers would be the teachers and other school staff, and the external customers would be the parents and students. Second, TQM advocates for a work culture in which exceeding standards, rather than just meeting them, is expected. As part of this mandate, efforts should be made to continuously experiment, learning from mistakes and diffusing the lessons across the organization. Third, as described earlier, TQM encompasses PDSA cycles that bring attention to improving the processes within an organization. And finally, TQM allows for improvement by providing workers with the motivation, skills, and authority to take action. Important to this TQM tenet is that those individuals directly involved in a particular product or service are likely to have the knowledge to perform improvements. Thus, TQM involves multifunctional, multidivisional teams that share a common objective toward meeting the needs of the customer (Juran, 1989). Many of the components of TQM are consistent with continuous quality improvement (CQI) approaches; thus the two terms are often used synonymously.

\section{From 1980 Through the 2000s, Industrial Quality Improvement Methods Were Adapted to the Civilian and Military Health Care Systems}

With the rapid growth of managed care organizations (HMOs) in the health care industry in the 1980s and 1990s, pressure to assess and monitor the quality of health care increased. Moreover, in 1999, the Institute of Medicine published a report, To Err is Human: Building a Safer Health Care System, that suggested patient safety problems had reached epidemic levels, with annual preventable death rates near 100,000 and serious non-fatal medical error rates in the millions (IOM, 1999). A later report, Crossing the Quality Chasm, was instrumental in raising the visibility of the overall quality of the health care system and making recommendations for quality improvement (IOM, 2001). Although efforts to transfer knowledge and lessons from the industrial quality management field to improve health care quality have increased, challenges remain in implementation (Nembhard et al., 2009). 
On the forefront of this movement was physician Donald Berwick, who was the quality assurance director for a large HMO in Boston in the early 1980s. While attempting to monitor quality, he recognized the challenges of collecting and using data in these settings to motivate and improve performance among health care workers. His own personal experiences with the health care system also fostered motivation for identifying methods to improve quality (Kenney, 2008). In collaboration with Paul Batalden, he discovered the teachings of Deming, which led him to study Shewhart, Juran, and Ishikawa's work and apply their teachings to hospital and other traditional health care settings. In 1991, Berwick, along with other visionaries, founded the Institute of Healthcare Improvement (IHI), a nonprofit organization that works to motivate improvement in health care organizations such as hospitals and medical clinics. Borrowing from the founders of CQI in industry, he argued that medical errors were the consequence of a fragmented and poorly designed system that perpetuates them (Kenney, 2008). At the same time, researchers at the RAND Corporation were developing methods to assess quality in health care settings. Using these novel methods, RAND reported that American adults receive the appropriate recommended care in hospital settings only about half the time (McGlynn et al., 2003). RAND was also instrumental in helping the Department of Defense adopt practice guidelines in its medical systems (Nicholas et al., 2001). As part of these efforts, RAND recommended the use of PDSA cycles to support implementation of practice guidelines into military medical settings.

\section{Performance Indicators Are Now a Key Aspect of Quality Improvement in Health Care}

One aspect of the CQI technique used in industry that both $\mathrm{IHI}$ and RAND adapted for health care settings is the establishment of performance indicators, also known as benchmarks, quality measures, and performance metrics. There are two types of performance or quality indicators, process and outcome indicators. Process indicators measure various aspects of the quality of the services delivered in an organization. For example, "wait time," or the elapsed time between when a client requests services and when he or she receive services, is a process indicator. "Number of visits" is another example of a process indicator-this type of process indicator can also be referred to as a delivery output because it measures the amount of service that was provided. Outcome indicators measure the result of the process, also known as the impact or effect that the services had on the problem the organization is trying to address. Severity of symptoms and mortality rates are examples of common outcome indictors in health care settings. Health care organizations have focused on both process and outcome indicators, because improvement of the process should also affect outcomes. Understanding the relationship between the two types of measures, process and outcome, is important to conducting CQI.

\section{Applying CQI to Community Service Organizations}

Measuring different aspects of performance (performance indicators) in manufacturing can be fairly straightforward-it is possible to quantify aspects of such as the number of units produced and the costs associated with producing a unit. In terms of quality and safety measures, industrial standards exist and outside or third-party testing is available. In large health care organizations, measurement is not that much different. Indicators such as length of a hospital stay and compliance with hand-washing protocols are helpful process measures, and the number of mortalities is a useful outcome measure. Hospitals are often required to report these kinds of indicators for accreditation purposes. However, even in organizations in which data seem to be more readily apparent, making deliberate effective use of data to improve services requires careful thought and effort. As a result of the prior work in industry and health care, there are a wide variety of quality improvement "recipes" available for use. You may have heard of some of these approaches, such as "Six Sigma," "lean improvement," "systems redesign," "A3," and "Toyota Production System (TPS)."

In CSOs, measuring quality can be challenging, and process and outcome indicators may not have been previously defined and tracked. This is in part because such indicators may be more difficult to identify and track than in industry and traditional health care settings. For CSOs that are involved in behavioral health (a broad area including mental health and substance abuse treatment and prevention), the outputs 
are often services delivered rather than a tangible product (as in manufacturing) or a specific procedure (as in hospital-based care). Therefore, corresponding outcome indicators may not be previously established. However, even if these types of indicators do not yet exist, they can be identified or developed through the processes described later in this guide-and gathering and making use of performance data in the context of a CSO CQI effort can be foundational steps toward improvement!

Though there are some challenges, many of the techniques and tools developed in industrial and health care fields are applicable-with some adaptation-to practicing CQI within CSOs. For example, PDSA cycles, managerial planning models, the multifunctional team approach, and problem-solving tools used in industrial and health care fields are all applicable. We will talk about implementing some of these approaches in later chapters. Learning from the previous work by IHI and RAND, in Chapter 6 we will discuss in more depth how indicators may be developed specifically for assessing CQI within CSOs.

\section{Chapter Summary}

CQI was initially developed in manufacturing and industry. In the late 20th century, it was adopted for hospital settings. CQI techniques used in manufacturing and health care are good starting points for the development of a CQI formula for CSOs. For example, process and outcome indicators need to be measured and evaluated. However, it is also important to note that there are some major differences between manufacturing and community service settings that make it more challenging to apply all the CQI concepts developed for use in the manufacturing and industrial world. For example, process and outcome indicators may not be as readily available. 


\title{
conters \\ CQI Step 1: Preparing to Conduct CQI
}

\author{
"The largest room in the world is the room for improvement." \\ Anonymous
}

In this chapter:

- The Importance of Practicing CQI for Community Service Organizations

- Build Support for Quality Improvement in Your Organization

- CQI Overview

\section{The Importance of Practicing CQI for Community Service Organizations}

As you prepare to engage in CQI, it is important to be aware of the reasons to do so. The health care field has identified several reasons for practicing CQI that also apply to CSOs, whose services also often aim to improve health and well-being (see Jain, Roadmap for Quality, no date).

CQI is:

- In line with social service providers' values. For both social service and health care providers who are interested in offering the most effective services possible for their clients, CQI is the "right thing to do."

- Enhances a CSO's reputation. Funding and sustainability of an organization may depend on the extent to which that organization demonstrates to the community that it can provide quality services consistently over time.

- Promotes consistently high-quality service delivery. Evidence from both the business and health care sectors suggest that engaging in CQI can help CSOs achieve better outcomes, meet service-delivery goals, and improve satisfaction of patients served (e.g., Nicolay et al., 2011). More funders and regulators are requiring monitoring through internal data collection, which can result in some investment of time and money by the CSO. But systematically studying and using data makes good business sense and, by providing important information on which to base service improvements, can actually help increase the return on the investment required to collect the data in the first place.

In addition, from our own experiences working with CSOs, we have identified three important reasons to practice CQI including helping organizational participants:

- Develop a better understanding of their organizations and programs. This increased understanding can help programs become more nimble in anticipating and responding to changes in demand for services or resources.

- Use data to make smarter, targeted choices. Learning to collect, study, and use data helps participants better understand the link between goals and outcomes within their organizations as well as how to use data to help reach those goals and outcomes.

- Feel more invested. Participating in CQI activities can energize employees by providing opportunities to improve their work processes. Previous CQI users in a CSO setting have said the CQI tools helped "keep them on track" and motivated them to improve their programs (Chinman, Hunter, Ebener, 2012). 
We have found that external forces often drive data collection in CSOs. Advisory boards, funders, and reporting will lead automatically to the use of that data for program improvement within the CSO. However, this is not always the case.

CSOs often lack the resources needed to gather, let alone use, data for program improvement. CSOs typically have limited budgets for evaluation and few in-house CQI resources and expertise. When CQI was initially developed in industry, it was common to designate a full-time person to implement CQI within an organization (Nolan, 2007). In CSOs, the job of doing CQI often falls to existing staff, whose main job responsibilities usually center around delivering services. They also face problems in trying to collect information from clients who do not return, cannot be contacted, or refuse to participate in follow-up interviews or evaluation surveys.

Given the challenges that CSOs might experience in conducting CQI, the approach used in industry and health care settings needs to be adapted to fit the realities of CSOs. In finding ways to help CSOs overcome challenges and become more data driven and quality-focused, we have "boiled down" some important foundational information and developed some approaches that, if applied, will help better support your CQI efforts. We present this information and approaches in the following chapters.

\section{EXAMPLE: How CQI CAN Be HelPful}

We worked with a CSO that supported student resource officers (SROs) based in several high schools and middle schools. As part of their CQI efforts, the schools were interested in tracking the impact of the SRO work in getting students linked to the services that they needed at school and in the community. In order to do this, we worked with the SRO management to set up a database that the SROs could access on campus to keep record of the students that they served. The database noted the number of visits the SRO had with each student, what sorts of referrals were made to the student (e.g., to another school based program that focuses on reducing drug and alcohol use among at-risk youth, or to a community agency, such as Planned Parenthood), and the types of services that the SRO delivered to the student, ranging from individual counseling to classroom-based lessons. The information gathered in the database was then aggregated by the CSO at the end of each semester and school year and used to train and manage staff at the different school sites to best meet student needs. The information from the database was also used to demonstrate the need for the SRO program with both school staff and other potential funders of the program. For example, the data were presented to principals and the school board to demonstrate the reach that the program had in meeting the needs of the students, and connecting them to resources to assist them—the particular outcome goal of this program.

\section{Build Support for Quality Improvement in Your Organization}

As you might have gathered by now, CQI is not a solitary venture. It is important to engage those involved with implementing or operating a program in the CQI process to ensure internal support, buy-in, and the inclusion of diverse perspectives and to think about the resources and data you need to support your efforts.

In this section, we describe six steps to help CSOs build internal support for CQI:

1. Identify a CQI Team.

2. Engage Leadership.

3. Encourage a Culture of Trust.

4. Develop and Support a CQI Champion.

5. Get Support with Resources and Data Systems.

6. Get a CQI Coach. 
1. Identify a CQI team with strong leadership. We recommend putting together a team of individuals to work on a particular CQI initiative. Similar to Ishikawa's quality circle approach (see "What Is CQI?"), consider including multiple levels of staff, from line staff to upper management. You will want to include those closest to the area targeted by the specific CQI work, including those with specific expertise, in the initial planning. During the initial and final phases, upper management and opinion leaders within the organization will be helpful for support and feedback. You may need to bring more people into the team once CQI efforts are underway or replace some individuals who will naturally become less involved as the CQI effort evolves.

In addition to the above, the CQI Team should follow the same practices of any effective workgroup, such as meeting regularly, developing a timeline and clear agendas, designating roles and responsibilities within the team including leadership roles, taking and distributing minutes, assigning tasks to different participants, and following up to ensure task completion.

Motivated teams with strong leadership and invested in quality improvement are associated with more successful CQI projects (Kaplan et al., 2010).

\section{TIP: IMPROVING GROUP FUNCTIONING}

If you need more information on structuring and managing a committee, a useful, online resource is The Community Tool Box, which offers skill-building tools for working with groups such as group facilitation and problem solving.

The homepage for the toolbox can be found at: http://ctb.ku.edu/en/

In particular, you may want to review "Chapter 16: Group Facilitation and Problem-Solving," located at:

http://ctb.ku.edu/en/tablecontents/chapter 1016.htm

see "Section 1. Conducting Effective Meeting" at:

http://ctb.ku.edu/en/tablecontents/section 1153.htm.

2. Engage top leadership. Improving quality depends on leaders encouraging and expressing a vision for CQI within their organization. Leadership support can be provided in a number of ways:

- Have strong, visible support from top leadership. This may come in the form of having top leadership present at CQI meetings to express support.

- Raise the visibility of CQI within the organization. This can be done by:

- Making it part of the organization's overall strategic plan.

- Including it in the organization's mission statement.

- Setting organizational goals for participating in CQI activities or for completing CQI projects.

- Make quality improvement an expectation among staff. Examples of this include:

- Crafting job descriptions to convey the message that "CQI is how we do things around here."

- Supporting staff who seem intrinsically motivated to lead CQI efforts.

$\circ \quad$ Allowing staff to be trained in CQI efforts.

- Allocating staff time to developing quality improvement actions, data collection and analyses, and dissemination of results. Technical support, such as computer resources, might also be needed. 
- Addressing participation in CQI processes as part of personnel performance reviews and positively reinforcing CQI efforts and involvement.

- Providing incentives (e.g., day off, parking spot, or other organizational perks) for employees who participate in CQI. For example, the CEO of the CSO with which we worked offered an extra vacation day to any program director who completed his or her CQI Action by a certain date.

Of note, simply having top leadership aware of CQI and using a top-down approach to lead it tends not to be associated with successful CQI implementation (Kaplan et al. 2010).

\section{Encourage a culture of teamwork, support, open communication, and respect} on the CQI team and within the organization in general. CQI requires that people on the team and, ideally, throughout the organization, feel empowered to undertake changes, take risks, openly discuss their program's strengths and weaknesses, and learn from mistakes. Research has shown that organizations with a culture of teamwork, support, and respect are more likely to be successful with their improvement efforts (Shortell et al., 1995; Deo et al, 2009; Baird, Hu, and Reeve, 2011; Rad, 2006; Kaplan et al., 2010). Suggestions for promoting a supportive and flexible organizational culture include:

- Ensure psychological safety. Psychological safety means that people can share their thoughts and feelings without fear of being punished, criticized, intimidated, or dismissed.

- Be open to honest communication from all levels of the organization. People need to feel comfortable talking about quality issues, both vertically (from leadership to line staff and vice versa) and horizontally (with peers). In CQI, people should feel like equals as team members with a shared goal of improving the organization.

- Emphasize system-level thinking. CQI requires in-depth examination of an organization's processes. Success and failure of the processes should be shared.

- Set clear expectations about the use of information. Sometimes CQI requires gathering information that is also reported to those outside of the organization, such as an external funder. Be clear about what information will be shared and with whom.

4. Develop and support one or more CQI champions. Another way to support CQI within your organization is to have an identified CQI leader, or "champion." A CQI champion is a person who is truly devoted to the CQI and who has certain qualities that will inspire others to dedicate themselves to doing CQI, such as:

- Being a leader others in the organization look to for support and guidance

- Being passionate about CQI.

A CQI champion could also lead meetings within the CSO on CQI, set agendas for CQI, and be the chief reporter to leadership on CQI efforts within the organization. To keep your efforts going, also think about others in your organization that may be able to fulfill these duties if your original CQI champion becomes unable to perform these duties. An organization may have more than one CQI champion at the same time to provide support and legitimacy to the CQI effort. It is important that leadership designates a champion to take on CQI responsibilities as it can improve the success of CQI efforts (Kaplan et al., 2010).

5. Get support with resources and data systems. Systems for organizing and managing data can contribute to successful CQI implementation and to overall organizational success (Kaplan et al., 2010).

6. Get a CQI coach. It might be useful to bring in someone from outside your organization who has some experience in conducting CQI to help provide input throughout the process. You may find someone that can help with particular phases of the work, such as planning an effort or studying its impact. A capable CQI coach will concentrate on teaching how to conduct CQI effectively, increasing the capability 
of the organization to make future improvements without added assistance. Technical assistance can facilitate organizational change (Hunter, Chinman, and Ebener, 2009).

\section{TIP: How TO FIND HELP}

If you need help finding a CQI coach, here are a couple suggestions for finding assistance in your community:

- Contact your local United Way office for assistance, http://www.unitedway.org/worldwide/

- Contact SCORE (Counselors of America's Small Business Owners), http://www.score.org/ SCORE is a national non-profit dedicated to helping small businesses. Headquartered in Herndon, Virginia, and Washington D.C., SCORE has over 300 chapters in the United States as well as in U.S territories. SCORE has more than 13,000 volunteers who are successful business professionals who volunteer their time to mentor small business owners.

\section{EXAMPLE: GetTING READY FOR CQI}

The CSO we consulted with formed a CQI Planning Committee four months prior to developing specific CQI Actions, which helped form good relationships necessary for CQI efforts and plan tasks. The committee was also responsible for informing others in the CSO about its progress, which helped the whole organization understand CQI. This committee was similar to the CQI Team mentioned earlier in that it was made of staff from across the organization all working on CQI across the organization. However, instead of tackling a specific CQI issue, this committee's role was to plan and launch the CQI work that would take place within each of the separate programs of this CSO. The planning committee was composed of eight people, including:

- A chairperson who was a director of one of the participating programs and was the one most interested in CQI becoming part of the organization. The chairperson served as the CQI champion. The chair did not have any prior or formal experience with CQI, but was supported by us in our role as coaches. This individual was familiar with the GTO framework and manual (see Appendix A). The chairperson was responsible for planning the meetings, including sending advance agendas, and distributing notes following each meeting.

- Committee members included directors from other programs responsible for conducting their own program-specific CQI Action and interested in planning the launch of the CQI effort.

- The CSO's executive director also attended meetings on occasion to provide feedback and support.

The committee met monthly as CQI planning efforts unfolded. As part of its work, committee members developed and completed the CQI worksheets (some of which will be discussed in upcoming chapters). The committee also delivered progress reports on its efforts at the organization's regular staff meetings. 


\section{CQI Overview}

In upcoming chapters, we detail how to implement a CQI initiative in your organization. Here, we provide an overview of the process and supporting materials to give you an overall framework for the CQI approach used in this manual. Please keep in mind that this is just one way in which to establish a CQI process within an organization. If you are setting up a CQI process for one program and not for an entire organization, you may need to alter this type of framework to meet your specific situation.

\section{Figure 3.2. CQI Overview}

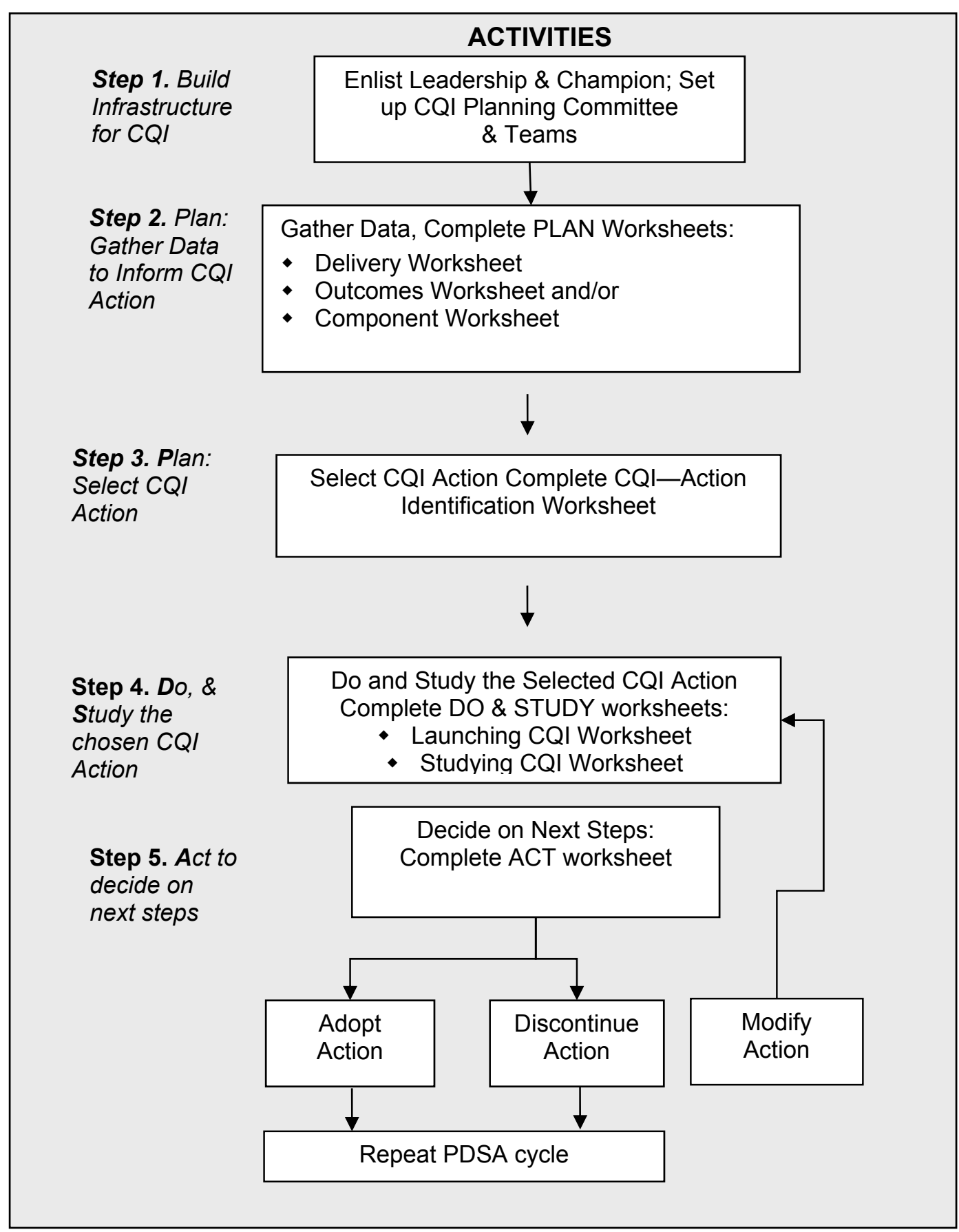


Step 1 (Build Infrastructure). As mentioned previously, one of the first steps in the CQI process is to mobilize the organization by enlisting the CEO or executive director, identifying a program champion, organizing a CQI planning committee, and organizing CQI Teams within programs that will participate in the CQI process.

Step 2 (Plan: Gather Data). Depending on resources available to you (see next chapter), program staff should complete worksheets we have labeled the Delivery Worksheet (DW), the Outcomes Worksheet (OW), and/or the Component Worksheet (CW). These worksheets are a way to organize program data and identify areas to target for CQI. As denoted in the figure, program staff should complete the DW and the OW in advance of completing the CW.

Step 3 (Plan: Select the CQI Action and plan for launching and studying). Using the data gathered in Step 2, staff are ready to select their CQI Action and complete the Action Identification.

Step 4 (Do \& Study the CQI Action). Now the CQI Action is ready to be launched and studied. Staff will follow the Launching CQI and Studying CQI worksheets.

Step 5 (Act: Determine Next Steps). Following implementation of the CQI Action, program staff should complete the Next Steps in CQI Worksheet to help them consider the impact of the CQI Action and what to do next, which could include making the improvement permanent (if successful) or revising it if holds promise, or developing a new one if it did not work.

\section{Chapter Summary}

In this chapter, we first provided motivation for practicing CQI in CSOs. Following this, tips were given to establish internal support for CQI within your organization. Finally, this chapter provided an overview of the CQI approach presented in this guide. 


\section{custares \\ CQI Step 2: Plan: Gather Data to Inform CQI Efforts}

"Even if accurate data are available, they will be meaningless if they are not used correctly. The skill with which a company collects and uses data can make the difference between success and failure" Masaaki Imai

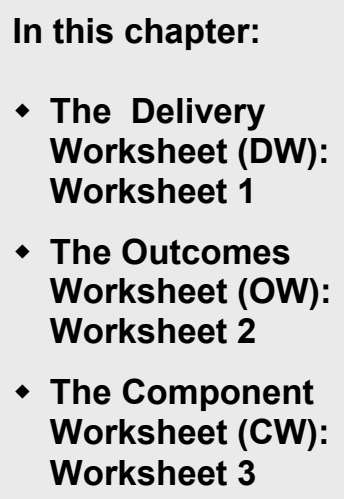

In this chapter:

- The Delivery Worksheet (DW): Worksheet 1

- The Outcomes Worksheet (OW): Worksheet 2

- The Component Worksheet (CW): Worksheet 3

In this chapter, we provide three "Plan" worksheets-the Delivery Worksheet (DW), the Outcomes Worksheet (OW), and the Component Worksheet (CW) that can help your organization gather data to inform CQI efforts. This step is important because you need to know where you are before you decide where to go.

\section{Who Should Be Involved?}

As discussed earlier, a team approach is at the heart of CQI. While the worksheets may be used by program directors or other staff engaged in operating a program, we encourage anyone implementing program services or involved with collecting data about the program to help complete these worksheets or participate in meetings to review them.

Also remember, a truly useful CQI process depends on you and your team being as honest as possible about the information requested in the worksheets. Reassure everyone involved that the completed worksheets are for internal use only. It is important to convey that the purpose of the work is to identify areas for improvement.

\section{Which Worksheet to Use?}

The worksheets are designed to help you organize what is known about your program to help you determine a CQI Action. The worksheets require that you have some information about your program. Your organization may use different terms for information than those used in the worksheets. You may find it helpful to refer to the glossary to clarify the terms.

Depending on your team's immediate goals (e.g., improve service delivery) and how much information you have about your program, you may want to complete one, two, or all three of the worksheets in this chapter. You will be surprised at how much information you have about your program, even if it is not formally documented anywhere! You will also learn a lot about your program and how to think about making changes to your program by going through the process of completing the worksheets. Here, we provide guidance on the purpose of the three worksheets, the information needed to complete them and when to use each worksheet and how they can be used to build on each other.

- Delivery Worksheet (DW)-Worksheet 1

- The DW focuses on service delivery and your program's processes.

- This worksheet is most helpful for teams that are interested in focusing CQI on service delivery. 
- Information on how your program is delivered (i.e., what you do), such as the types of activities offered and how much service is provided, will be helpful for this worksheet.

- Use the DW to help you see how well the current services align with the program's goals and objectives.

\section{- Outcomes Worksheet (OW)-Worksheet 2}

- The OW focuses on the results of your program, or your program's outcomes.

- This worksheet is most helpful for teams that have already evaluated their program (or have outcome data that are readily available) and are interested in doing CQI to improve outcomes.

- A formal program evaluation is an ideal source for this information. This might come from an internal document analyzing program records on participants before they started the program and after they completed it, reports to funders, or outside evaluations completed for your organization.

- Use the OW to help you see what impact your program's services have and on whom in order to identify areas for improvement. This information will help you critically analyze the different aspects of your program and will help you think about what might need to change.

\section{- Component Worksheet (CW)—Worksheet 3}

- The CW examines different components or stages of your program, including processes and outcomes.

- General knowledge about how your program operates will help you complete the worksheet.

- Complete the CW last if you are able to complete the DW or OW, because the CW prompts you to think about topics you may have already explored in greater detail through the other worksheets.

- Use the CW to help you document what works well and not so well in various components of your program.

- Any program can complete the CW-this worksheet is helpful for teams that are just starting CQI as well as teams that are already doing CQI and want to reassess their program. However, only using the CW (and not the other worksheets) might prevent you from assessing critical process and outcome targets that would help you monitor the success of CQI. Note that your CQI analyses (i.e., whether CQI worked to improve your program) will be stronger if it is based on objective data collected about the program rather than on perceptions of program strengths and weaknesses.

After you complete each worksheet, you should be able to identify specific strengths and weaknesses about your program that might be areas to focus on as part of a CQI effort. Even if you are not able to answer every question in a worksheet, this exercise can still be helpful! The questions can make you more familiar with CQI and help you think about CQI. In addition, places in the worksheet where there are gaps because of missing/unknown information may suggest areas to focus on in a CQI initiative (i.e., the work of CQI may involve establishing a process that will ensure this type of data is regularly available in the future).

For each worksheet, we provide a blank copy in Appendixes A-G for you to complete for your program. When working in larger groups, you might find it helpful to work on a whiteboard or flipchart and transfer your answers to the worksheet later for documentation. In addition, sample completed worksheets are provided in this chapter to give you an example of how these worksheets can be used. 


\section{TIP: WORKSHEets ARE A WORK IN PROgRess!}

As you start the worksheets, keep in mind that they are designed to help you in a variety of ways, such as:

- Brainstorming-The questions and ideas can help you and your staff generate ideas. There are no right or wrong answers.

- Guides - If parts of the worksheet do not make sense for your organization, do not feel obligated to complete them. If the worksheet seems to be missing key information important to you, feel free to add it! One approach you might want to take is if a section is not applicable to your program, fill in as "N/A" and move on to the next section. That way, if you or someone else reviews it again, you know that you did not skip over or miss that item; it just was not relevant to your program.

- Snapshots-The worksheets are designed to gather discrete pieces of information about a program at a point in time; it is expected that this information will change over time.

- Timing-You might not be able to complete a given worksheet in one sitting, as it may require information from a variety of sources. If you have trouble answering a question, don't get discouraged! Skip the question and move on to the next one to see if you can complete other sections of the worksheet. 


\section{The Delivery Worksheet (DW)—Worksheet 1: Overview}

The Delivery Worksheet, or DW for short, helps you gather information about how your program is delivered. You can view samples of the completed worksheet pages on the following pages of this chapter (pages 20,22, and 25) and a blank one that you can use to complete for your own program is located in the Worksheet Appendix. As stated at the top of the worksheet, the purpose of the DW is to help identify whether the program's delivery objectives are being met (e.g., Is the program delivering an adequate number of services to a targeted number of participants?). In order to complete this worksheet, you will need to know your program's delivery objectives and information about the population your program serves. By delivery objectives, we mean the service goals for your program.

If you are not familiar with your program's delivery objectives, check with others in your organization to see if there are objectives specified for your program. Program delivery objectives may have been specified as part of your program's funding requirements, and you might find them in the grant application that was used to fund the program. They may also be part of your organization's strategic planning documentation. If your program does not have program delivery objectives, you should strongly consider developing them, and the Getting To Outcomes $®$ (GTO) manual (see Appendix A for more information about accessing it) may help you.

\section{Example: Program Delivery Objective}

Program delivery objectives are sometimes referred to as the "McDonald's number," as they can sometimes be written as "the number served," similar to the famous signage found in front of McDonald's fast food restaurants in terms of the number (typically represented in millions or billions) of hamburgers served at that particular establishment. Such a number might look impressive, but it is important to examine what that number represents and whether it is meaningful to your larger goals. For example, the "McDonald's number" might not provide a very useful example for CSOs, as it represents a "duplicated" number of customers. That is, if a customer buys more than one hamburger or comes back every day for a hamburger, they are counted more than once. This analogy may work for some service organization activities (e.g., the number of condoms distributed), but often times CSOs are not only interested in the duplicated number, but also in the "unduplicated counts"-meaning it is important for CSOs to track individuals to determine whether a particular person receives more than one service or attends more than once (think of a program activity that includes several sessions). Not counting unique individuals separately will limit your ability to understand the "reach" of the program. By "reach," we mean the depth or range of individuals that are served. How you define and measure your program delivery objectives will depend on your organization's priorities and goals.

\section{Contents}

Here we will introduce you to each section of the worksheet. Each section is formatted with a list of prompts. The DW consists of three pages or sections:

1) Page 1: program needs and delivery objectives

2) Page 2: description of program delivery

3) Page 3: meeting program delivery objectives.

Next, we will describe what is meant by the prompts in each of the sections in order to help you think about how to fill in the worksheet with information about the delivery of your program. 


\section{Instructions to Complete the Delivery Worksheet (DW)}

\section{Delivery Worksheet Page 1, Program Needs and Objectives}

The first section of the worksheet asks you to describe the purpose of your program in several different ways. You have probably provided similar kinds of information to program funders and other stakeholders in grant applications and progress reports. To help fill in some of the information, you may want to have on hand previous evaluations or progress reports in order to record information, such as the number of participants in a program over time.

The worksheet asks you to think about the following:

- The needs or problems your program is designed to address-On the left-hand side of the worksheet (labeled "A"), fill in the problems that your program is designed to address. Examples might include reducing truancy among 10th graders or lack of positive role models for adolescents. Your program may be addressing only one problem or several; the worksheet has room to fill in up to three.

- Program delivery objectives-Next, on the right-hand side of the worksheet (labeled "B"), fill in the program service delivery objectives of your program. These could be information, such as the number of people to be served or the number of program sessions to be delivered. Program delivery objectives are sometimes referred to as output objectives. You may find the content for completing this section under the proposed goals in a grant application or funder progress reports.

Are you puzzled by the terms "delivery objectives" and "outcome objectives"? Delivery objectives refer to the services you are expected to provide over the course of the program. In the DW example on page 20, the first delivery objective is, "To provide one-on-one mentoring in two elementary sites to 125 students who score below average in reading level." In most cases, it is easy to see whether you met a delivery objective at the end of the program by reviewing administrative records-e.g., how many students did you mentor, what kind of readers were they, and at how many sites? Outcome objectives refer to the desired results of the program services by comparing at least two time points. Outcomes are often harder to observe and require you to collect and analyze data from before and after the program. In the OW example on page 29 , the outcome objective is "Improve reading scores for $75 \%$ of the mentees." To assess whether you met this objective, you must compute the change in reading scores for all the mentees and calculate the proportion of them that improved.

Try to be as specific as possible with the information you provide on this page. For example, broadly stating that your program "targets alcohol use" is not as useful as "reducing alcohol use by $25 \%$ among high school students." For your program delivery objectives, also consider the timeframe. Is your goal to serve 100 teens this semester or this year? Being specific about the who, what, and when of your program will make it easier for you during the CQI process to see how you are doing. We'll talk about this more in relation to the OW. 


\section{What Did You Learn by Completing Page 1 of the DW?}

Do the program service delivery objectives connect with the problems that the program is designed to address? Sometimes program objectives are not clearly aligned with problems the program is trying to solve. For example, your program may be trying to address truancy by providing afterschool activities for ten 9th graders. However, the ten 9th graders who are not attending school are least likely to participate in an afterschool program. Moreover, serving ten youth may not impact the truancy rate for the entire 9th grade class. Completing this first section and reviewing the program needs and objectives together might help you reconsider the program delivery goals and design of the program. These potential inconsistencies could be areas in which to focus your CQI process; for example, extending the reach of your program so that truant teens are more likely to participate in programming designed to address truancy. 


\section{WORKSHEET 1: DELIVERY WORKSHEET (DW)}

Program Name: $\quad$ Mentoring Project

Date: $3 / 30 / 2015$

The purpose of this worksheet is to help you identify whether you are meeting your program's delivery objectives (e.g., your program's process or plan is "on track"; the program is delivering an adequate number of services to a targeted number of participants). You will need to know your program's delivery objectives and information about the population your program served to complete this worksheet.

\section{PROGRAM NEEDS AND DELIVERY OBJECTIVES}

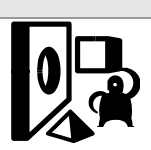

A. What are the problems your program addresses?

1. $68 \%$ of students in targeted schools are below average in reading level

2. Although research suggests that mentoring that lasts longer than 12 months is most likely to impact outcomes, fewer than $25 \%$ of mentees receive mentoring longer than 12 months

3. Rates of alcohol use among middle school students are higher than the national norm by $25 \%$
B. What are your program delivery objectives?

1. To provide one-on-one mentoring on two elementary school sites to 125 students who score below average in reading level

2. To provide one on one mentoring that lasts at least one year

3. To train mentors in alcohol prevention 


\section{Delivery Worksheet Page 2, Program Delivery Description}

On the next page of this worksheet, you will detail how the program was delivered during a specified time period (section labeled "C"). The time period you select for this worksheet should be long enough to let you compare delivery information with the objectives documented in the first section of the DW. It will be up to you and your team to decide on a time period in which to take this snapshot of your program delivery, but it makes sense to select a period in which the most recent data on a program are availableprobably within the past year.

The key questions to answer in this section of the worksheet include:

- What time period are you reporting on?

- Who did you plan to reach with your program during the specified time period? Specify:

- The number of participants you planned to reach

- The characteristics of intended participants (age, race/ethnicity, need for program)

- Other relevant characteristics of the intended participants-for example, all youth referred by probation

- During the specified time period, how many participants attended your program even once?

- In general, did you offer the entire program's intended content (i.e., curriculum or treatment protocol) during this time period? Indicate yes or no.

- If no, what percentage or how much of the program was delivered, on average? For example, if the curriculum contains ten sessions but only five were offered, you would have delivered $50 \%$ of the program's intended content.

- In treatment settings, this section could be used to document, on average, how many sessions or other types of clinical contacts youth participated in.

\section{$\otimes$}

\section{What Did You Learn by Completing Page 2 of the DW?}

The information on this page gives you a summary of program delivery during a specified time period. It asks about the key dimensions: how many you planned to serve, how many you actually served, the characteristics of those you served, whether you delivered the program as it was designed. You may find areas here that suggest the need for improvement, either in the number or type of individuals served or in the content of the program delivered. The next page of this worksheet will help you further identify possible areas for improvement. 


\section{DESCRIBE PROGRAM DELIVERY}

C. What time period are you reporting on?

$\underline{2014-2015 \text { school year }}$

mitii

D. Who did you plan to reach with your program during this time period?

1. Number: 125

2. Target 4th-6th graders at John Adams and Roosevelt Elementary schools

Characteristics:

Below average reading level, at risk for delinquency

E. How many attended your program even once during

this time period?

100

F. In general, did you offer the entire program's content (for example, curriculum) during this time period?

$\triangle$ Yes $\square$ No $\square$ Not Applicable

If no, what percentage or how much of the program was delivered (for example, how many sessions were delivered? 


\section{Delivery Worksheet Page 3, Program Delivery Objectives}

The third section of the DW helps you compare the delivery objectives specified in the first section of this worksheet to what you achieved, as documented in the second section or page of this worksheet.

The key questions to answer in this section of the worksheet include:

- My Program Delivery Objective - Copy the program delivery objective(s) that you filled in on page 1 under $\mathrm{G}, \mathrm{H}$, and I. We have made room for up to three delivery objectives; your program may have more or fewer objectives.

\section{TIP: WORKSHEETS ARE FLEXIBLE}

The worksheet has space for you to document up to three program delivery objectives. Your program may have more or less than three, so modify the worksheet to fit your needs. You may also need to modify the worksheet if you have more than two measures per objective.

- Measure(s) - In this section, describe what you are measuring to figure out whether you are meeting the program delivery objective. For example, if the objective is to deliver the afterschool program to 10 students, your measure may be the number of students who actually completed the afterschool program, as documented in program attendance records.

- Benchmark - In this section, fill in the standard or requirement your program is expecting to reach. You may need to define your goals. In the example provided, "completed" the afterschool program would be defined as attending at least half the sessions.

- My program's \#-In this section, note your program's number during the time period you indicated on page 2 on this measure. For example, if your program delivery goal was to deliver 10 sessions last semester, how many actual sessions were delivered last semester? If your program delivery goal was to serve 100 teens last fiscal year, "my program number" would be the actual number of teens served last fiscal year.

- Met objectives? For this section, you are first asked to indicate whether you met, missed, or exceeded your benchmark. "Met" means that you met your program delivery objective, e.g., 10 students attended more than half of the afterschool program. You "missed" your program delivery objective if, in our example, you had fewer than 10 students attend more than half of the afterschool program. "Exceeded" means that you had more than 10 students attend more than half the program. Next, this section prompts you to answer the question "What is the trend?" This is asking you, if it is possible with the data you have access to, to compare the findings from this time period (e.g., did you hit, miss, or exceed?) with findings from last two or three time periods to determine whether the program's performance is better, worse, or about the same as before.

- Action needed? Here, the worksheet is prompting you to consider whether you need to take action based on what you learned (comparing your benchmark with your actual performance). Do you think you need to take action on this objective/measure? If you are not meeting your objectives or the trend is getting worse, you might want to check yes. You probably will check no if you are meeting or exceeding your objectives, and therefore no action is needed. 


\section{What Did You Learn by Completing Page 3 of the DW?}

Go through the process outlined above for each program delivery objective. You may see that some measures will require action, whereas others may not. You may find that you have not collected the information needed to assess whether your program is meeting its objectives. These issues all point to areas that you may want to consider as part of your CQI Action, which will be covered in greater detail in "Chapter 5: Developing a CQI Action." 


\section{MEETING PROGRAM DELIVERY OBJECTIVES}

G. My Program Delivery Objective \#1: (see page 1) To provide one-on-one mentoring in two elementary school sites to 125 students who score below average in reading level

\begin{tabular}{|c|c|c|c|c|}
\hline $\begin{array}{l}\quad \text { Measure(s): } \\
\text { What you are measuring to figure } \\
\text { out whether you are meeting the } \\
\text { program delivery objective? }\end{array}$ & $\begin{array}{l}\quad \text { Benchmark(s): } \\
\text { The standard or requirement } \\
\text { your program is expecting to } \\
\text { reach }\end{array}$ & $\begin{array}{c}\text { My Program's \# } \\
\text { Your program's actual \# }\end{array}$ & $\begin{array}{l}\text { Met Objectives? } \\
\text { Is the actual number the same as (met), } \\
\text { less than (missed), or more than } \\
\text { (exceeded) the benchmark number? }\end{array}$ & $\begin{array}{l}\text { Action Needed? } \\
\text { Based on this } \\
\text { information, does } \\
\text { something in the } \\
\text { program need to } \\
\text { change? }\end{array}$ \\
\hline $\begin{array}{l}\text { Review of student report } \\
\text { cards to determine } \\
\text { eligibility for the program }\end{array}$ & $\begin{array}{l}100 \% \text { of mentees will } \\
\text { have below-average } \\
\text { scores on reading test }\end{array}$ & $85 \%$ & $\begin{array}{l}\square \text { Met } \quad \square \text { Missed } \square \text { Exceeded } \\
\text { What is the trend from prior periods? } \\
\square \text { Better } \quad \square \text { Same } \square \text { Worse }\end{array}$ & $\triangle$ Yes $\square$ No \\
\hline $\begin{array}{l}\text { Number of students } \\
\text { matched with mentor }\end{array}$ & 125 & 100 & $\begin{array}{l}\square \text { Met } \quad \square \text { Missed } \square \text { Exceeded } \\
\text { What is the trend from prior periods? } \\
\square \text { Better } \quad \square \text { Same } \square \text { Worse }\end{array}$ & $\triangle$ Yes $\square$ No \\
\hline
\end{tabular}

H. My Program Delivery Objective \#2: (see page 1): To provide one on one mentoring that lasts at least one year

\begin{tabular}{|c|c|c|c|c|}
\hline $\begin{array}{l}\text { Length of mentoring } \\
\text { relationships }\end{array}$ & $\begin{array}{l}100 \% \text { of relationships } \\
\text { will last at least one } \\
\text { year }\end{array}$ & $50 \%$ & $\begin{array}{l}\square \text { Met } \quad \square \text { Missed } \square \text { Exceeded } \\
\text { What is the trend from prior periods? } \\
\square \text { Better } \quad \square \text { Same } \square \text { Worse }\end{array}$ & $\triangle$ Yes $\square$ No \\
\hline
\end{tabular}

I. My Program Delivery Objective \#3: (see page 1) To train mentors in alcohol prevention

\begin{tabular}{|c|c|c|c|c|}
\hline $\begin{array}{l}\text { Number of mentors trained } \\
\text { in alcohol prevention } \\
\text { curriculum }\end{array}$ & $75 \%$ & $75 \%$ & $\begin{array}{l}\bigotimes \text { Met } \square \text { Missed } \square \text { Exceeded } \\
\text { What is the trend from prior periods? } \\
\bigotimes \text { Better } \square \text { Same } \square \text { Worse }\end{array}$ & $\square$ Yes $\bigotimes$ No \\
\hline
\end{tabular}




\section{Delivery Worksheet (DW) Summary}

The DW helps you determine whether your program is meeting its intended benchmarks and identify areas that need improvement.

Next Steps: It is now time to reflect on what you have filled in on the DW. You may want to share the information at a staff meeting, so that everyone involved in the program has a chance to respond to what has been learned and suggest ways to make improvements. Page 3 of the worksheet is designed to tell you exactly the areas that need additional attention (i.e., "Action Needed? Yes or No"), however there may be other places in the worksheet that you were unable to complete because information was not available. Not having the information to complete the worksheet may also suggest an area to focus on for quality improvement. The next worksheet (Outcomes worksheet, or OW) will allow you to assess whether the program is having an impact on program participants.

\section{TIP: How to Organize Your Work}

To organize your findings from the worksheet, you might consider placing the information in three categories: "?," "+," or "!," as follows:

? The "?" Category: First, find on your worksheet areas where information was missing, unknown, or contradictory. Think about whether you need more information to address these areas. If so, circle them and put a "?" next to them to identify those areas that need further information.

+ The "+" Category: Second, find where your program is doing well. Think about whether those aspects of your program can be sustained over time and whether they will need attention to be maintained. If so, circle those areas and put a "+" next to them.

! The "!" Category: Third, look for places on your worksheet that suggest room for improvement. Circle those areas and put a "!" next to them. How can you tackle those weaknesses in your program?

These three categories suggest areas in which you might want to focus your CQI efforts (especially if you have more than one symbol by them!). For some items you have put in the first category (denoted by a "?"), you may need to go on a fact-finding mission to learn more about your program. The items you have put in the second category (denoted by a "+") are program strength that you might want to sustain over time. The items in the third category (denoted by a "!") are weaknesses that need attention. Any one of these categories can be further fleshed out as part of your quality improvement initiative, which we call a CQI Action. A CQI Action is the quality improvement initiative that you decide to undertake to improve your program. We will talk more about that in Chapter 5. 


\section{The Outcomes Worksheet (OW)-Worksheet 2: Overview}

Whereas the DW allows you to determine whether the program is meeting its broad service delivery objectives, the Outcomes worksheet, or OW for short, helps you identify whether your program is having an impact on program participants. In order to complete this worksheet, you will need to have two sets of information (if you don't have all of the information, this worksheet can still help you think about how you could assess whether your program is effective).

First, you will need to know your program's desired outcome objectives. By program outcome objectives, we mean the specific changes expected in the target population as a result of program participation. Note these are different from the program delivery objectives you identified in the DW worksheet. Program outcome objectives may be related to changes in individual participants' knowledge, attitudes, or behaviors or can be related to community-level changes, such as changes in community awareness, policies, or actions around a certain issue, such as underage drinking. In other words, a program outcome objective is the actual benefit or improvement intended for the population served by the program. If you are not familiar with your program's outcome objectives, you may want to check with others in your organization to see whether there are outcome objectives specified for your program. Program outcome objectives may have been specified as part of your program's funding requirements or they may be part of your organization's strategic planning documentation. If your program does not have program outcome objectives, you may want to consider developing them. (The Getting To Outcomes $\circledR$ (GTO) manual (see Appendix A) may help you with that).

Second, you will need information on the results of a recent program evaluation or data that provide participant outcomes from at the start of and after the program. This might come from an internal document analyzing program records, reports to funders, or evaluations completed for your organization. Ideally, you will have information on participants from before they started the program (often referred to as a baseline, intake, or pre- assessment) and the same type of information after they completed the program (often referred to as a follow-up, discharge, or post- assessment). If you do not have this kind of information, completing this worksheet can still be a helpful exercise, but you may want to refer to the GTO manual to learn more about evaluating your program (see Appendix A).

In the next section of the guide, we will introduce you to each section of the worksheet and provide information to help you develop the worksheet content based on your program.

\section{Contents}

The OW consists of three pages or sections:

1) Page 1: program needs and outcomes objectives

2) Page 2: describe the program's evaluation

3) Page 3: program outcomes. 


\section{Instructions to Complete the Outcomes Worksheet (OW)}

\section{Outcomes Worksheet Page 1, Program Needs and Objectives}

Page 1 of this worksheet should look familiar to you if you completed the DW. Essentially it is asking you to do a similar sort of information gathering and analyses, but in reference to your program outcome objectives rather than your program delivery objectives.

The worksheet asks you to think about the following:

- A. The needs or problems your program is designed to address. On the left-hand side of the worksheet $(A)$, fill in the problems that your program is designed to address. Examples might include improving reading among mentees. Your program may address one problem or several. The worksheet is designed to list up to three issues, but you can customize this as needed.

- B. Program outcome objectives. Next, on the right-hand side of the worksheet (B), fill in the outcome objectives of your program. Outcome objectives refer to the impact that your program is expected to have on participants.

\section{Confused between delivery objectives and outcome objectives?}

Delivery objectives refer to the services you are expected to provide over the course of the program. In the DW example on page 20, the first delivery objective is, "To provide one-on-one mentoring on two elementary sites to 125 students who score below average in reading level." In most cases, it is easy to see whether you met a delivery objective at the end of the program by reviewing administrative recordse.g., how many students did you mentor, who were they (what kind of reader), and at how many sites?

Outcome objectives refer to the desired impact of the program services (most often on its participants) by comparing at least two time points. Outcomes are often harder to observe and require you to collect and analyze data from before and after the program. In the OW example on page 29, the outcome objective is "Improve reading scores for $75 \%$ of the mentees." In order to assess whether you met this objective, you must compute the change in reading scores for all the mentees and calculate the proportion of them that improved.

\section{TiP: How to Document your Program Outcome ObJectives}

Try to be as specific as possible with the information you provide on this page-specify what will change, by how much, in whom, by when. For example, broadly stating that your program "reduces alcohol use" as an outcome is not as helpful as stating that your program aims to "reduce alcohol use [what] among 9th graders [who] by $20 \%$ [how much] by the end of the school year [when]." Specificity is helpful in conducting CQI because you can easily check your program's work against clearly stated goals and objectives. 


\section{WORKSHEET 2: OUTCOMES WORKSHEET (OW)}

Program Name: Mentoring Project

Date: $3 / 30 / 2015$

The purpose of this worksheet is to help you identify whether your program is having an impact on program participants. For example, does the program improve communication skills? You will need to have pre-post program data to complete this worksheet.

\section{PROGRAM NEEDS AND OBJECTIVES}

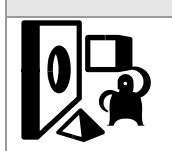

A. What are the problems your program addresses?

1. $68 \%$ of students in targeted schools are below average in reading level

2. Over $70 \%$ of students in the targeted schools are at risk for delinquency

3. Rates of alcohol use among middle school students are higher than the national norm by $25 \%$
(1)

B. What are your program outcome objectives?

1. Improve reading scores for $75 \%$ of the mentees to the averages for their grade level

2. Reduce the number of unexcused absences for mentees by $50 \%$

3. Increase the percentage of mentees who report perceptions of harm from frequent use of alcohol by $80 \%$ 


\section{What did you Learn by Completing Page 1 OF the OW?}

Reflect on the information provided in sections A and B. Do the program outcome objectives connect with the problems that the program is designed to address? Sometimes program objectives are not clearly aligned with problems the program is trying to solve. You may have already done a similar comparison if you completed the DW. For example, a stated outcome objective may be to improve reading scores, but is the program designed to address reading? Does the program have sufficient content related to improving mentee reading scores? For example, you may be operating a mentoring program that everyone hopes will affect reading scores, but the program does not provide any support to assist mentors to help mentees improve with reading (e.g., instead they work on social skill development or math). Completing this first section of the OW worksheet can reveal inconsistencies between program design and intended objectives. These potential inconsistencies in programming, objectives, or evaluation could be areas in which to focus on in CQI. 


\section{Outcomes Worksheet Page 2, Describe the Program's Outcome Data}

On the next page of this worksheet, you are asked to detail the outcome data from your program. By outcome data, we mean data from program participants that measure whether your program had an impact. Usually, such data are captured from assessing participants before and after the program on measures that assess the key objectives of the program (e.g., reading ability). The questions in this section are designed to help you think about different aspects of the data you have available to you that might lead to biased results. For example, after documenting information about which and how many people's outcome data you have available to examine, you will be asked to reflect on how well these participants reflect the population served by the program. This is important because sometimes participants drop out before you can get their feedback or are not interested in helping to fill out surveys even if they do stay in a program. As a result, your program's evaluation data might not be an accurate reflection on your program. Detecting some of these discrepancies could help identify potential areas to focus on as part of your CQI efforts.

C. What time period are you reporting on? For this section, the time period you select should be long enough to let you compare the outcome data with the objectives documented in the first section of the OW. It will be up to you and your team to decide on a time period, but it probably makes sense to select the most recent period in which data on a program are available. If you also completed the DW, you might want to use the same time period that you used in that worksheet so that the information documented across worksheets is comparable. Note that, like in the DW, you also will be asked to take note of "trends" over time; outcome data from the past two or three periods (if available) will help you do this.

D. How many did you plan to reach with your program? For this question, fill in the number of individuals you intended to serve during the time period specified in section C. You may have already gathered this information as part of completion of the DW.

E. How many attended your program even once? For this question, fill in the number of individuals that attended your program at least once. This may include the number of people who showed up once for an intake interview or the first session of your program but never came back. Again, you may have already documented this if you completed the DW.

F. How many people are included in the outcome dataset? For this question, fill in the number of people analyzed for this period (C). Typically this number is fewer than the numbers given in $D$ and $E$. Next, you are asked to compute a couple of percentages. First (a), the percentage of the target population included the outcome dataset. This is computed by dividing the number included in the outcome dataset (from section F) by the number you intended to serve (from section D) and then multiplying it by one hundred. For example, perhaps you intended to serve 100 teens and you were able to get outcome data from 57 teens. Then the percentage of the target population that participated in the evaluation would be $57 \div 100=0.57 ; .57 \times 100=57 \%$. Next (b), you are asked to compute the percentage of those served that are included in the outcome dataset. This is computed by dividing the number included in the outcome dataset (section F) by the number who attended the program at least once (section E) and then multiplying that number by 100 . For example, perhaps you have outcome data from 57 of the 90 teens who attended the program at least once, so you have $63 \%$ of the number served represented in your evaluation data.

In the next row of the worksheet, you are asked "G. Who was included in the outcome dataset?" You are prompted to check all that apply from the following list:

- Program leaders

- Program completers

- Regular attendees

- Everyone who ever attended

- Others. 
The final question on this page of the worksheet asks "H. How well does your outcome dataset represent the population you serve?" and you are given a five-point scale to respond as to whether the evaluation represents the population "very well" to "not at all well." Think about your program's goals and your responses to the previous questions to answer this question. Was everyone in your target population included in the outcome dataset? (i.e., how close to $100 \%$ did you get in section $\mathrm{F}$, item a?) If not, who did and who did not? It's important to think about the representativeness of your outcome dataset within the context of your program. If your target population is or was large, it might make sense that only a small percentage were included in the outcome dataset, but if your program delivers onsite services, you might expect everyone to be included. Did your evaluation include responses from those the program intended to serve (i.e., how close to $100 \%$ did you get in section $\mathrm{F}$, item b)? Were you able to collect information from participants who stopped attending? What did you learn from those participants that stopped attending? You might find it helpful to think about whether you included different groups, such as regular attendees versus infrequent attendees or other important subgroups related to age, gender, or race/ethnicity. Your program's specific goals can help you identify what characteristics are important to consider when thinking about how well your evaluation represents the population you serve.

\section{Q6}

\section{What Did You Learn by Completing Page 2 of the OW?}

Page 2 of the $\mathrm{OW}$ is designed to help you critically analyze the different aspects of the outcome data to help you think about how you might want to respond to the results. For example, if you learn from this worksheet that your outcome dataset does not represent the target population or the population you served, you might want to think of ways that you could improve your outcome data so that you can draw better conclusions from the results. This and other responses from this page may give you some ideas for developing a CQI initiative. 


\section{DESCRIBE THE PROGRAM'S DATA}

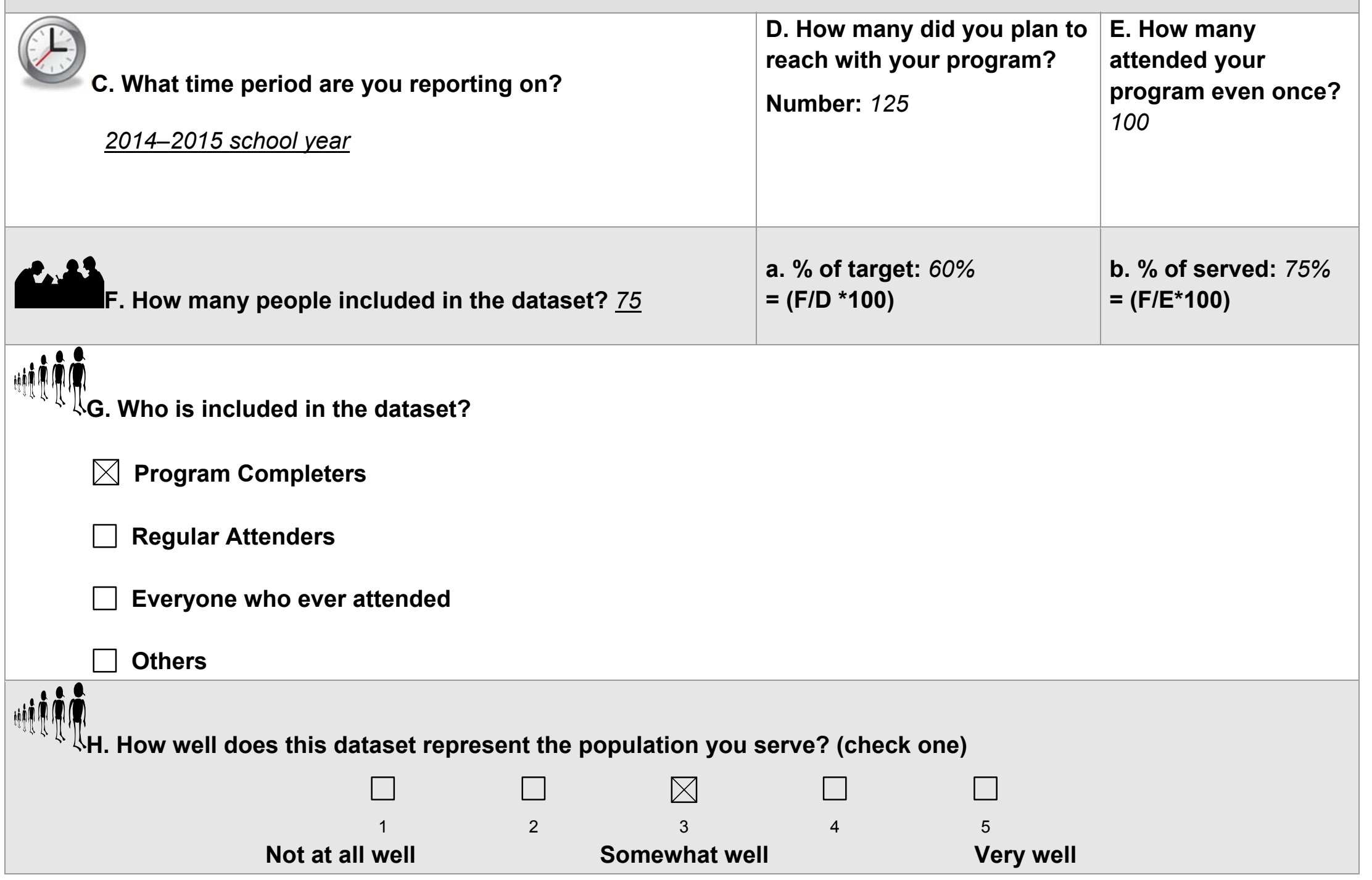




\section{Outcomes Worksheet Page 3, Program Outcomes}

Page 3 of the OW helps you compare the proposed outcome objectives (that you specified in the first section of this worksheet) with the actual program outcomes, that is, what actual impacts occurred. This page is similar to page 3 of the DW, but now you will be filling in information about the program's outcome objectives rather than the program delivery objectives.

The key questions to answer in this section of the worksheet include:

- My Program Outcome Objective-Copy the program outcome objective(s) that you filled in on page 1 under I, J, and K. We have made room for up to three outcome objectives; your program may have more or fewer objectives.

- Measure(s) - In this section, describe what you are measuring to figure out whether you are meeting the program outcome objective. For example, you may have an objective to reduce how favorable participants' attitudes are towards anti-social behavior by $20 \%$.

- Pre-In this section, fill in the pre-program value (from the baseline or intake) on the measure. For attitudinal items from a survey, you may fill in the average value from the participants specified on page 2. For example, if you are measuring anti-social attitudes, you may enter the average value from the pre-survey in this section. In addition to attitudes, another way you might look at pre- and post-data is to determine how many participants behaved in a certain way on a measure. So if you are looking at, for example, reduction in truancy, you may put in the average days truant in the semester prior to the introduction of your program as the pre-value. Note that when calculating your pre-value, you may want to only use data from participants that you have collected both pre- and post-data, so as to not bias your results.

- Post -In this section, note the post-program value (from the follow-up or discharge period) for your outcome. Enter the average value across participants included in the outcome dataset as specified on Page 2.

- Difference/change-For this section, note whether there is a difference between your pre- and post- results and whether the changes were in the expected direction (e.g., did the reading scores improve over time?). One useful way to look for change is to count the number of participants that changed their scores in the expected direction and compute a percentage of participants who experienced change. For example, if you are looking at truancy rates, you might count the number of participants who reduced their days truant from the pre-period (e.g., the semester prior to the program) to the post-period (e.g., the semester after the program ended). If you have the resources to conduct a basic statistical probability test, you can determine whether the values from the pre- and post- measures are "statistically significant"; that is, the likelihood that the changes were not due to chance alone. For more information on how to conduct statistical probability tests on your data, you may want to refer to Cozby (2004).

- Met objectives? For this section, you are first asked to indicate whether you hit, missed, or exceeded your objective. "Hit" means that you met your program outcome objective, e.g., the truancy rate was reduced by $10 \%$ or positive attitudes towards anti- social behavior was reduced by $20 \%$. "Missed" means, in our example, that you had fewer than a $10 \%$ reduction in the truancy rate or less than a $20 \%$ reduction in positive attitudes towards anti-social behavior. "Exceeded" means that you had more than a $10 \%$ reduction in truancy and over a $20 \%$ reduction in positive attitudes towards anti-social behavior.

- Next, this section prompts you to answer the question "What is the trend?" This is asking you to compare the findings from this time period (see Section $C$ on page 2 to remind yourself of the time period from findings from prior periods) to determine whether the program's performance is better, worse or about the same as before. 
- Action needed? Here, the worksheet is prompting you to consider whether you need to take action (comparing your objective to your actual). Do you think you need to take action on this objective/measure? If you are not meeting your objectives or the trend is getting worse, check yes. Check no if you are meeting or exceeding your objectives, and therefore no action is needed.

\section{Z1 What Did You Learn by Completing Pages 3 of the OW?}

Go through the process outlined in "Tip: How to Organize Your Work" for each program outcome objective. You may see that some measures will require action, whereas others may not. You may find that you have not collected the information needed to assess whether your program is meeting its objectives. These issues all point to areas that you may want to consider as part of your CQI initiative, which will be covered in greater detail in "Chapter 5: Identifying a CQI Action."

\section{Outcomes Worksheet (OW) Summary}

Now it is time to reflect on what you have filled in on OW. You may want to share the information at a staff meeting so everyone involved in the program has a chance to respond to what has been learned and suggest ways to make improvements. Page 3 of the worksheet is designed to tell you exactly the areas that need additional attention (Action Needed? Yes or No), however, that there may be other places on the OW that you were unable to complete because information was not available. Not having the information to complete the worksheet may also suggest an area to focus on for CQI. 


\section{PROGRAM OUTCOMES}

1

I. My Program Outcome Objective \#1: (see page 1) Improve reading scores for $75 \%$ of the mentees

\begin{tabular}{|c|c|c|c|c|c|c|}
\hline $\begin{array}{l}\text { Measure(s) } \\
\text { What are you measuring to } \\
\text { figure out whether you are } \\
\text { meeting the program outcome } \\
\text { objectives? }\end{array}$ & $\begin{array}{l}\text { Pre } \\
\text { The value before } \\
\text { the program }\end{array}$ & $\begin{array}{l}\text { Post } \\
\text { The value after the } \\
\text { program }\end{array}$ & $\begin{array}{l}\text { Difference/Change } \\
\text { The difference between the } \\
\text { pre and post value }\end{array}$ & \multicolumn{2}{|c|}{$\begin{array}{c}\text { Met Objective? } \\
\text { Is the difference/change the same as (met), less } \\
\text { than (missed), or more than (exceeded) the } \\
\text { objective? }\end{array}$} & $\begin{array}{l}\text { Action Needed? } \\
\text { Based on this information, } \\
\text { does something in the } \\
\text { program need to change? }\end{array}$ \\
\hline $\begin{array}{l}\text { Reading scores on } \\
\text { report cards from Spring } \\
2014 \text { and Spring } 2015\end{array}$ & $\begin{array}{l}\text { Must look at } \\
\text { individual } \\
\text { value (1 = } \\
\text { needs } \\
\text { improvement } \\
\text { and } 4= \\
\text { excellent) }\end{array}$ & $\begin{array}{l}\text { Must look at } \\
\text { individual value } \\
(1=\text { needs } \\
\text { improvement } \\
\text { and } 4= \\
\text { excellent })\end{array}$ & $\begin{array}{l}40 \% \text { of mentees } \\
\text { improved their reading } \\
\text { scores }\end{array}$ & \multicolumn{2}{|c|}{$\begin{array}{l}\square \text { Met } \quad \square \text { Missed } \quad \square \text { Exceeded } \\
\text { What is the trend from prior periods? } \\
\square \text { Better } \quad \text { Same } \square \text { Worse }\end{array}$} & $\triangle$ Yes $\square$ No \\
\hline & 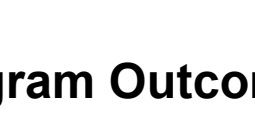 & 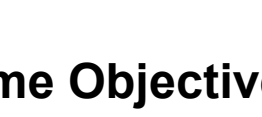 & 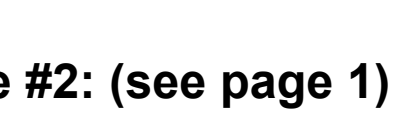 & \multicolumn{3}{|c|}{$\begin{array}{l}\text { Reduce the number of unexcused absences for mentees } \\
\text { by } 50 \%\end{array}$} \\
\hline Measure(s) & Pre & Post & Difference/Change & \multicolumn{2}{|r|}{ Met Objective? } & Action Needed? \\
\hline $\begin{array}{l}\text { Unexcused absences } \\
\text { (from school records) } \\
\text { from Spring } 2014 \text { and } \\
\text { Spring } 2015\end{array}$ & $\begin{array}{l}\text { Average } \\
\text { number }=13\end{array}$ & $\begin{array}{l}\text { Average } \\
\text { number }=10\end{array}$ & $-3(23 \%$ reduction) & \multicolumn{2}{|c|}{$\begin{array}{l}\square \text { Met } \quad \square \text { Missed } \quad \square \text { Exceeded } \\
\text { What is the trend from prior periods? } \\
\square \text { Better } \quad \square \text { Same } \square \text { Worse }\end{array}$} & $\triangle$ Yes $\square$ No \\
\hline K. Мy & & $10 \mathrm{~J}$ & & \multicolumn{3}{|c|}{$\begin{array}{l}\text { Increase the percentage of mentees who report } \\
\text { perceptions of harm from frequent use of alcohol by } 80 \%\end{array}$} \\
\hline Measure(s) & Pre & Post & Difference/Change & \multirow{2}{*}{\multicolumn{2}{|c|}{$\begin{array}{l}\square \text { Met } \quad \square \text { Missed } \square \text { Exceeded } \\
\text { What is the trend from prior periods? } \\
\square \text { Better } \quad \square \text { Same } \square \text { Worse }\end{array}$}} & Action Needed? \\
\hline $\begin{array}{l}\text { Pre-post mentee survey } \\
\text { item about perceived } \\
\text { harmfulness of daily } \\
\text { alcohol use (very harmful = } \\
3 \text {, somewhat harmful = 2, } \\
\text { not at all harmful = 1) }\end{array}$ & $\begin{array}{l}75 \% \text { of mentees } \\
\text { perceive daily } \\
\text { alcohol use as } \\
\text { harmful }\end{array}$ & $\begin{array}{l}93 \% \text { of mentees } \\
\text { perceive daily } \\
\text { alcohol use as } \\
\text { harmful }\end{array}$ & $18 \%$ improvement & & & $\begin{array}{l}\square \text { Yes } \square \text { No } \\
\text { It is already quite high, } \\
\text { cannot improve by } 80 \%\end{array}$ \\
\hline
\end{tabular}




\section{The Component Worksheet (CW)-Worksheet 3: Overview}

The CW is organized by the four phases or stages of a program: referrals, intake, service delivery, and outcomes. We consider these phases descriptive of the stages many programs go through, although we know for some programs there may be other phases called by different names. For example, if your program is a media campaign, you may not have an "intake" phase. And in this case, the "referrals" section might be outreach or recruiting. You may need to think about how the questions and guidance offered can be adapted to fit the unique needs of your program. Also, this worksheet can be used by both new and experienced CQI teams to provide a holistic look at your program.

\section{Contents}

The CW, which is just one page, is organized into four sections or columns that correspond with four program phases:
1) Section $A$ : referrals
2) Section B: intake
3) Section C: services and
4) Section D: outcomes.

The boxes in the center of the worksheet contain prompts in the form of questions for you to consider for each of the four program phases (i.e., referrals, intake, services, and outcomes). The boxes above these are designed for listing strengths of each phase, and the boxes below are designed for listing weaknesses. We will next describe what is meant by the prompts in order to help you think about how to fill in information about your program's strengths and weaknesses.

\section{TIPS FOR COMPLETING THE WORKSHEET:}

- List as many items as your team can think of for each of the four phases. It is okay if not everyone agrees on the entire list. On the first pass, write down all the ideas you can come up with and, if there is doubt, put a question mark next to the item in question. You can try to reach consensus among your group later.

- Do not worry if you cannot think of any particular items. Noting the lack of items in any one phase can be just as useful to the CQI process as listing many.

When listing weaknesses, concentrate on elements that are within your control to change. For example, if you list "poor attendance" as a weakness, it is possible that you could adjust the hours of program operation as part of your CQI effort, but if you list "poor attendance due to lack of access to a bus route," it is unlikely that you can reroute city buses. 


\section{Instructions to Complete the Component Worksheet (CW)}

\section{Component Worksheet Section A: Referrals}

On the left-hand side of the CW, the first box is titled "A. Referrals." The first stage of many service programs is to recruit participants and/or receive referrals and/or applications to participate in the program. For many CSO programs, participants may be referred by other community organizations, different parts of the same CSO, or through self-referral. The term "referral" is not limited to formal systems, but is intended to include all the ways in which participants might learn of or initially access your program such as outreach and recruitment. This section is designed to have you think about different aspects of your program's referral process and the strengths and weaknesses of it. The box in the middle of the first column of the CW worksheet titled Referrals provides a short list of prompts to help you think about the strengths and weaknesses of your program's referral process:

- Marketing materials/efforts used? Think about the current and past marketing efforts for the program; have you been successful at recruiting the program target population to the program?

- Funding fit? Consider whether the current referrals are in line with program funding; is your program receiving referrals that fit with funder's requirements? For example, if funders require referrals of individuals who are on public assistance, is the program currently serving public assistance clients?

- Reaching intended population? Does the program serve the "right" number of the "right" people?

- Program perceived valuable? Is the program valued in the community it serves or from which referrals come?

- Process user-friendly? Is it easy for other agencies/organizations/individuals to refer to the program? What is the process?

- Personal relationships? Do appropriate relationships exist among other agencies, organizations, and/or individuals in the community that make referrals to your program?

- Coordination with related programs? Is there an understanding across the organization in which the program lives to support referrals to the program? Are other program staff "aware" of the program and knowledgeable about how to refer to it?

- Other? There may be other factors that influence referrals to the program, such as policy (e.g., there is state mandate for program participation), community (e.g., the local probation department refers all first-time offenders to the program), and organizational factors (e.g., staff from another program in your agency consistently refers clients to your program).

Your analysis of your marketing, referral process, existing relationships, etc., should identify the strengths and weaknesses that make it easy or difficult to access your program.

The box above the prompts is labeled "Strengths" to denote where you should document aspects of the referral process that make it easy to refer to or facilitate the referral process for your program.

The box below the prompts is labeled "Weaknesses" to denote where you should document the aspects that slow down or prevent the referral process from working properly. 
First, consider what aspects may positively impact the referral process to your program (i.e., "Strengths"). These could be things going on in your community, related to organizations that refer to your program, specific to your CSO, or related to the family/individual being referred. Example strengths include:

- Free or low-cost services

- Incentives for participants or referral sources

- Easy access

- Mandates require attendance

- Reputation.

The above list is not exhaustive, but gives you a flavor of the kind of aspects that encourage referrals to a program. In the box in the upper left-hand portion of the worksheet in the box labeled "Strengths," list any positive aspects that you and your team think makes it easy to refer to or makes the referral process work well for your program.

Now, think about the opposite side of the coin. What are the things that may slow down or prevent referrals to your program? Document these "Weaknesses" in the box located below the Referrals box. Like the strengths of the referral process, the weaknesses can be things happening in your community, related to referral organizations, specific to your CSO, or about the family/individual that is being referred. Example weaknesses include:

- Inconvenient location

- Not well known

- The program duplicates services already provided in the community

- $\quad$ Lengthy and time-consuming process

- Wait list.

You may find that your program has weaknesses that contradict some of the strengths. For example, having a free program may be perceived as both a strength (i.e., there are no cost barriers to keep people from participating) and a weakness (i.e., there is a long wait to obtain services because they are free). Later on in the CQI process, you might want to address the pros and cons of having a free program and make a decision to test the usefulness of a low-cost, rather than free program. The overall goal of this section is to identify all the strengths and weaknesses related to the referral process operating in the program, and it is possible to have contradictory information. The negative aspects (i.e., weaknesses) especially are possible candidates for tackling in a CQI initiative. 


\section{WORKSHEET 3: COMPONENT WORKSHEET (CW)}

Program Name: Mentoring Program

Date: $3 / 30 / 2015$

The purpose of this worksheet is to document strengths and weaknesses of the different program phases (i.e., referrals, intake, service delivery and outcomes).

A. Referrals

\begin{tabular}{l}
\multicolumn{1}{c|}{ Strengths } \\
Strong Advisory Board with good \\
networks in the community \\
Local business provides incentives \\
to employees for mentoring \\
Strong school support for program, \\
we have enough referrals
\end{tabular}

\section{1}

\section{A. Referrals}

- Marketing materials/efforts used?

- Funding fit?

- Reaching intended population?

- Program perceived valuable?

- Process user- friendly?

- Personal relationships?

- Coordination with related programs?

- Other?

\section{$\checkmark$}

\section{Weaknesses}

Do not have enough mentors

(especially for boys)

Some teachers refer students who do not score below average on reading
B. Intake to Program

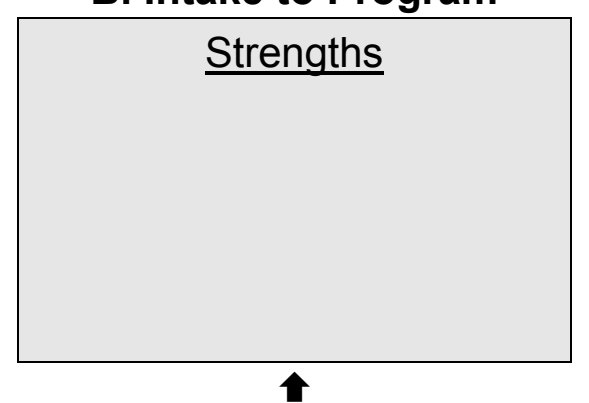

B. Intake to Program

- Schedule meets clients' needs?

- Adequate numbers/waiting list?

- Resources?

- Follow up with referral/client?

- Assessment process?

- Coordination/cross referral?

- Evaluation of intake process?

- Other?
C. Service Delivery

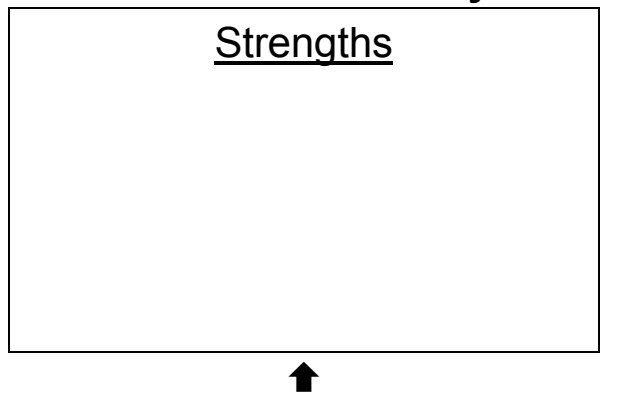

\section{Service Delivery}

- Evidence-based?

- Quality and consistency?

- Attendance/completion/retention?

- Adequate/quality materials?

- Client satisfaction /experience?

- Serving intended population?

- Resources (staff training, curriculum)?

- Follow-up?

- Other? $v$

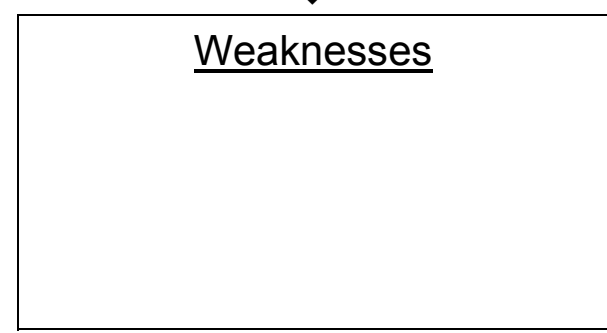

D. Outcomes

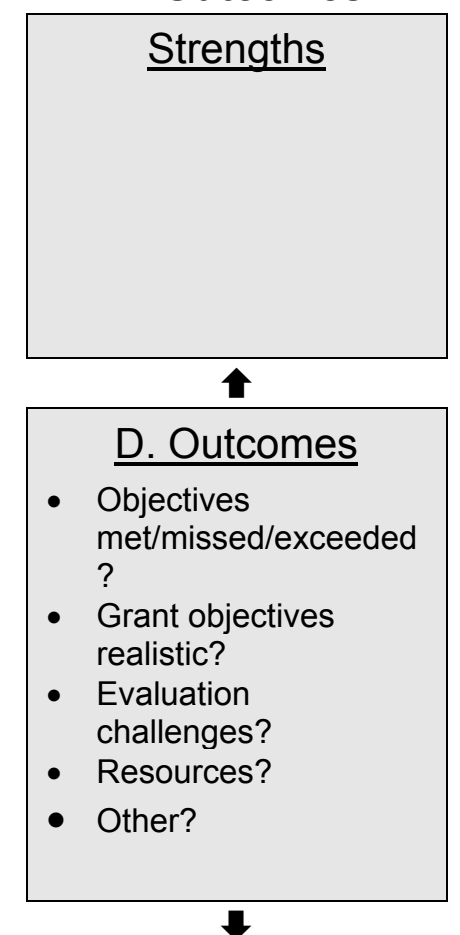

Weaknesses 


\section{Component Worksheet (CW) Section B: Intake to Program}

The next section tackles the intake process. By intake process, we mean any steps necessary before a participant begins receiving the program. For some programs, an intake process may not exist (e.g., in a classroom-based prevention program), may be as brief as a five-minute telephone call, or may be as intensive as an in-person interview. Whatever the form of intake process your program has, in the next section of the CW (Section B. Intake, second column from the left), you are asked to think about its strengths and weaknesses.

The box titled B. Intake to Program provides several prompts to help you think about the strengths and weaknesses of your program's intake process. Some of these prompts may or may not be relevant to your particular program (e.g., a classroom-based prevention program), but may stimulate your thinking. Consider these questions as you read through the prompts:

- Schedule meets clients' needs? Does the program's intake schedule meet the clients' needs? Are intakes offered at times that the potential clients are available (e.g., afternoons, evenings, weekends)?

- Adequate numbers/waiting list? Do potential clients have to wait to receive the program? And vice versa, are there enough intakes to promptly offer the program to interested clients?

- Resources? Are there adequate staff, skills, training, facilities, and transportation to conduct program intakes?

- Follow-up with referral/client? Is there adequate follow-up with clients to ensure that they receive appropriate services?

- Assessment process? Do you use an assessment tool at intake? How is that information used to provide appropriate services to clients? What happens when you assess a client that is not appropriate for your program? How do you get them the services that they need?

- Coordination/cross referral? What coordination with other service provider(s) is there? Is there a process to appropriately share information? If it's appropriate, is there a shared database to access and exchange client information?

- Evaluation of intake process? Is there any evaluation of your program's intake process? Do you know how many referrals fail to make it to intake? Why?

- Other? Are there other issues about your program's referral process to consider?

As you ask these questions, think about categorizing your responses into the strengths and weaknesses of your program's intake process. Also, think about the factors that make your intake process work smoothly as compared to the factors that slow down or impede your program's intake process. Examples of the strengths of a program's intake process include:

- No waiting lists

- Flexible scheduling

- Offered where clients live/work/attend school.

Conversely, examples of weaknesses include:

- Long waiting lists

- Inconvenient intake times

- Lack of bilingual staff

- Barriers, such as paperwork or other requirements needed for intake

- Not enough space or privacy to conduct intakes

- Intake process is redundant with referral agencies, increasing burden on clients. 
Again, brainstorming about both the strengths and weaknesses associated with the intake process for your program may help to identify possible areas on which to focus during your CQI initiative. 


\section{WORKSHEET 3: COMPONENT WORKSHEET (CW)}

Program Name: Mentoring Program

Date: $3 / 30 / 2015$

The purpose of this worksheet is to document strengths and weaknesses of the different program phases (i.e., referrals, intake, service delivery and outcomes).

\section{A. Referrals}

\section{Strengths}

Strong Advisory Board with good networks in the community

Local business provides incentives to employees for

mentoring

Strong school support for program, we have enough referrals

1

\section{A. Referrals}

- Marketing materials/efforts used?

- Funding fit?

- Reaching intended population?

- Program perceived valuable?

- Process user- friendly?

- Personal relationships?

- Coordination with related programs?

- Other?

\section{$\sqrt{2}+2$}

\section{Weaknesses}

Do not have enough mentors (especially for boys)

Some teachers refer students who do not score below average on reading

\section{B. Intake to Program}

\section{Strengths}

Staff go to schools and meet with teachers and students to do

intake-easy for mentees

\section{1}

\section{B. Intake to Program}

- Schedule meets clients needs?

- Adequate numbers/waiting list?

- Resources?

- Follow up with referral/client?

- Assessment process?

- Coordination/cross referral?

- Evaluation of intake process?

- Other?

7

\section{Weaknesses}

It is challenging to get mentorsneed help screening and streamlining process (TB test, fingerprinting)

\section{Service Delivery}

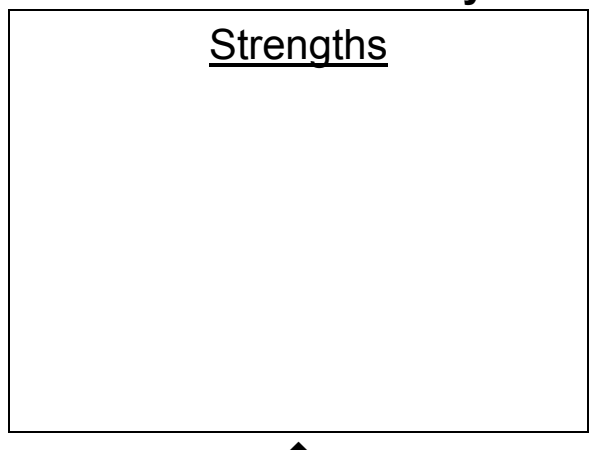

\section{Service Delivery}

- Evidence-based?

- Quality and consistency?

- Attendance/completion/retention ?

- Adequate/quality materials?

- Client satisfaction /experience?

- Serving intended population?

- Resources (staff training, curriculum)?

- Follow-up?

- Other?

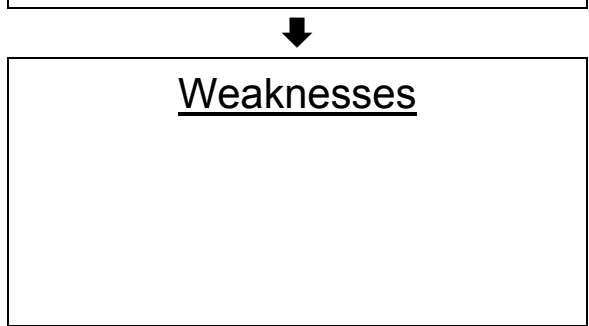

\section{Outcomes}

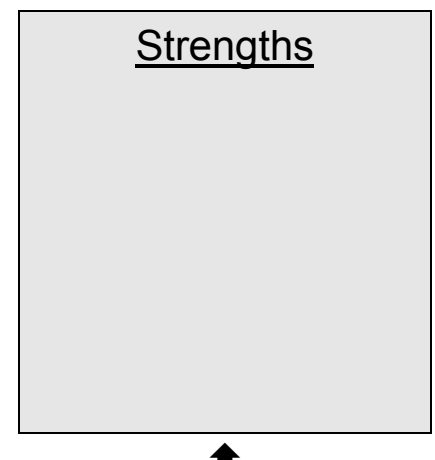

\section{Outcomes}

- Objectives $\mathrm{met} / \mathrm{missed} / \mathrm{exceeded}$

- Grant objectives realistic?

- Evaluation challenges?

- Resources?

- Other?

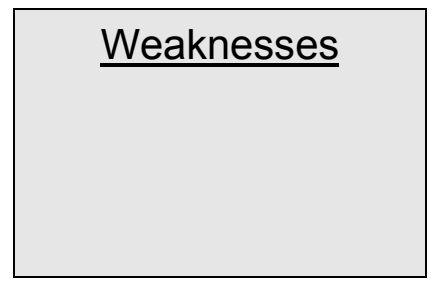




\section{Component Worksheet (CW) Section C: Service Delivery}

After an individual finishes a program's intake process, the next stage is usually to start receiving the program's services. Services may have strengths or weaknesses in their delivery that influence the program's quality. In the next section of this worksheet (C. Program Services), you are asked to consider the quality of the program's service delivery. If you completed the DW, have it handy as you complete this section, as the information on the DW may be relevant to include as a strength or weakness in this section of the CW. Hopefully you will have some information about whether the program achieved its desired program delivery objectives; we mean the service goals for your program, for example, the amount of a particular target population (e.g., at-risk youth) served, the number of program components delivered (e.g., six sessions delivery annually), retention, or other factors related to how much of the program was delivered. Although you might not have quantitative data about your program's service delivery, you may still be able to reflect on the strengths and weaknesses on it.

In the box titled "C. Service Delivery," you are provided with several prompts to help you think about the aspects of program services that enhance or reduce its quality. Frequently, the quality of services delivered may be unknown. If you completed the DW, what did you learn from that exercise? Did you identify some strengths and weaknesses of your program's service delivery? Consider these questions as you read through the prompts:

- Evidence-based? Is the program evidence-based, meaning has the program that you are delivering been tested and shown to be effective? If not, can it be modified to make it more in line with evidence-based practices and principles, such as those suggested by available research, professional associations you belong to, or accreditation bodies?

- Quality and consistency? Is the delivery of services consistent with the program intent, procedures, and principles? Are the "core components" considered to be critical to making the program successful consistently delivered to each client? The extent to which core components of the program are delivered as intended by the developers of the program is often called fidelity. Is fidelity being monitored? If yes, what is the level of fidelity of the program?

- Attendance/Completion/Retention? Are rates of program attendance, completion, and retention meeting program delivery objectives? Why or why not?

- Adequate/quality materials? Does the program have adequate materials (e.g., equipment, handouts, and visual aids) needed to deliver content?

- Client satisfaction/experience? Are the program participants satisfied with the services they received?

- Serving intended population? Is the program a good match for the population it is serving?

- Resources? Are there adequate resources (staff, skills, training, facilities, and transportation) to deliver the program as intended?

- Follow-up? Were participants referred to appropriate services following or in lieu of participation in your program?

- Other? Are there other issues about your program's service delivery to consider?

Again, as you address these prompts, categorize your responses into "strengths" and "weaknesses" of your program. If the answers to most of these questions are not known, you might need to consider collecting data to address them. Examples that suggest program service delivery of higher quality (i.e., strengths) are:

- Use of evidence-based guidelines or curricula

- High attendance and completion rates 
- Adequate handouts, videos or other materials used to present content

- High client satisfaction/positive client experience

- Intended population is served (e.g., 100 at-risk 9 th graders)

- Referrals are made at last session as appropriate.

Examples that suggest program service delivery is of unknown or lower quality (i.e., weaknesses) include:

- Not aligned with evidence-based guidelines/curricula

- Fidelity is low or not regularly monitored

- Incomplete program delivery (e.g., only $50 \%$ of the program's lessons are taught)

- Attendance/completion/retention are low or not regularly monitored

- No training for staff delivering program

- No provision for follow-up services

- Transportation to and from the service is not available or was discontinued. 


\section{WORKSHEET 3: COMPONENT WORKSHEET (CW)}

Program Name: Mentoring Program

Date: $3 / 30 / 2015$

The purpose of this worksheet is to document strengths and weaknesses of the different program phases (i.e., referrals, intake, service delivery and outcomes).

\begin{tabular}{|l|}
\multicolumn{1}{c|}{ A. Referrals } \\
\multicolumn{1}{c|}{ Strengths } \\
Strong Advisory Board with good \\
networks in the community \\
Local business provides incentives \\
to employees for mentoring \\
Strong school support for program, \\
we have enough referrals \\
\hline
\end{tabular}

\section{1}

\section{A. Referrals}

- Marketing materials/efforts used?

- Funding fit?

- Reaching intended population?

- Program perceived valuable?

- Process user- friendly?

- Personal relationships?

- Coordination with related programs?

- Other?

\section{$\sqrt{2}$}

\section{Weaknesses}

Do not have enough mentors (especially for boys)

Some teachers refer students who do not score below average on reading

\section{B. Intake to Program}

\section{Strengths}

Staff go to schools and meet with teachers and students to do intake-easy for mentees

\section{1}

\section{B. Intake to Program}

- Schedule meets clients' needs?

- Adequate numbers/waiting list?

- Resources?

- Follow up with referral/client?

- Assessment process?

- Coordination/cross referral?

- Evaluation of intake process?

- Other?

\section{$\sqrt{7}$}

\section{Weaknesses}

It is challenging to get mentorsneed help screening and streamlining process (TB test, fingerprinting)

\section{Service Delivery} Strengths

Monthly training program offered to mentors

Events during school year for mentors/mentees and families to participate

1

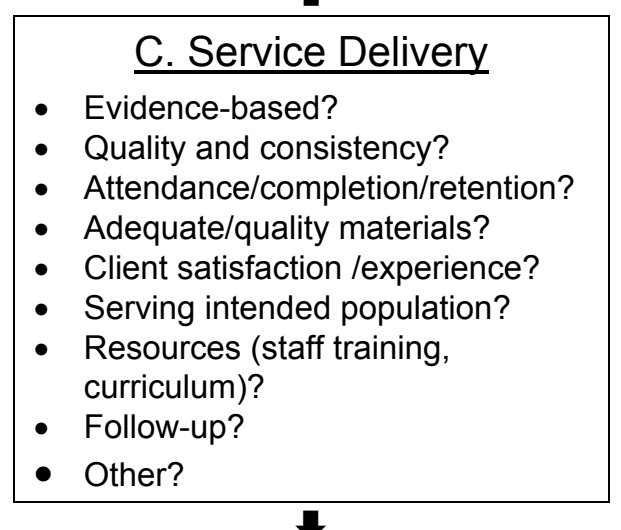

\section{Weaknesses}

Most mentoring relationships last less than one year

We had trouble meeting target number because we did not have enough male mentors

\section{Outcomes}

\section{Strengths}

1

\section{Outcomes}

- Objectives met/missed/exceeded ?

- Grant objectives realistic?

- Evaluation

challenges?

- Resources?

- Other?

7

$\underline{\text { Weaknesses }}$ 


\section{Component Worksheet (CW) Section D: Outcomes}

Once a program is delivered, you will want to know whether the program was effective in the final stage, outcomes. The fourth column of the CW is titled "D. Outcomes." It is helpful to have some information about whether the program achieved its desired program outcome objectives, that is, the specific changes expected in the target population as a result of program participation. Program outcome objectives may be related to changes in individual participants' knowledge, attitudes, or behaviors or can be related to community-level changes, such as changes in community awareness, policies, or actions around a certain issue such as underage drinking. Remember that in order to see a change, you must have information from at least two time points-before the program and after the program. Ensuring that your program collects useful data can sometimes be a CQI challenge. If you do not have quantitative, numeric data about your program's outcomes (e.g., pre- and post-program survey data), you may still complete this part using what you know about your program's outcome objectives. If you completed the $\mathrm{OW}$, have that information handy as you complete this section of the $\mathrm{CW}$-it may be relevant to include some of the information as a strength or weakness in this section of the CW.

In the box titled "D. Outcomes," you are provided with several prompts to help you consider the strengths and weaknesses of the program's outcomes. Consider these questions as you read through the prompts:

- Objectives met/missed/exceeded? Were the program's outcome objectives met, missed, or exceeded? Of course, this requires having agreed upon outcome objectives. Not having agreed upon outcome objectives for the program may be something that you could document as a weakness.

- Grant objectives realistic? Are your program's outcome objectives, outlined in grant or other documentation, realistic? Could they be easily achieved by those that fully participated in the program?

- Evaluation challenges: Were there challenges with the program's evaluation or assessment of objectives that need more attention? For example, were you able to get information from all program participants to assess outcomes?

- Resources? Does your program have enough resources (e.g., staff time, evaluation expertise and support) to monitor and meet the program's objectives?

- Other? Are there other issues about your program's outcomes to consider?

As with previous sections of the $\mathrm{CW}$, next consider your responses to these prompts as either strengths or weaknesses. Examples that suggest the outcomes component of the program is strong are:

- Objectives were exceeded (e.g., there was a significant increase in skills).

- Objectives were realistic (e.g., plans to serve 100 students in the current fiscal year were met).

- New staff were trained on completing both the pre-test at intake and post-test at exit interview with each participant.

Examples that suggest that the outcomes component of a program is weak include:

- No baseline data were collected, so outcomes could not be assessed.

- Objectives were not met.

- It was difficult to obtain outcome data (e.g., schools would not share data on grades or truancy).

- There was difficulty in administering surveys (e.g., no staff available). 


\section{WORKSHEET 3: COMPONENT WORKSHEET (CW)}

Program Name: Mentoring Program

Date: $3 / 30 / 2015$

The purpose of this worksheet is to document strengths and weaknesses of the different program phases (i.e., referrals, intake, service delivery and outcomes).

\section{A. Referrals}

\begin{tabular}{|l|}
\multicolumn{1}{c|}{ Strengths } \\
Strong Advisory Board with good \\
networks in the community \\
Local business provides incentives to \\
employees for mentoring \\
Strong school support for program, \\
we have enough referrals
\end{tabular}

\section{1}

\section{A. Referrals}

Marketing materials/efforts used?

Funding fit?

Reaching intended population?

Program perceived valuable?

Process user- friendly?

Personal relationships?

- Coordination with related programs?

- Other?

\section{7}

\section{Weaknesses}

Do not have enough mentors (especially for boys)

Some teachers refer students who

do not score below average on reading

\section{B. Intake to Program}

\section{Strengths}

Staff go to schools and meet with teachers and students to do intakeeasy for mentees

\section{1}

\section{B. Intake to Program}

Schedule meets clients' needs? Adequate numbers/waiting list?

\section{Resources?}

Follow up with referral/client?

Assessment process?

Coordination/cross referral?

Evaluation of intake process?

- Other?

\section{7}

\section{Weaknesses}

It is challenging to get mentorsneed help screening and streamlining process (TB test, fingerprinting)

\section{Service Delivery}

\section{Strengths}

Monthly training program offered to mentors

Events during school year for mentors/mentees and families to participate

\section{1}

\begin{tabular}{|l|}
\multicolumn{1}{|c|}{ C. Service Delivery } \\
- Evidence-based? \\
- Quality and consistency? \\
- Attendance/completion/retention? \\
- Adequate/quality materials? \\
- Client satisfaction /experience? \\
- Rerving intended population? \\
- currources (staff training, \\
- Follow-up? \\
- Other? \\
\hline
\end{tabular}

\section{Weaknesses}

Most mentoring relationships last less than one year

We had trouble meeting target number because we did not have enough male mentors

\section{Outcomes}

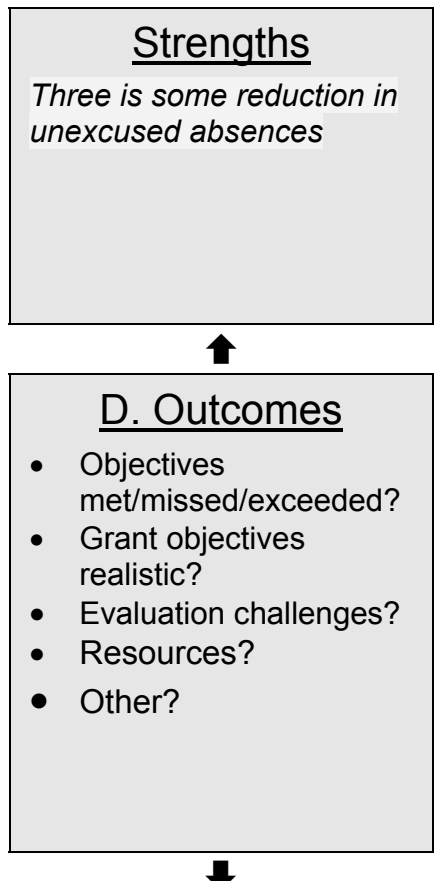

\section{Weaknesses}

It is difficult to achieve outcomes if mentoring relationship doesn't last

long enough to have impact

Re-evaluate objectives, most already perceive alcohol as harmful, no room for improvement 


\section{Component Worksheet (CW) Summary}

Once you have finished brainstorming about your program's strengths and weaknesses, congratulate yourselves! You have just completed a systems approach to analyzing your program as you have thought about each phase of your program and considered what is working and not working well. This is one of the first steps in conducting your CQI process.

In future efforts, you may have more objective assessments on which to base your assessment of the program components than relying on the brainstorming method outlined in the $\mathrm{CW}$. We encourage you to think about moving toward objective assessments of your program components rather than relying on brainstorming sessions on program strengths and weaknesses as you become more experienced with CQI.

\section{TIP: How to ORganIze YOUR WORK}

Here are a few suggestions on how to organize your findings from the worksheet:

? The "?" Category: First, find on your worksheet areas where information was missing, unknown, or contradictory. Think about whether you need more information to address these areas. If so, circle them and put a "?" next to them to identify those areas that need further information.

+ The "+" Category: Second, find where your program is doing well. Think about whether those aspects of your program can be sustained over time and whether they will need attention to be maintained. If so, circle those areas and put a "+" next to them.

! The "!" Category: Third, look for places on your worksheet that suggest room for improvement. Circle those areas and put a "!" next to them. How can you tackle those weaknesses in your program?

These three categories suggest areas in which you might want to focus your CQI efforts (especially if you have more than one symbol by them!). For some items you have put in the first category (denoted by a "?"), you may need to go on a fact-finding mission to learn more about your program. The items you have put in the second category (denoted by a "+") are program strengths that you might want to sustain over time. The items in the third category (denoted by a "!") are weaknesses that need attention. Any one of these categories can be further fleshed out as part of your quality improvement initiative, which we call a CQI Action. A CQI Action is the quality improvement initiative that you decide to undertake to improve your program. We will talk more about that in Chapter 5.

Now that you have gathered all your ideas, it is time to go back and reflect on what you have written. Use the "!," "+," and "?" symbols on your strengths and weakness in each of the four components. You may find that some require action where others may not. Circle or highlight the areas that require action. You may want to share the information at a staff meeting so everyone involved in the program has a chance to respond to what has been learned and suggest ways to make improvements. 


\section{EXAMPLE: PLAN A CQI WORKSHOP}

Acting as CQI coaches, we assisted a CSO in organizing a one-day CQI Workshop once the worksheets in this chapter were completed by program staff. The workshop provided an opportunity for everyone with a stake in the program's efforts to come together to develop a CQI Action based on the review of the worksheets. We provide the details of how to plan your own CQI Workshop in Appendix C.

\section{Chapter Summary}

Consistent with proven CQI methods, you have now successfully gathered data about your program in a systematic way. The DW, OW, and CW should have helped you take a useful snapshot of your program. This is consistent with the "Planning" phase of the PDSA cycle because you systematically gathered information about your program. In the next chapter, we will discuss how to apply what you gathered and learned about your program to help make the next set of planning decisions about how to specifically improve your program.

\section{Checklist}

Once you have finished this chapter, you will have accomplished the following:

Identified strengths and weaknesses of your program's major components

Identified areas where information about your program's major components is missing, unknown, or contradictory as well as flagged possible areas for improvement

Described program needs and objectives

Documented program delivery

Examined how well the program delivery and outcome objectives were met

Documented the program outcomes and how well they reflect on the program

Identified areas where information about program delivery, objectives, and impact is missing, unknown, or contradictory as well as flagged possible areas for improvement. 


\section{conatest \\ CQI Step 3: Plan: Identifying a CQI Action}

Experience has taught me that you have to improve all the time-little bit by little bitand not keeping starting everything from new.

Jean Alesi

To improve is to change; to be perfect is to change often. Winston Churchill

In this chapter:

The CQI-Action Identification

Worksheet

(CQI-AIW)

assess the different aspects of your program, prioritize, and identify what to focus on for CQI. Next, we provide you with prompts to help guide you in selecting a CQI Action from your assessment of your program. Recall that a CQI Action is a quality improvement initiative that you decide to undertake to improve your program.

\section{Who Should Be Involved?}

You need to consider the scope of the CQI effort and, based on this, determine as a result who should be involved. CQI can happen on different levels within a CSO. Perhaps you have determined that programs within and outside your CSO could do a better job of communicating with one another to improve referrals to your program, improve service delivery, or help achieve better outcomes. How do you address this? Very often, CQI is an organization-wide effort. You may want to involve staff from multiple departments or programs in the CQI effort. To facilitate this, a multifunctional team, similar to what Ishikawa described as a "quality circle" (see Chapter 2), will need to be convened and time must be set aside for them to work on the issue at hand. This involves coordinating across departments or programs and may involve people who have not yet worked together (see Chapter 3).

In contrast, perhaps you have determined that CQI Action is about the quality of services delivered by program staff, and the effort could be easily addressed by including just program-related staff in the CQI Action. In this case, you will need to consider bringing together staff that may already know one another. This may bring up different issues than normally found in agency-wide CQI efforts. Both can be challenging in different respects but can lead to successful CQI in an organization.

\section{The CQI Action Identification Worksheet (CQI-AIW)- Worksheet 4: Overview}

For this worksheet, it will be helpful to have on hand completed copies of the DW, OW, and CW, as you may want to refer back to them to fill in sections of the CQI Action Identification Worksheet, or CQI-AIW for short. You may wish to have a copy of the CQI-AIW worksheet for reference and note taking as you read through the next sections. You can find a blank version of the CQI-AIW in Worksheet Appendix. 


\section{Contents}

The first page of the CQI-AIW is divided into five sections (in columns). The first column contains the program components listed in the $\mathrm{CW}$. The sections are:

1) Column 1: Identified program components for program action, these could be aspects of the program's referrals, intake, service delivery or outcomes

2) Column 2: My program's performance

3) Column 3: Known challenges

4) Column 4: Setting priorities

5) Column 5: Rationale for priority.

We have allowed you to list up to four program components to consider for action. You may have already thought about focusing on one or two; that is a fine approach too.

On page 2, you will to describe the CQI-Action that you plan to undertake based on your assessment on page 1 of the CQI-AIW.

\section{Instructions to Complete the CQI-Action Identification Worksheet (CQI-AIW)}

\section{CQI-AIW Page 1}

\section{Program Issue}

In this column, list any issue you have identified earlier as needing additional attention. For example, if you identified weaknesses with the program's service delivery, you could list here service delivery as a program issue you would like to consider for CQI. This worksheet allows you to list up to four issues; you may have already identified fewer or more issues.

\section{My Program's Performance}

For each issue you have identified in the first section, answer the following questions:

1. Compared with analysis conducted in a previous time period (e.g., last semester, quarter or last year), identify the trend in your program's performance. Is it better, the same, or worse?

2. Compared with national standards or program benchmarks, is your program's performance better, the same, or worse than expected?

3. Did your program meet, miss, or exceed its objectives?

The work you have done on the worksheets from the last chapter (DW, OW, and CW) will help you to answer these questions. You may not be able to answer all three questions. If you do not know the answers, try to obtain input from other staff before moving on. Unless it is a new program, reports from prior years could give you information about how the program has performed in the past. You could also review previously written grant proposals for your program's funding to glean program objectives and funders' requirements that may give you insight into the program's objectives. You can also read reports about similar programs, available on national, state or local organization or government websites.

\section{Known Challenges}

Next, report known challenges for each of the program issues you have listed. Are there things that make it difficult to meet the program's goals in terms of referral rates? How about outcomes? Document any known challenges. These likely will be similar to or the same as the "weaknesses" you listed for each program component on the CW (Worksheet 3).

\section{Setting Priorities}

Now consider setting priorities among the different issues you have listed. Consider what you have documented about performance and challenges. Is there a need to address less than stellar service 
delivery or is there a particular challenge that is preventing intakes from being completed? You probably have multiple ideas about how your program could be improved. Where do you start? It may be difficult or nearly impossible to make changes to some of the areas that have been identified. You will need to think about which of the issues can be improved and prioritize their need for improvement based on such factors as:

- Need: What is the most important issue that you have identified that requires change?

- Capacity: You might recall from the previous chapter that capacity refers to resources (e.g., staff, skills, training, facilities). What resources do you have to devote to making a change?

- Even with resources, do you have the authority to change the current situation?

- Impact: What change will yield the biggest impact on those served by the program?

- Evidence-base: What change will help move the program to be more in line with the evidence base in your field?

- Scope:

- Sometimes it is best to accomplish a small win in order to build momentum for future CQI activities that are more ambitious.

- No matter what you do, what is most important is that you do not try to do too much at once and to select small quickly achievable changes. By doing so, you will build your capacity to do CQI effectively, which will make future cycles easier.

- If you've identified large-scale problems with your worksheets, these issues require a longer timeframe and strategic planning to create broad organizational change and may be more effectively addressed outside a CQI framework. 
WORKSHEET 4: CQI ACTION IDENTIFICATION WORKSHEET (CQI-AIW)
Program Name:
Mentoring Program
Date: $4 / 15 / 2015$

The purpose of this worksheet is to help you assess your program, prioritize it, and identify what to focus on for CQI.

\begin{tabular}{|c|c|c|c|c|}
\hline 1. Program Issues & 2. My Program's Performance & 3. Known challenges & 4. Setting Priorities & 5. Level Rationale \\
\hline $\begin{array}{l}\text { We don't have enough } \\
\text { male mentors }\end{array}$ & $\begin{array}{l}\text { Compared with prior, what's the trend? } \\
\square \text { Better } \square \text { Same } \square \text { Worse } \\
\text { Compared with national standards or } \\
\text { program benchmarks: } \\
\square \text { Better } \square \text { Same } \square \text { Worse } \\
\text { My program objectives were: } \\
\square \text { Met } \square \text { Missed } \square \text { Exceeded }\end{array}$ & $\begin{array}{l}\text { It is difficult to find } \\
\text { male mentors }\end{array}$ & $\begin{array}{l}\text { Is this a priority } \\
\text { area? } \\
\qquad \begin{array}{l}\square \text { High } \\
\square \text { Medium } \\
\square \text { Low }\end{array}\end{array}$ & $\begin{array}{l}\text { We will better meet our } \\
\text { target population if we can } \\
\text { get more male mentors but } \\
\text { first we need to make sure } \\
\text { the program lasts at least } \\
\text { one year }\end{array}$ \\
\hline $\begin{array}{l}\text { Mentors have to wait } \\
\text { and process to get TB } \\
\text { and fingerprinting } \\
\text { lengthens time }\end{array}$ & $\begin{array}{l}\text { Compared with prior, what's the trend? } \\
\square \text { Better } \square \text { Same } \square \text { Worse } \\
\text { Compared with national standards or } \\
\text { program benchmarks: } \\
\square \text { Better } \square \text { Same } \square \text { Worse } \\
\text { My program objectives were: } \\
\square \text { Met } \square \text { Missed } \square \text { Exceeded }\end{array}$ & $\begin{array}{l}\text { It would be helpful if it } \\
\text { was easier for mentors to } \\
\text { enroll, no wait time for TB } \\
\text { and fingerprinting }\end{array}$ & $\begin{array}{l}\text { Is this a priority } \\
\text { area? } \\
\qquad \begin{array}{l}\square \text { High } \\
\square \text { Medium } \\
\square \text { Low }\end{array}\end{array}$ & $\begin{array}{l}\text { We do not have control over } \\
\text { programs that offer TB and } \\
\text { fingerprinting, could look for } \\
\text { alternative options to get this } \\
\text { done }\end{array}$ \\
\hline $\begin{array}{l}\text { Numbers and length of } \\
\text { mentoring not meeting } \\
\text { program goals }\end{array}$ & $\begin{array}{l}\text { Compared with prior, what's the trend? } \\
\square \text { Better } \square \text { Same } \square \text { Worse } \\
\text { Compared with national standards or } \\
\text { program benchmarks: } \\
\square \text { Better } \square \text { Same } \square \text { Worse } \\
\text { My program objectives were: } \\
\square \text { Met } \square \text { Missed } \square \text { Exceeded }\end{array}$ & $\begin{array}{l}\text { We didn't meet our target } \\
\text { number of students } \\
\text { served and not all } \\
\text { mentees received one full } \\
\text { year of mentoring }\end{array}$ & $\begin{array}{l}\text { Is this a priority } \\
\text { area? } \\
\qquad \begin{array}{l}\square \text { High } \\
\square \text { Medium } \\
\square \text { Low }\end{array}\end{array}$ & $\begin{array}{l}\text { We can work on developing a } \\
\text { summer program so that } \\
\text { mentors/mentees can } \\
\text { continue to meet }\end{array}$ \\
\hline $\begin{array}{l}\text { Not meeting program } \\
\text { outcome objectives }\end{array}$ & $\begin{array}{l}\text { Compared with prior, what's the trend? } \\
\square \text { Better } \square \text { Same } \square \text { Worse } \\
\text { Compared with national standards or } \\
\text { program benchmarks: } \\
\square \text { Better } \square \text { Same } \square \text { Worse } \\
\text { My program objectives were: } \\
\square \text { Met } \square \text { Missed } \square \text { Exceeded }\end{array}$ & $\begin{array}{l}\text { It is difficult to obtain } \\
\text { outcomes when not all } \\
\text { participants are getting } \\
\text { enough mentoring }\end{array}$ & $\begin{array}{l}\text { Is this a priority } \\
\text { area? } \\
\qquad \begin{array}{l}\square \text { High } \\
\square \text { Medium } \\
\square \text { Low }\end{array}\end{array}$ & $\begin{array}{l}\text { For future funding } \\
\text { opportunities, we need to } \\
\text { better understand what } \\
\text { objectives we can meet, but } \\
\text { need to address service } \\
\text { delivery issue first }\end{array}$ \\
\hline
\end{tabular}

Worksheet 4: CQI Action Identification Worksheet (CQI-AIW) - page 1 
Next, determine whether each of the issues you have identified as a priority are a high, medium, or low priority for action.

\section{Rationale for Priority Level}

Finally, you want to document the reasons for the selected priority level. What makes an issue a high or low priority for action in your case?

Once you have reviewed the different aspects of your program and documented priority levels, you should have a better sense of what you will do as part of your CQI Action.

\section{Assess for Feasibility}

For your first CQI Action, we recommend that you try to select an activity that you think your team can accomplish within three months. If you select an activity that will take several months or over a year to accomplish, it is going to be difficult to establish an ongoing CQI process in your organization because it will take too long for your staff to experience what it is like to complete it. Consider making small changes to improve either your program's referral, intake, services, and/or outcomes.

\section{EXAMPLE: LESS IS MORE}

It should be noted that in our work with a CSO, CQI Actions designed to make large-scale changes to the program (e.g., revise an entire curriculum, add a whole new program component) did not succeed as well as efforts that were smaller in scope (e.g., revising program content, changing staff meetings).

\section{CQI-Action Identification Worksheet (CQI-AIW) Page 2, Describe CQI Action}

Once you have assigned priorities among the issues identified on page one and assessed feasibility, you are now ready to identify a CQI Action for your first CQI initiative. In the space provided on page 2 of the worksheet titled 5a. Describe Action, identify one high-priority area to work on as your CQI Action and some details about the action you will undertake to improve your program. For example, describe what the CQI Action will be, why you are undertaking it, and how you think the CQI Action will improve the program. In the next chapter, the worksheets will help you flesh out the details to implement your CQI Action so you should also be thinking about who will be involved, what resources you will need to undertake the Action and the steps needed to implement the Action, as you will be working on that next. 
5a. DESCRIBE YOUR CQI ACTION (SELECT ONE HIGH RANKING PRIORITY AREA FOR CQI AND DEVELOP THE ACTION. l.e., What is the Action? How will it be undertaken? Who will be responsible and what is the timeline for doing it? ):

Describe Action: Support mentors/mentees in meeting over the summer months by providing opportunities for mentors/mentees to meet to increase the length of the mentoring relationship.

Rationale for Action: Research suggests that the mentoring relationship will be beneficial if it lasts at least 12 months, we need to make it easier for the mentors to meet with the mentees over the summer months when school is closed where they typically meet so that the relationship can continue.

How will it be undertaken: The Mentoring project will develop activities for mentors and mentors to participate in over the summer months.

Who will be responsible / timeline: Mentoring program staff will be involved in developing, marketing and hosting activities. 


\section{CQI-Action Identification Worksheet (CQI-AIW) Summary}

At this point, you have now identified at least one CQI Action to work on for the next several weeks. You may want to share this information with others in the organization who might be influenced by it. For example, will your CQI Action require you to collaborate with others in your organization that you typically don't interact with?

\section{Chapter Summary}

In this chapter, you used the information that you have carefully gathered about your program to identify at least one CQI Action to consider for the "Do-Study-Act" portion of PDSA cycle. The Action was identified while considering the priority and feasibility of making a change in the area(s) you have identified as needing action. Now that you have identified your CQI Action, you can move on to the next chapter where you will further plan how your CQI Action will be successfully launched in your organization.

\section{Checklist}

Once you have finished this chapter, you will have accomplished the following:

Prioritized a list of program challenges to target for CQI

Identified and described at least one CQI-Action. 


\title{
chanest \\ CQI Step 4: Do and Study: Launching and Studying CQI's Effects on Impacts
}

\author{
Excellent firms don't believe in excellence- \\ only in constant improvement and constant change. \\ Tom Peters
}

\begin{tabular}{|l|}
\hline In this chapter: \\
- Launching CQI \\
Worksheet \\
Studying CQI \\
Worksheet \\
Setting Up a CQI \\
Monitoring \\
Process \\
\hline
\end{tabular}

Now that you have gathered important information about your program (see Steps 2 Plan: Gathering Data and 3: Identifying a CQI Action), this chapter will help you carry out a CQI Action.

At the launch of a CQI Action, it is important to have a plan that specifies what specific tasks will be undertaken, who will do them, when they will be done, and whether you are making the changes you had planned as part of your CQI Action. In this chapter, you will find the:

$\begin{array}{ll}- & \text { Launching CQI Worksheet } \\ \text { - } & \text { Studying CQI Worksheet. }\end{array}$

The purpose of the Launching CQI Worksheet (on page 61) is to document your plans for launching and implementing the CQI Action. The second worksheet is designed to help you study the CQI Action that you implement to see whether it had the desired impact. We will next walk you through the steps needed to complete the worksheets to help guide you through this process.

\section{Who Should Be Involved?}

These tools may be used by program directors or other staff engaged in operating a program. We encourage anyone implementing program services and collecting data about the program to help complete the worksheets in this chapter. We encourage you to work with individuals in your organization who will assist or will be affected by the CQI Action so that the plans you make will be influenced by their experiences.

Before filling out the worksheets in this chapter, you need a completed CQI-Action Identification Worksheet (more specifically, you need a CQI Action identified, see CQI Step 3). Like the other worksheets in this guide, the Launching and Studying CQI worksheets are designed to provide a roadmap to generate ideas and document decisions. Not every section of each worksheet may directly apply to your situation. Don't worry how these worksheets look when you finish with them; they are designed for internal use only.

\section{Launching CQI Worksheet-Worksheet 5: Overview}

The Launching CQI worksheet is organized to help you prepare to DO your CQI Action. In CQI Steps 2 and 3, you completed much of the PLAN phase of the PDSA process-that is, you collected and analyzed data and developed a solution in the form of a CQI Action. Now that you have accomplished this, it is time to consider how to effectively launch your chosen CQI Action. A full-size copy of the 
worksheet can be found in the Worksheet Appendix. You may wish to make a copy of the worksheet for reference and note-taking as you read through the following sections.

\section{Contents}

Page 1 of the Launching CQI Worksheet guides you through the process of doing your CQI Action. The worksheet is designed to help you successfully launch your CQI Action by identifying particular tasks needed to complete the CQI Action, documenting the key people and resources needed to complete the tasks, and setting up a timeline to complete work.

\section{Instructions to Complete the Launching CQI Worksheet}

Launching CQI Worksheet, Specify CQI Action: In this section, fill in the CQI Action that you developed as part of "Step 3 CQI Action Identification Worksheet" on the lines provided at the top of the worksheet. This is to help you stay focused on the CQI Action you identified earlier. This worksheet helps you to document the activities required to complete your CQI Action, assign them to staff, and monitor for progress. Successful CQI efforts have detailed action plans with clearly assigned tasks and deadlines.

\section{A. Tasks}

Next, identify the specific tasks or activities that will be needed to accomplish your CQI Action. Think of the different things that will need to happen to accomplish your CQI Action and write them in under "A. Tasks" in the left-hand side of the worksheet. Make sure that the tasks you record here are not too big (e.g., change the organization's mission), too small (e.g., have post-it notes at all CQI meetings), or too vague (e.g., improve communication). Some successful examples from previous projects include implementing an evidenced based curricula, developing a staff training materials, developing a program monitoring tool, and providing staff training in customer service. Think of these activities as the building blocks of getting your overall CQI Action completed. The worksheet is designed to allow up to five activities, but you may identify more or fewer than five tasks related to your CQI Action that will need to be planned. Feel free to revise the sheet accordingly.

\section{B. Responsibilities}

To ensure completion of the proposed tasks associated with your CQI Action, in the column next to each task that you have filled in on the worksheet (column B), write in the name of the lead person and any other staff that will all be involved for that particular task. To the right of that information, there is a space for you to outline the key responsibilities each person will have for accomplishing the specified task.

\section{TIP: THINK AHEAD}

As part of this launching phase, you will need to think ahead to the study phase of the PDSA cycle, too, which we summarize starting on page 62 By thinking now about how you want to measure the impact of your tasks, you can anticipate ways to collect critical information that will help determine whether your CQI Action made a difference. We will discuss this further under "Studying CQI" section.

\section{Tools and Resources}

To the right of the information you have filled in so far, there is a space (column C) for you to specify any tools or resources needed to accomplish each of the tasks you have outlined on your worksheet. 


\section{Timeline}

In the right-hand side of this worksheet (column D), for each task, provide information about when the tasks will start and finish. First, think about whether there are any subcomponents of the actions that may happen earlier and logically follow from one another? A subcomponent of a task is a small piece of the task that together with other subcomponents makes up the entire task. For example, running a meeting may involve many subcomponents, such as developing a meeting agenda, distributing the agenda to meeting participants, reserving a meeting room and/or conference line, making handouts for the meeting, and so on. The worksheet also prompts you to consider whether you will accomplish the tasks in one month, two months, or six months? Perhaps it is an ongoing task that will happen all year long? In the boxes to the right of each task, designate the start and end dates corresponding to the months in which you expect the tasks to start and end. The purpose of this part of the Launching CQI worksheet is to set up some documentation to help with accountability for ensuring the work gets done.

\section{TIP: ENHANCING YOUR SUCCESS}

- Be flexible. It is not unusual to modify your tasks and/or CQI Action over time. In fact, assessing your progress and adjusting your course as necessary is part of a disciplined PDSA process! You should not stick to a particular task or CQI Action if it proves to be too difficult to implement. You might need to consider different ways to get it done or think about alternative $\mathrm{CQI}$ Actions that better fit the resources available to you.

- $\quad$ The more the merrier. We found that some CQI Actions needed to be changed once aired with a larger group within the organization. Also, giving individuals a chance to weigh in on the CQI Action, especially those that may be affected by it, may help gain support and momentum for completing the CQI Action. We also found discussing the CQI Action among a larger group within the organization helped CQI teams complete their Actions by gaining access to additional resources.

\section{Launching CQI Worksheet Summary}

You now have a detailed plan to help you undertake your CQI Action. You may want to keep this in a highly visible location so that you and your staff can be reminded of the tasks and deadlines set up to accomplish your CQI Action. Don't be discouraged if you have to revise your tasks and deadlines to meet the realities of completing your CQI Action. 


\section{WORKSHEET 5: LAUNCHING CQI}

Program Name: $\quad$ Mentoring Program

Date: $4 / 15 / 2015$

The purpose of this worksheet is to document your plans for launching and implementing your CQI Action.

Specify CQI Action: Support mentors/mentees over the summer months to increase the length of the mentoring relationship to $>12$ months

\begin{tabular}{|c|c|c|c|c|}
\hline $\begin{array}{c}\text { A. Define tasks to carry out } \\
\text { your CQI Action }\end{array}$ & $\begin{array}{l}\text { B. Design } \\
\text { staff involve }\end{array}$ & $\begin{array}{l}\text { te the lead for the task, other } \\
\text {, and key task responsibilities. }\end{array}$ & $\begin{array}{l}\text { C. Identify the tools and } \\
\text { resources for the task. }\end{array}$ & $\begin{array}{l}\text { D. Identify } \\
\text { the timeline }\end{array}$ \\
\hline $\begin{array}{l}\text { Task \#2 } \\
\text { Market summer programming to } \\
\text { mentors, mentees and their families }\end{array}$ & $\begin{array}{l}\text { Lead: Rafael } \\
\text { Other Staff: } \\
\text { Felicia }\end{array}$ & $\begin{array}{l}\text { Develop marketing materials } \\
\text { Disseminate marketing materials } \\
\text { Sign-up lists } \\
\text { Phone call reminders }\end{array}$ & $\begin{array}{l}\text { Contact information for } \\
\text { mentors/mentees } \\
\text { Computer/paper to develop } \\
\text { flyers, keep track of } \\
\text { attendees } \\
\text { Time to contact families and } \\
\text { mentors } \\
\text { Mentor Advisory Board }\end{array}$ & $\begin{array}{l}\text { Start date: } \\
5 / 15 \\
\text { End date: } \\
8 / 30\end{array}$ \\
\hline $\begin{array}{l}\text { Task \#3 } \\
\text { Execute programming }\end{array}$ & $\begin{array}{l}\text { Lead: Felicia } \\
\text { Other Staff: } \\
\text { Doug, Marcia, } \\
\text { Rafael }\end{array}$ & $\begin{array}{l}\text { Develop/obtain any event specific } \\
\text { materials } \\
\text { Attend event } \\
\text { Track attendance at event }\end{array}$ & $\begin{array}{l}\text { Funding to purchase event } \\
\text { materials (food, games, } \\
\text { tickets, etc) } \\
\text { Time to attend event } \\
\text { Contact list for attendance }\end{array}$ & $\begin{array}{l}\text { Start date: } \\
6 / 15 \\
\text { End date: } \\
8 / 31\end{array}$ \\
\hline
\end{tabular}




\section{Studying CQI Worksheet-Worksheet 6: Overview}

Next, you want to plan how you will determine whether the tasks of your CQI Action get done and assess whether your CQI Action is working. This is called the STUDY phase of the PDSA cycle. It is important to plan this phase before launching your CQI Action to figure out a way to track the potential impact of your CQI Action before the impact happens. If you don't plan this in advance, you might miss an opportunity to document it!

The Studying CQI Worksheet prompts you to consider two things: (1) how you will assess whether the specific tasks that are part of your CQI Action were accomplished and (2) how you will assess whether your CQI Action made a difference. In other words, the purpose of this worksheet is to develop a monitoring plan to see what difference your CQI Action makes to your program, your organization, or your clients and/or community.

\section{Contents}

The first or upper section of this worksheet is organized by the Tasks you identified in column A of the Launching CQI Worksheet. In this worksheet, you are prompted to describe how you will assess completion of each of these tasks. In the second section of the worksheet, you are asked to consider a broader issue-how you will assess whether your CQI Action made a positive impact on your program or organization.

\section{Instructions to Complete the Studying CQI Worksheet}

\section{Part 1. How will you document the tasks? (e.g., How will you know that the task happened?)}

\section{Tasks}

Start the Studying CQI Worksheet by copying in the tasks you have outlined for your CQI Action in the column on the left-hand side of the worksheet.

Next, you will need to develop a monitoring plan for each of the tasks.

\section{Measure}

Next, to each task, you are asked to fill in a "measure." By "measure," the worksheet is simply prompting you to write in what measure you will use to show you that the task was accomplished. Examples of different types of measures are provided in the sample worksheet below. You may need to consider more than one measure for a particular task. Be creative and resourceful; it is easier to use a "measure" that already exists or would not take additional resources to put into place.

\section{Data Source}

To the right of the "Measure" column, you are prompted to fill in the "data source." This refers to where you will get the measure that is the evidence that you have accomplished your task. The data source may be a person (e.g., Joe the data analyst) or a place (e.g., the staff tab in the database, the attendance sheets located in supervisor's filing cabinet).

\section{Monitoring Schedule}

The final prompt for each task, located on the right-hand side of the worksheet, asks you to describe the "Monitoring Schedule." This refers to how frequently you plan to examine the measure. For most tasks, you may only need to monitor one time or for a short period of time to assess whether it happened or not. 
For example, if you planned to develop a monitoring tool or a training, it may be whether the tool was developed or the training was offered. For some ongoing actions, such as monitoring attendance or consumer satisfaction, you may want to schedule quarterly or semi-annual reviews of the measure.

\section{Part 2. How will you know whether the CQI Action worked? (Did your CQI Action improve anything? How will you know?)}

It is also important to think about the measure(s), data source, and monitoring schedule, not only for each task, but for your overall CQI Action. How will you know whether your overall CQI Action is working? Think about the ways in which you will measure its impact, how you will get that information, and how often you should review it to make sure your program is on track. Fill in the measure, data source, and monitoring schedule related to your CQI Action under the Part 2 section of the worksheet. For example, if you plan a staff training to make your program more customer-focused, this may ultimately serve to increase program participant retention. So your CQI tasks may be to develop and deliver the staff training, with the assessment of whether it made a difference in improvements in program participation and completion. 


\section{WORKSHEET 6: STUDYING CQI WORKSHEET}

Program Name: Mentoring Program

Date: $4 / 15 / 2015$

Specify CQI Action: Support mentors/mentees over the summer months to increase the length of the mentoring relationship to $>12$ months

The purpose of this worksheet is to document how you will study the impact of your CQI Action.

Part 1. How will you study the CQI Action tasks? (e.g., How will you know that the task happened? How will you know the outcome of the tasks?)

\begin{tabular}{|l|l|l|l|}
\hline \multicolumn{1}{|c|}{$\begin{array}{c}\text { Tasks: } \\
\text { Activities that will be needed to } \\
\text { accomplish your CQI Action }\end{array}$} & $\begin{array}{c}\text { Measure: } \\
\text { A measure that would show } \\
\text { you that the task was } \\
\text { accomplished }\end{array}$ & $\begin{array}{c}\text { Data Sources: } \\
\text { Where you will get the } \\
\text { measure that is the } \\
\text { evidence that you have } \\
\text { accomplished your task }\end{array}$ & $\begin{array}{c}\text { Monitoring Schedule: } \\
\text { How frequently you plan to examine the } \\
\text { measure }\end{array}$ \\
\hline $\begin{array}{l}\text { Task \#1 } \\
\text { Develop programming in the } \\
\text { community during summer months } \\
\text { that mentors/mentees can attend }\end{array}$ & $\begin{array}{l}\text { We will have at least one activity to } \\
\text { market for all three summer months }\end{array}$ & $\begin{array}{l}\text { We will have planned at least } \\
\text { three events during the summer } \\
\text { months for participants to attend }\end{array}$ & $\begin{array}{l}\text { We will measure this in May and } \\
\text { throughout the summer months. If we fall } \\
\text { short, will continue to work on } \\
\text { developing events until mid-August. If } \\
\text { successful, we will start the planning } \\
\text { process each Spring }\end{array}$ \\
\hline $\begin{array}{l}\text { Task \#2 } \\
\begin{array}{l}\text { Market summer programming to } \\
\text { mentors, mentees and their families }\end{array}\end{array}$ & $\begin{array}{l}\text { The staff will note the number of } \\
\text { mentors and mentees that have been } \\
\text { invited to event }\end{array}$ & $\begin{array}{l}\text { Program staff will note how } \\
\text { many flyers were distributed, } \\
\text { how many events were } \\
\text { attended, and number of phone } \\
\text { calls }\end{array}$ & $\begin{array}{l}\text { We can monitor this activity on a monthly } \\
\text { basis to see how well we are doing at } \\
\text { marketing the June, July, and August } \\
\text { events }\end{array}$ \\
\hline $\begin{array}{l}\text { Task \#3 } \\
\text { Execute programming }\end{array}$ & Event will occur! & Program staff, attendance list & $\begin{array}{l}\text { After each event, we will assess whether it } \\
\text { was a success or not to help inform what } \\
\text { we will do next year }\end{array}$ \\
\hline
\end{tabular}




\begin{tabular}{|c|c|c|c|}
\hline & $\begin{array}{c}\text { Metric: } \\
\text { A measure that would show } \\
\text { you that the CQI Action helped } \\
\text { improve something }\end{array}$ & $\begin{array}{l}\text { Data Sources: } \\
\text { Where you will get the } \\
\text { measure that is the } \\
\text { evidence that your } \\
\text { CQI Action task was } \\
\text { accomplished }\end{array}$ & $\begin{array}{l}\text { Monitoring Schedule: } \\
\text { How frequently you plan to examine the } \\
\text { measure }\end{array}$ \\
\hline $\begin{array}{l}\text { Give examples here of } \\
\text { how you will study your } \\
\text { CQI Action-what will you } \\
\text { study, how, when }\end{array}$ & $\begin{array}{l}\text { We will measure duration of } \\
\text { mentoring relationships as follows: } \\
\text { Less than } 3 \text { months } \\
3 \text { to just under } 6 \text { months } \\
6 \text { to just under } 12 \text { months } \\
12 \text { months or more }\end{array}$ & $\begin{array}{l}\text { We keep track of the length of } \\
\text { the mentoring relationship-from } \\
\text { the mentor database }\end{array}$ & $\begin{array}{l}\text { On a quarterly basis (Sept, Dec, Mar, } \\
\text { June) }\end{array}$ \\
\hline
\end{tabular}




\section{Studying CQI Worksheet Summary}

You now have a detailed plan to STUDY your CQI Action. You have done all the planning work needed to successfully launch your CQI Action. Keep in mind that the PDSA process suggests that you not only "DO" your CQI Action but simultaneously "STUDY" it at the same time, so keep in mind the monitoring schedule you have outlined in this worksheet as you launch your CQI Action.

\section{Setting Up a CQI Monitoring Process}

Once you have established a plan for gathering data and evidence about your work, as demonstrated by completing the information you are prompted to provide in the Studying CQI Worksheet, it might be helpful to set up a review process that allows the people who will work on the CQI Action (i.e., your CQI "team") to present progress to leadership and possibly other members in your organization engaged in CQI to get feedback.

IHI guidelines suggest that it is useful to set up a regular review process of a CQI Action (Nolan, 2007). The review should focus on making sense of the data you have collected. The review can also focus on problem solving, that is, ways to improve your CQI efforts. For example, if you are being prevented from executing your CQI Action, you may bring this issue to the CQI review and have members help you troubleshoot or brainstorm on possible solutions. Another example may be that you get input at these reviews about making a decision on whether to continue or change course following the execution of your CQI Action (which we will cover in more detail in Step 5). These are the type of activities that would be helpful to discuss at a regularly scheduled CQI review within your organization. Consider monthly, inperson reports to executive leadership and quarterly reviews with a larger team responsible for CQI in the organization. In sum, the purpose of these meetings is to:

- Find out whether your CQI Action is on track or in need of revision

- Make sense of the CQI data and plan next steps

- Provide input to fine tune and revise the action or tasks along the way

- Provide encouragement and recognition to the CQI team.

As part of the reviews, CQI teams may present their progress to date on their action and, if accomplished, evidence that it has been implemented and is improving the program, organization, or community outcomes. Teams may discuss what is working and not working in terms of accomplishing their action.

\section{Chapter Summary}

In this chapter, the Launching and Studying CQI worksheets are presented to help launch and monitor the implementation of a CQI Action. The worksheets provide prompts and allow for documentation of the key tasks and monitoring plans for the specific tasks associated with the CQI Action. You are now ready to execute your CQI Action!

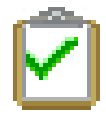

\section{Checklist}

Once you have finished this chapter, you will have accomplished the following:

Outlined specific tasks that will accomplish the program's stated CQI Action

- Designate leads, responsibilities, and timeline for completion of tasks 
Considered how the timeline for the CQI Action interacts with other program activities

$\square$ Outlined a plan to study the CQI Action

- Identified measures and monitoring schedule to determine progress on the CQI Action

Set up a regular process to review the CQI Action's implementation. 


\section{consumer \\ Step 5: Act: Taking Next Steps in CQI}

Follow effective action with quiet reflection. From the quiet reflection will come even more effective action.

Peter Drucker

We are what we repeatedly do. Excellence, then, is not an act, but a habit.

Aristotle

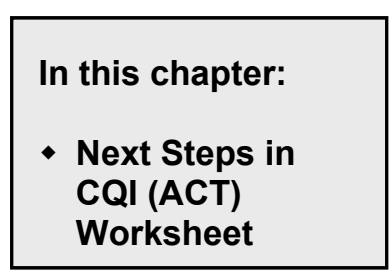

After you have planned, implemented, and studied your CQI Action, it is time to decide what to do next: Do you put into permanent practice, make changes to, or discontinue the new practice(s) undertaken in your CQI Action? This is the ACT part of the PDSA cycle. This chapter and accompanying worksheet is designed to guide you through this decisionmaking process. As part of this phase of CQI, you are asked to take stock of your work thus far and make a decision as to whether the new practices conducted in your CQI Action are ready to be adopted into routine use, need to be modified and/or further studied, or should be discontinued.

The purpose of the Next Steps in CQI Worksheet (on page 72) is to serve as a guide to help you make the decision to adopt, modify, or discontinue your CQI Action. In the next sections, we will walk you through the steps needed to complete the worksheet.

\section{Who Should Be Involved?}

These tools may be used by program directors or other staff engaged in operating a program. This worksheet may be used by those involved in the execution and study of the CQI Action. Before completing the worksheet in this chapter, you will need to have launched a CQI Action (see Chapter 6). As with the other worksheets in this manual, the Next Steps in CQI worksheet is designed to ask questions to stimulate discussion within the CQI team. Not every section of this worksheet may directly apply to your situation. The worksheet is designed for internal use.

\section{The Next Steps in CQI Worksheet-Worksheet 7: Overview}

The Next Steps in CQI Worksheet is organized to help you make decisions following the DOing and STUDYing of your CQI Action. Page 72 shows an illustration of the worksheet, and a full-size copy of the worksheet can be found in the Worksheet Appendix. You may wish to make a copy of the worksheet for reference and note-taking as you read through the following section.

We consider this worksheet a "decision tree" because there are a few different branches that you could follow to help decide whether you should adopt as routine, modify and further study, or discontinue your CQI Action.

NOTE: You may go ahead and launch a new or revised CQI Action based on what you have learned from the Study phase and don't need to systematically work through this chapter. Or you may be thinking of discontinuing your CQI Action. If you are having trouble deciding what to do next after you have studied your CQI Action, then this chapter and the Next Steps Worksheet may be useful to you. 


\section{Contents}

This worksheet guides you through five prompts to determine whether your CQI Action should be adopted, modified, or discontinued. The five prompts allow you to document how you studied the impact of your CQI Action, what you learned from it, what others things may account for your findings, and whether you can tell if your CQI Action made an impact. Considering these questions, you are guided on what you should do next: adopt, modify, or discontinue your CQI Action.

\section{Instructions to Complete the Next Steps in CQI Worksheet}

\section{How did you study the impact of your CQI Action?}

For this first question, you are prompted to consider whether you have adequate information about your CQI Action. Respond by writing how you ended up studying your CQI Action. You may have followed the plan you outlined on the Studying CQI Worksheet or you may have ended up doing something else. Some things to consider are:

- What sort of data did you collect? Did you ask staff or clients about it or did you collect other types of data? For example, perhaps you looked at staff morale or client satisfaction, referral rates to your program, the time it takes for clients to receive an intake, or the number of services delivered? Data could be collected formally (e.g., from surveys, information available in databases) or informally (e.g., a poll at staff meetings). How do these data reflect on your CQI Action?

- How systematically were the data collected? Were you able to survey all staff or clients, or just the ones that happened to show up one day? How did that survey process influence the survey results? In other words, do the survey results represent responses from all the staff and clients you serve or some small proportion? What does that mean for studying the impact of the new practices conducted in your CQI Action?

Your answers to this question should suggest how robust or comprehensive the findings about your CQI Action may be. For example, collecting data from multiple sources may lead to more comprehensive conclusions than data from a single source. Also, collecting data more systematically may lead to more conclusive findings. However, the resources needed to do data collection need to be weighed against the conclusions you can draw from your efforts.

\section{What did you learn from the data, observations, or other feedback?}

Did you find that the CQI Action improved your program or organization in some way? If so, what evidence is there for the improvement? For example, did referral rates improve or client, or staff satisfaction increase, or was there no change?

\section{What accounts for the results? (i.e., Did your CQI Action make a difference or did something else occur that might have had an impact on the program?)}

Consider whether the results you reported are due to the CQI Action or to something else. It may be difficult to determine whether any changes that you observed were due to the CQI Action or to other changes that occurred at the same time. For example, if a funding cut reduced the number of staff while you were studying the CQI Action, you may not know whether the changes observed were due to the change in staffing or the CQI Action. 


\section{EXAMPLE: FIgURING OUT WHAT ACCOUNTED FOR YOUR CQI IMPACT}

Imagine that you studied client satisfaction ratings before and after a staff training to improve customer relations. At the same time, the fees for the program increased, something that you didn't have control over. Perhaps the changes in client satisfaction ratings you see were not the result of the staff training but because of the change in program fees. You may not be able to conclude from the client satisfaction ratings whether the customer relations training has made a difference and instead might need to identify other ways to measure its impact.

As you might have noticed from the example, you will need to be thoughtful as to whether the data you collected about your CQI Action could have been affected by other aspects of your program and/or the larger environment (changes in the staff, organization, community, or clientele).

\section{Were you able to tell whether your CQI Action made a difference?}

Next, the worksheet asks you to consider whether the CQI Action made a difference and whether you are satisfied with the results.

YES. If you feel confident that your study was "conclusive," meaning that your study findings are the result of your CQI Action, then your response here would be "yes" and you may be able to make a decision about whether the new practices conducted in your CQI Action should be continued, modified, or discontinued. Follow the arrow underneath the "Yes" response to:

\section{5a. Given these results, what is your next step? Will you continue, modify, or discontinue your CQI Action?}

Once you feel confident that the results from studying your CQI Action are sound, you are ready to make the decision about its future. There are essentially three options:

1) Continue. If the results of the study of your CQI Action show it is working as hoped, then Continuing it is the right choice. To do this, it will be important to ensure that the new practices conducted in your CQI Action becomes part of the routine operations of the organization. This means you may need to think about:

- Whether there are adequate resources to continue it

- How all relevant staff are made aware of it

$\circ$ How to ensure training is provided.

2) Modify. If the new practices conducted in your CQI Action showed potential but did not go exactly as intended (either it was not totally implemented as planned and/or did not have all the desired impacts), then it may need to be Modified. This means that the CQI team should come together to think about revising the CQI Action, launching it again, and then studying it again to see whether it had the desired impact-this means essentially redoing the D-S-A parts of the PDSA cycle with the newly revised CQI Action (go back to Chapter 5).

3) Discontinue. If the CQI Action was implemented well, but did not have any of the desired impacts, then the right choice may be to Discontinue it and try another CQI Action through a new PDSA cycle. You may want to revisit Chapters 4 and/or 5 to develop a new CQI Action.

NO. If you do not feel confident that you have all the information that you need to determine whether your CQI Action is making a difference, then your response here would be "No" and you should follow the arrow underneath the "No" response to the additional questions on the right-hand side of the worksheet. The next question to consider is: 


\section{5b. Did we ask the right questions/capture the right information?}

If you think you collected the information needed to evaluate your CQI Action, follow the arrow underneath the "YES" response to this question.

You may find that you don't have all the information you need to determine whether your CQI Action is making a difference. If this is the case, then your response to this question would be "NO." As stated on the worksheet, if you answer "NO" to this question, you may want to revisit the measures, data sources, and monitoring plan that you developed earlier (see Chapter 6, Studying CQI Worksheet). Your next step may be to find new ways to assess the impact of your CQI Action.

\section{5c. Were our data accurate and credible?}

If you answered "YES" to the previous question ("Did we ask the right questions/capture the right information?"), you may also want to consider whether the information or data that you collected were accurate or credible. If not, you may want to rethink the measures, data sources, and monitoring plan for your CQI Action or tasks. Is there a better way to get the information you need or a different measure to use that better reflects whether or not the CQI Action is happening and having an impact? It may be useful to go back and revise your measures, data sources or monitoring plan (see Chapter 6, Studying CQI Worksheet).

\section{$5 d$. Is there any other reason for your findings?}

If you answered "YES" to the previous question ("Were your data accurate and credible?") then there may be a different reason why you cannot tell whether your CQI Action made a difference. You may need to consider studying your CQI Action longer or retrying your CQI Action. You may want to consult with others in your organization on what your next steps should be and think about revisiting Chapters 5 and 6. 


\section{WORKSHEET 7: CQI NEXT STEPS WORKSHEET}

Program Name: $\quad$ Mentoring Program

Date: $9 / 30 / 2015$

The purpose of this worksheet is to help you determine whether to adopt, modify, or discontinue your CQI Action.

Specify CQI Action: Support mentors/mentees over the summer months to increase the length of the mentoring relationship to $>12$ months

1) How did you study the impact of your CQI Action? (e.g., did you use surveys, look at databases, gather/make observations?)

We studied the impact by examine the percentage of mentoring relationships that were "active" in September as compared to last September.

2) What did you learn from the data, observations, or other feedback? (e.g., did the CQI Action work as planned/not work as planned, was the CQI Action effective/not effective?)

We learned that more relationships were still active in the Fall when we provided programming over the summer months for participants.

3) What accounts for this? Anything else? (e.g., did your CQI Action make a difference, or did you end up learning something else about your program or organization?)

We can't think of anything else that can account for our finding. The results were not as dramatic as we would have liked because some mentors/families like to take breaks and are hard to reach over the summer months. Even so, having at least two events each month at different times of the day and week helped gain more participation.

4) Were you able to tell whether your CQI Action made a difference? (Check one)

\section{\YES}

5a) Given these results, what is your next step? Will you ... (Check one).

$\triangle$ Adopt CQI Action-It worked! Plan to make CQI Action permanent.

$\square$ Modify CQI Action-It may work, but didn't yet. Go back to "Worksheet 5: Launching CQI" and make the necessary changes to redo the CQI Action.

$\square$ Discontinue CQI Action-It did not work. Go back to the CW and develop a new CQI Action. $\square$ No

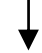

5b) Did you ask the right questions/ capture the right information? $\square$ YES<smiles>[3H]CC[3H]</smiles>

5c) Were your data accurate and credible? $\square \mathrm{NO} \rightarrow$ Revisit metrics, data sources, and monitoring
NO $\rightarrow$ Examine data for reporting errors/rethink data sources
$5 d)$ Is there any other reason for your findings? 


\section{Next Steps in CQI Worksheet Summary}

With completion of this worksheet, you should have come up with a plan to "ACT" on your CQI Action. Will you adopt, modify, or discontinue your CQI Action? Depending on what you decide, you may enter back into the PDSA cycle by identifying a new CQI Action or studying a modified version of your prior Action.

\section{Chapter Summary}

In this chapter a worksheet is presented to help make a decision on how to complete the "ACT" portion of the PDSA cycle. The worksheet helps document CQI implementation and provides prompts to inspire further CQI.

\section{Checklist}

Once you have finished this chapter, you will have accomplished the following:

Systematically considered whether your CQI Action is having its intended impact

- If you are unsure of its impact, determine ways to better study it

Made a decision as to whether to continue, modify, or discontinue your CQI Action.

\section{Conclusions}

This chapter concludes our guide to utilizing the Plan-Do-Study-Act approach to continuous quality improvement. The chapters and other resources in this guide may be referred to in an iterative fashion as a program undertakes continual PDSA cycles over time. Continuous quality improvement has the potential to reduce program inefficiencies and improve program outcomes. We hope this guide will enhance CQI practice in community service organizations. 


\section{Acknowledgments}

Promoting Success: A Getting To Outcomes ${ }^{\circledR}$ Guide to Implementing Continuous Quality Improvement for Community Service Organizations owes much of its development to the Council on Alcoholism and Drug Abuse, a nonprofit, community-based organization dedicated to delivering substance abuse prevention and treatment services in Santa Barbara, California. Specifically, the chief executive officer, Ms. Penny Jenkins, gave her support for the development of this work. She gave the authors access to attend staff meetings and supported her staff to plan and attend two annual daylong CQI workshops. Ms. Lisa Moore, the clinical supervisor of the agency at the time of this project, became a program champion for CQI within the organization. She volunteered to chair the CQI workshop planning committee and provided feedback on the processes and worksheets outlined in this guide. Many other staff members at the council contributed significantly by attending planning meetings and providing helpful feedback on the workshops. Staff demanded that the information meet the needs of community practitioners and inspired the authors to develop materials that would be relevant to this audience. We appreciate the contribution of everyone at the council who was involved with this CQI effort. That project was funded through a grant from the Centers for Disease Control and Prevention awarded to Matthew Chinman (CCR921459-02). The draft manual was then further tested by nine programs operated by Behavioral Health Services, Inc., in Los Angeles, CA between 2012 and 2014. Staff from both residential and outpatient substance use treatment programs participated in one year's worth of training and support for CQI using a previous version of this manual. This work was supported by a grant from the National Institute on Drug Abuse awarded to the first author, Sarah Hunter (R34 DA032041). The worksheets in the manual were also piloted with program managers at Skid Row Housing Trust in Los Angeles, CA, in 2011-2013 and with program staff at LIVESTRONG in Austin, TX, in 2012.

To develop this guide, the authors relied on work from several sources. As cited in the first section, much of the CQI conceptual approach was borrowed from the Institute for Healthcare Improvement (IHI), which has been instrumental in developing CQI tools for use in health care settings (see http://www.ihi.org). This guide also draws on RAND's work in improving practice guideline implementation in the U.S. Army's medical systems (Nicolas et al., 2001). In addition, RAND's collaborative quality improvement project funded through the National Institute on Drug Abuse (R01 DA14969 awarded to Suzanne Wenzel) with Phoenix House, a national substance abuse treatment organization, also helped to inform this work. The authors also relied on the larger evaluation community, including attendees at the American Evaluation Association's national conferences, especially Margaretta Fox and Rashi Rohatgi, who shared their experiences at the 2006 conference, including tools and worksheets, from their CQI effort at the Harlem United Community AIDS Center in New York, NY. We also collaboratively shared early versions of our work with existing Getting To Outcomes efforts being conducted elsewhere (Promoting Science-Based Approaches to Teen Pregnancy Prevention Using Getting To Outcomes: Oklahoma Summary). We consider ourselves fortunate to have a community of scholars and practitioners that support the GTO model and are engaged in CQI efforts within CSOs that helped weigh in on this effort to further the development of GTO.

In producing this guide as a RAND publication, we are also indebted to our reviewers, Mr. Kenneth Segel and Dr. Peter Mendel, who provided valuable comments and suggestions. We also thank Ms. Magdalen Paskell and Ms. Tiffany Hruby for help with formatting this document. 


\section{References}

Baird, Kevin, Kristal Jia Hu, and Robert Reeve, "The relationships between organizational culture, total quality management practices and operational performance," International Journal of Operations \& Production Management, Vol. 31, No. 7, 2011, pp. 789-814.

Bauer, John E., Grace L. Duffy, and Russell T. Westcott, The quality improvement handbook, Second ed., Milwaukee, WI: ASQ Quality Press, 2002.

Center of Substance Abuse Prevention, Centers for the Application of Prevention Technologies Event Feedback Form. OMB Project Number 0930-0197, Washington, D.C.: Substance Abuse and Mental Health Administration, 2007.

Chinman, Matthew, Sarah B. Hunter, and Patricia Ebener, "Employing continuous quality improvement in community-based substance abuse programs," International Journal of Health Care Quality Assurance, Vol. 25, No. 7, 2012, pp. 604-617.

Connor, Marcia L., "Andragogy and Pedagogy. Ageless Learner, 1997-2004," 2004. As of October 22: http://agelesslearner.com/intros/andragogy.html

Cozby, Paul C., Methods in Behavioral Research, 8th ed., New York, NY: McGraw-Hill, 2004.

Deming, W. Edwards, Out of Crisis, Cambridge, MA: MIT Press, 2000.

Deo, Sarang, Keith McInnes, Charles J. Corbett, Bruce E. Landon, Martin F. Shapiro, Ira B. Wilson, and Paul D. Cleary, "Associations between organizational characteristics and quality improvement activities of clinics participating in a quality improvement collaborative," Medical Care, Vol. 47, No. 9, Sep, 2009, pp. 1026-1030.

Fetterman, David M., Shakeh Kaftarian, and Abraham Wandersman, Empowerment Evaluation: Knowledge and tools for self-assessment, evaluation capacity building and accountability, Second ed., Thousand Oaks, CA: Sage, 2015.

Fisher, Deborah, Pamela S. Imm, Matthew Chinman, and Abe Wandersman, Getting To Outcomes with Developmental Assets: Ten Steps to Measuring Success in Youth Programs and Communities, Minneapolis, MN: Search Institute, 2006. As of October 22, 2015: http://www.searchinstitutestore.org/ProductDetails.asp?ProductCode $=0158 \% 2 \mathrm{DW}$

Hannah, Gordon, Sharon McCarthy, and Matthew Chinman, Getting To Outcomes in Services for Homeless Veterans: 10 Steps for Achieving Accountability, Philadelphia, PA: National Center on Homelessness Among Veterans, 2011.

Hunter, Sarah B., Matthew Chinman, Patricia Ebener, Pamela S. Imm, Abraham Wandersman, and Gery W. Ryan, "Technical assistance as a prevention capacity-building tool: a demonstration using the getting to outcomes framework," Health Education and Behavior, Vol. 36, No. 5, Oct, 2009, pp. 810828.

Imm, Pamela S., Matthew Chinman, Abraham Wandersman, David Rosenbloom, Sarah Guckenburg, and Roberta Leis, Preventing Underage Drinking: Using Getting to Outcomes with the SAMHSA Strategic Prevention Framework to Achieve Results. TR-403-SAMHSA, Santa Monica, CA: RAND Corporation, 2007. As of October 22, 2015:

http://www.rand.org/pubs/technical reports/TR403/ 
Institute of Medicine, To Err is Human: Building a Safer Health Care System, Washington, DC.: National Academy Press, 1999.

Crossing the Quality Chasm: A New Health System for the 21st Century, Washington, D.C.: National Academy Press, 2001.

Jain, Manoj, "Road Map for Quality Improvement: A Guide for Doctors," no date. http://www.mjainmd.com/medicine/roadmap for quality improvement.pdf

Johnson, Knowlton, Deborah Fisher, Kellen Diamanti, Abraham Wandersman, David Collins, and Pam White, Sustainability for Prevention Using Getting To Outcomes Toolkit, Nashville, TN: Tennessee Department of Mental Health and Developmental Disabilities, 2009.

Juran, J. M., Juran on Leadership for Quality: An Executive Handbook, New York, NY: The Free Press, 1989.

Kaplan, Heather C., Patrick W. Brady, Michele C. Dritz, David K. Hooper, W. Matthew Linam, Craig M. Froehle, and Peter Margolis, "The influence of context on quality improvement success in health care: a systematic review of the literature," Milbank Quarterly, Vol. 88, No. 4, Dec, 2010, pp. 500-559.

Kenney, Charles, The Best Practice, New York, NY: Public Affairs, 2008.

Lee, Pui-Mun, PohWah Khong, Dhanjoo N Ghista, and Ali Mohammad Mosadegh Rad, "The impact of organizational culture on the successful implementation of total quality management," The TQM Magazine, Vol. 18, No. 6, 2006, pp. 606-625.

Levinson-Johnson, Jody, Jennifer Dewey, and Abraham Wandersman, Getting To Outcomes® in Systems of Care: 10 Steps for Achieving Results-Based Accountability, Atlanta, GA: ICF Macro, 2009.

Mattox, Teryn, Sarah B. Hunter, Rebecca M. Kilburn, and Shelley H. Wiseman, Getting To Outcomes® for Home Visiting: How to Plan, Implement, and Evaluate a Program in Your Community to Support Parents and Their Young Children, Santa Monica, CA: RAND Corporation, TL-114-SNM, 2013. As of August 12, 2015: http://www.rand.org/pubs/tools/TL114

McGlynn, Elizabeth A., Steven M. Asch, John Adams, Joan Keesey, Jennifer Hicks, Alison DeCristofaro, and Eve A. Kerr, "The quality of health care delivered to adults in the United States," New England Journal of Medicine, Vol. 348, No. 26, Jun 26, 2003, pp. 2635-2645.

McKinney, Jerome B., and Lawrence C. Howard, Public Administration: Balancing Power and Accountability, Westport, CT: Greenwood Publishers, 1998.

Nembhard, Ingrid M., Jeffrey A. Alexander, Timothy J. Hoff, and Rangaraj Ramanujam, "Why does the quality of health care continue to lag? Insights from management research," Academy of Management Perspectives, Vol. 23, No. 1, 2009, pp. 24-42.

Nicholas, Will, Donna O. Farley, Mary E. Vaiana, and Shan Cretin, Putting Practice Guidelines to Work in the Department of Defense Medical System: A Guide for Action, Santa Monica, CA: RAND Corporation, MR-1267-A, 2001. As of August 18, 2015: http://www.rand.org/pubs/monograph reports/MR1267

Nicolay, C. R., S. Purkayastha, A. Greenhalgh, J. Benn, S. Chaturvedi, N. Phillips, and A. Darzi, "Systematic review of the application of quality improvement methodologies from the manufacturing industry to surgical healthcare," British Journal of Surgery, Vol. 99, No. 3, 2012, pp. 324-335. 
Nolan, Thomas W., Execution of Strategic Improvement Initiatives to Produce System-Level Results. IHI White Paper., Cambridge, MA: Institute for Healthcare Improvement, 2007. http://www.ihi.org/resources/Pages/IHIWhitePapers/ExecutionofStrategiclmprovementInitiativesWhite Paper.aspx

Osborne, David, and Ted Gaebler, Reinventing Government, Boston, MA: Addison-Wesley Publishing Company, 1992.

Shortell, Stephen M., Charles L. Bennett, and Gayle R. Byck, "Assessing the impact of continuous quality improvement on clinical practice: what it will take to accelerate progress," Milbank Quarterly, Vol. 76, No. 4, 1998, pp. 593-624, 510.

Shortell, Stephen M., James L. O'Brien, James M. Carman, Richard W. Foster, E. F. Hughes, Heidi Boerstler, and Edward J. O'Connor, "Assessing the impact of continuous quality improvement/total quality management: concept versus implementation," Health Services Research, Vol. 30, No. 2, Jun, 1995, pp. 377-401.

Wandersman, Abraham, Pamela S. Imm, Matthew Chinman, and Shakeh Kaftarian, Getting To Outcomes: Methods and tools for planning, self-evaluation, and accountability, Rockville, MD: Center for Substance Abuse Prevention, 1999.

Westphal, James D., Ranjay Gulati, and Stephen M. Shortell, "Customization or conformity? An Institutional and Network perspective on content and consequences of TQM adoption," Administrative Science Quarterly, Vol. 42, No. 2, 1997, pp. 366-394.

Wiseman, Shelley H., Matthew Chinman, Patricia A. Ebener, Sarah Hunter, B., Pamela S. Imm, and Abraham Wandersman, Getting To Outcomes: 10 Steps for Achieving Results-Based Accountability, Santa Monica, CA: RAND Corporation, TR-101/2-CDC, 2007. As of October 22, 2015: http://www.rand.org/pubs/technical reports/TR101z2.html 


\section{List of Appendixes}

A. Getting To Outcomes

B. Worksheets

1. Worksheet 1: Program Delivery Worksheet (DW)

2. Worksheet 2: Outcomes Worksheet (OW)

3. Worksheet 3: Component Worksheet (CW)

4. Worksheet 4: Continuous Quality Improvement-Action Identification Worksheet (CQIAIW)

5. Worksheet 5: Launching CQI Worksheet

6. Worksheet 6: Studying CQI Worksheet

7. Worksheet 7: Next Steps in CQI Worksheet

C. How to Set up a CQI Workshop

1. Steps in Planning a Workshop

2. Example Presentation Materials for Workshop Welcome/Introduction by the Leader

3. Example Presentation Materials for the GTO and CQI Descriptions

4. Example Presentation Materials and Handouts for Group Discussion

5. Example Event Feedback Form

6. Post Workshop CQI Activities 


\section{Appendix A. Getting to Outcomes ${ }^{\circledR}$ (GTO)}

We believe that CQI is best introduced and used within a larger, more comprehensive planning approach to service delivery. We recommend the use of Getting To Outcomes ${ }^{\circledR}$ (GTO), which is a ten-step process to plan, implement, evaluate, and sustain programs and community initiatives. Originally articulated in a 1999 manual designed to help CSOs implement substance abuse prevention programming (Wandersman et al., 1999), GTO was updated in 2004 to broaden its scope and applicability to a wider range of programs and organizations (Johnson et al., 2009). Since that time, the GTO framework has been successfully applied in teen pregnancy prevention, positive youth development (Fisher et al., 2006), underage drinking prevention (Imm et al., 2007), emergency preparedness (Levinson-Johnson, Dewey, \& Wandersman, 2009), homeless veterans services (Hannah, McCarthy \& Chinman, 2011), and home visiting (Mattox, Hunter, Kilburn, \& Wiseman, 2013). Research suggests, "using GTO can lead to increased capacity in prevention programs and better performance" (Wiseman et al., 2007).

Grounded in an empowerment evaluation approach, the various GTO publications are written as selfhelp manuals for community service organizations. Similar to predominant quality improvement models used in industry, GTO seeks to empower community practitioners by providing information and tools for skill building in the areas of planning, implementation, and evaluation. Though GTO's specific steps are written at the level of a program or initiative, the process can be easily adapted for use by an entire organization.

All the GTO versions blend together several different theoretical approaches to program accountability, which refers to the systemic inclusion of critical elements of planning, implementation, and evaluation in order to achieve results. In addition to traditional and empowerment evaluation approaches, GTO borrows from the result-based accountability movement and work by Osborne and Graebler (1992) as well as the Government Performance and Results Act of 1993, which moves practitioners away from simply counting output information, such as the number served, toward answering bottom-line questions about program effectiveness. GTO also borrows from the total quality management movement developed and successfully tested in industrial and health care settings to continuously strive to improve quality, reduce errors and costs, and increase customer satisfaction.

The graphic in Figure A.1 depicts the iterative nature of the original ten-step GTO process. The first six steps emphasize program planning. Steps 1 and 2 focuses on understanding the needs of the program or community as well as the potential resources available to meet those needs, and then establishing program or initiative goals and outcomes to meet the identified needs. Similar to CQI, GTO recommends setting measurable goals that are well known throughout an organization. 


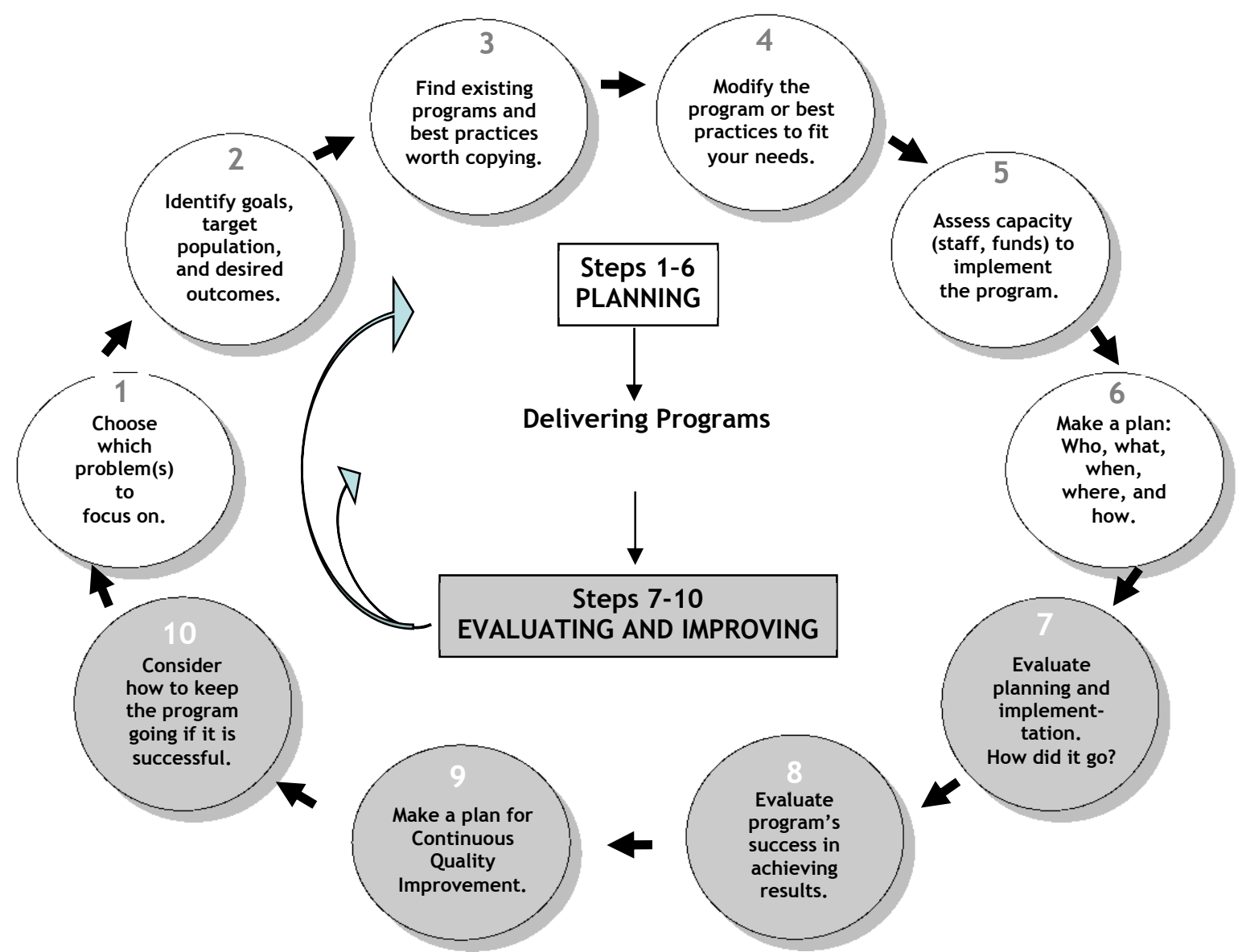

Figure A.1. The 10-step Getting To Outcomes Process

Engaging in quality improvement as "the right thing to do" means providing the most effective services possible for clients, but what is meant by the most effective services possible? The GTO process suggests that social service providers consider the available evidence-base for their practices and adapt such practices to fit local needs. Steps 3 (use of evidence-based or best practices) and 4 (fit) of the GTO model address these points.

Steps 5 and 6 of the GTO process focus on considering the resources needed to conduct quality programming (Step 5), and then actually planning the implementation of a program or initiative (Step 6). These steps help practitioners take into account that, although they may have the best intentions, they must bear in mind the organizational resources realistically needed to successfully implement the goals, outcomes, and potential programs identified in Step 3. Sometimes CSOs face the challenge of implementing a program deemed evidence-based in settings very different from the ones in which the program was originally developed and tested, and with far fewer resources. A review of the capacity (i.e., resources) needed to deliver the program is therefore an important component to consider prior to implementation.

Implementation refers to the actual delivery of program services. Implementing a program occurs between program planning (Step 6) and process (Step 7) and outcome (Step 8) evaluation. In the GTO process, CSOs are encouraged to review Steps 7 and 8 before program implementation so that evaluation activities are developed in alignment with implementation. 
Steps 7 and 8 focus on two types of evaluation. Step 7 describes process evaluation, that is, whether the program or initiative is implemented with quality and fidelity. Step 8 provides information to evaluate the program or initiative's effectiveness or how well it works. While GTO notes that it is important to set up a plan to collect the data necessary to address these steps prior to program implementation, it is only during and after program implementation that some information becomes available to complete Steps 7 and 8.

Steps 9 and 10 refer to activities following evaluation. Step 9 of the GTO process is the continuous quality improvement (CQI) step; guiding users through reflection on the prior eight steps to identify what should stay the same and what should change in the future. Step 10 emphasizes sustainability. If the program or initiative is successful, Step 10 outlines ways to keep them operational.

In our work with CSOs, we found that staff were not always sure about how to use the data from the GTO-related process and outcome evaluations developed in Steps 7 and 8 to help them improve programs and then continuously use the feedback to inform their program planning as recommended by the GTO process. Step 9 of the GTO process specifies reviewing Steps 1-8 in light of findings from the evaluation to improve programming. As stated in the GTO manual, the purpose of Step 9 is to:

- Document program components that worked well to help ensure that future implementation will be successful.

- Assess what program components did not work well to identify areas that need improvement.

- Use evaluation findings to increase interest in investing in evaluation.

While the older GTO manuals treatment of CQI referred to in the above bullets offer a good start to quality improvement, in practice they did not provide enough guidance for CSOs to put their data to work. Therefore, this guide was developed as a supplement to the original GTO manual in order to help CSOs engage in CQI. Upcoming chapters of this document provide additional guidance on how to perform the CQI activities noted above.

\section{Find OUt MORE ABOut GTO:}

The original GTO (2004) manual provides definitions of each of the ten steps of the GTO process' reasons why each step is important and an example of how each step was applied to a real community service organization.

The GTO (2004) manual is available online and can be downloaded without charge from the following website: http://www.rand.org/pubs/technical reports/TR101/

Several other documents related to GTO are also available without charge, including:

- A Spanish version:(http://www.rand.org/pubs/technical reports/TR101.1/)

- A shorter "mini" version: (http://www.rand.org/pubs/technical reports/TR101.2/) 


\section{Appendix B. CQI Worksheets}

Worksheet B.1. Program Delivery Worksheet (DW)

Worksheet B.2. Outcomes Worksheet (OW)

Worksheet B.3. Component Worksheet (CW)

Worksheet B.4. Continuous Quality Improvement-Action Identification Worksheet (CQI-AIW)

Worksheet B.5. Launching CQI Worksheet

Worksheet B.6. Studying CQI Worksheet

Worksheet B.7. Next Steps in CQI Worksheet 


\section{WORKSHEET 1: DELIVERY WORKSHEET (DW)}

Program Name:

Date:

11

The purpose of this worksheet is to help you identify whether you are meeting your program's delivery objectives (e.g., your program's process or plan is "on track"; the program is delivering an adequate number of services to a targeted number of participants). You will need to know your program's delivery objectives and information about the population your program served to complete this worksheet.

\section{PROGRAM NEEDS AND DELIVERY OBJECTIVES}

\section{四}

A. What are the problems your program addresses?

1.

2.

3.

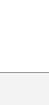

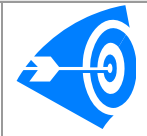

B. What are your program delivery objectives?
1.

2.

3. 


\section{DESCRIBE PROGRAM DELIVERY}

C. What time period are you reporting on?

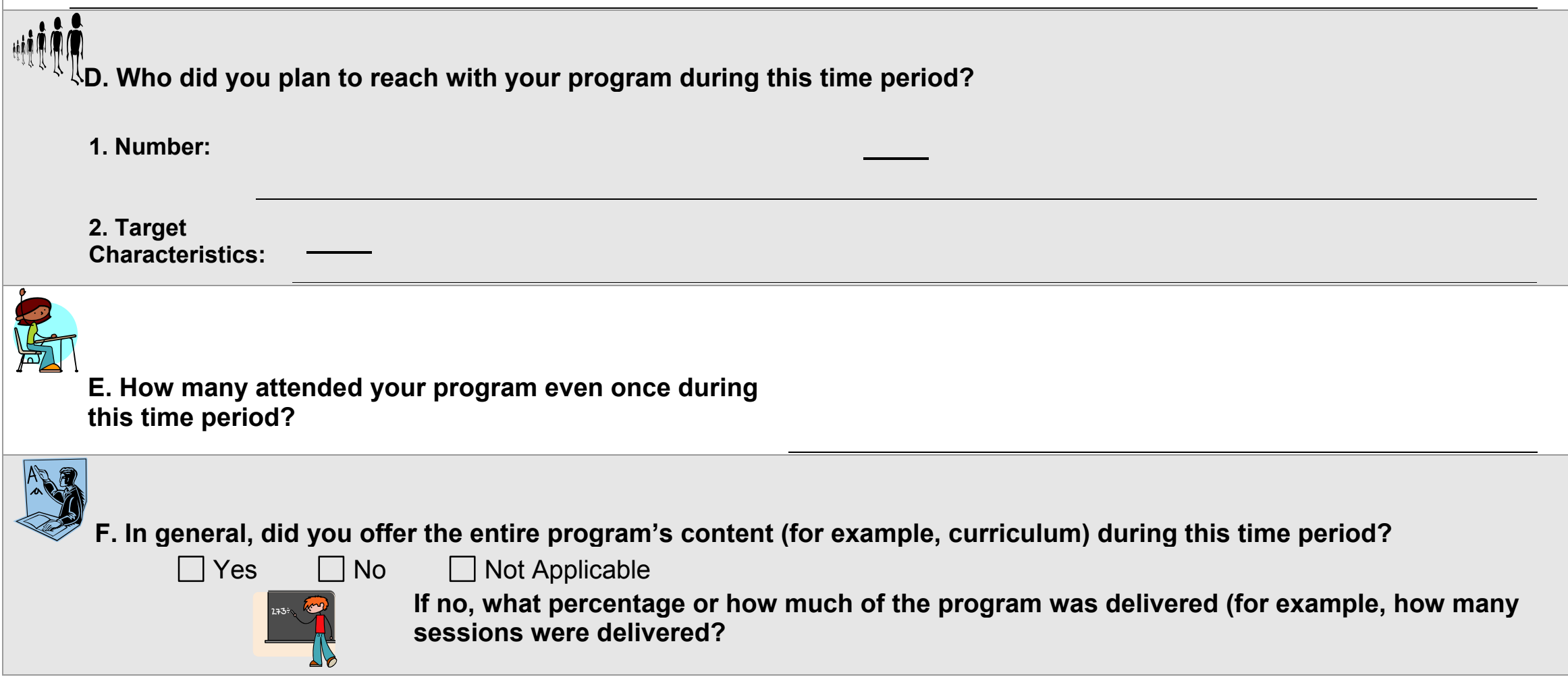




\section{MEETING PROGRAM DELIVERY OBJECTIVES}

\section{G. My Program Delivery Objective \#1: (see page 1)}

\begin{tabular}{|c|c|c|c|c|}
\hline $\begin{array}{l}\quad \text { Measure(s): } \\
\text { What you are measuring to figure } \\
\text { out whether you are meeting the } \\
\text { program delivery objective? }\end{array}$ & $\begin{array}{l}\quad \text { Benchmark(s): } \\
\text { The standard or requirement } \\
\text { your program is expecting to } \\
\text { reach }\end{array}$ & $\begin{array}{c}\text { My Program's \# } \\
\text { Your program's actual \# }\end{array}$ & $\begin{array}{l}\text { Met Objectives? } \\
\text { Is the actual number the same as (met), } \\
\text { less than (missed), or more than } \\
\text { (exceeded) the benchmark number? }\end{array}$ & $\begin{array}{l}\text { Action Needed? } \\
\text { Based on this } \\
\text { information, does } \\
\text { something in the } \\
\text { program need to } \\
\text { change? }\end{array}$ \\
\hline & & & $\begin{array}{l}\square \text { Met } \square \text { Missed } \square \text { Exceeded } \\
\text { What is the trend from prior periods? } \\
\square \text { Better } \square \text { Same } \square \text { Worse }\end{array}$ & $\square$ Yes $\square$ No \\
\hline & & & $\begin{array}{l}\square \text { Met } \square \text { Missed } \square \text { Exceeded } \\
\text { What is the trend from prior periods? } \\
\square \text { Better } \square \text { Same } \square \text { Worse }\end{array}$ & $\square$ Yes $\square$ No \\
\hline \multirow[t]{3}{*}{ Measure(s) } & Benchmark(s) & My Program's \# & Met Objectives? & Action Needed? \\
\hline & & & $\begin{array}{l}\square \text { Met } \square \text { Missed } \square \text { Exceeded } \\
\text { What is the trend from prior periods? } \\
\square \text { Better } \quad \square \text { Same } \square \text { Worse }\end{array}$ & $\square$ Yes $\square$ No \\
\hline & & & $\begin{array}{l}\square \text { Met } \square \text { Missed } \square \text { Exceeded } \\
\text { What is the trend from prior periods? } \\
\square \text { Better } \square \text { Same } \square \text { Worse }\end{array}$ & $\square$ Yes $\square$ No \\
\hline \multirow[t]{3}{*}{ Measure(s) } & Benchmark(s) & My Program's \# & Met Objectives? & Action Needed? \\
\hline & & & $\begin{array}{l}\square \text { Met } \square \text { Missed } \square \text { Exceeded } \\
\text { What is the trend from prior periods? } \\
\square \text { Better } \square \text { Same } \square \text { Worse }\end{array}$ & $\square$ Yes $\square$ No \\
\hline & & & $\begin{array}{l}\square \text { Met } \square \text { Missed } \square \text { Exceeded } \\
\text { What is the trend from prior periods? } \\
\square \text { Better } \square \text { Same } \square \text { Worse }\end{array}$ & $\square$ Yes $\square$ No \\
\hline
\end{tabular}




\section{WORKSHEET 2: OUTCOMES WORKSHEET (OW)}

Program Name:

Date:

I I

The purpose of this worksheet is to help you identify whether your program is having an impact on program participants. For example, does the program improve communication skills? You will need to have pre-post program data to complete this worksheet.

\section{PROGRAM NEEDS AND OBJECTIVES}

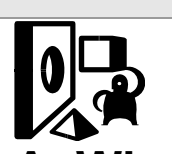

A. What are the problems your program addresses?

1.

2.

3.

3.

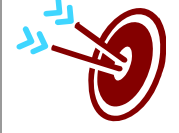

B. What are your program outcome objectives?

1.

2.

3. 


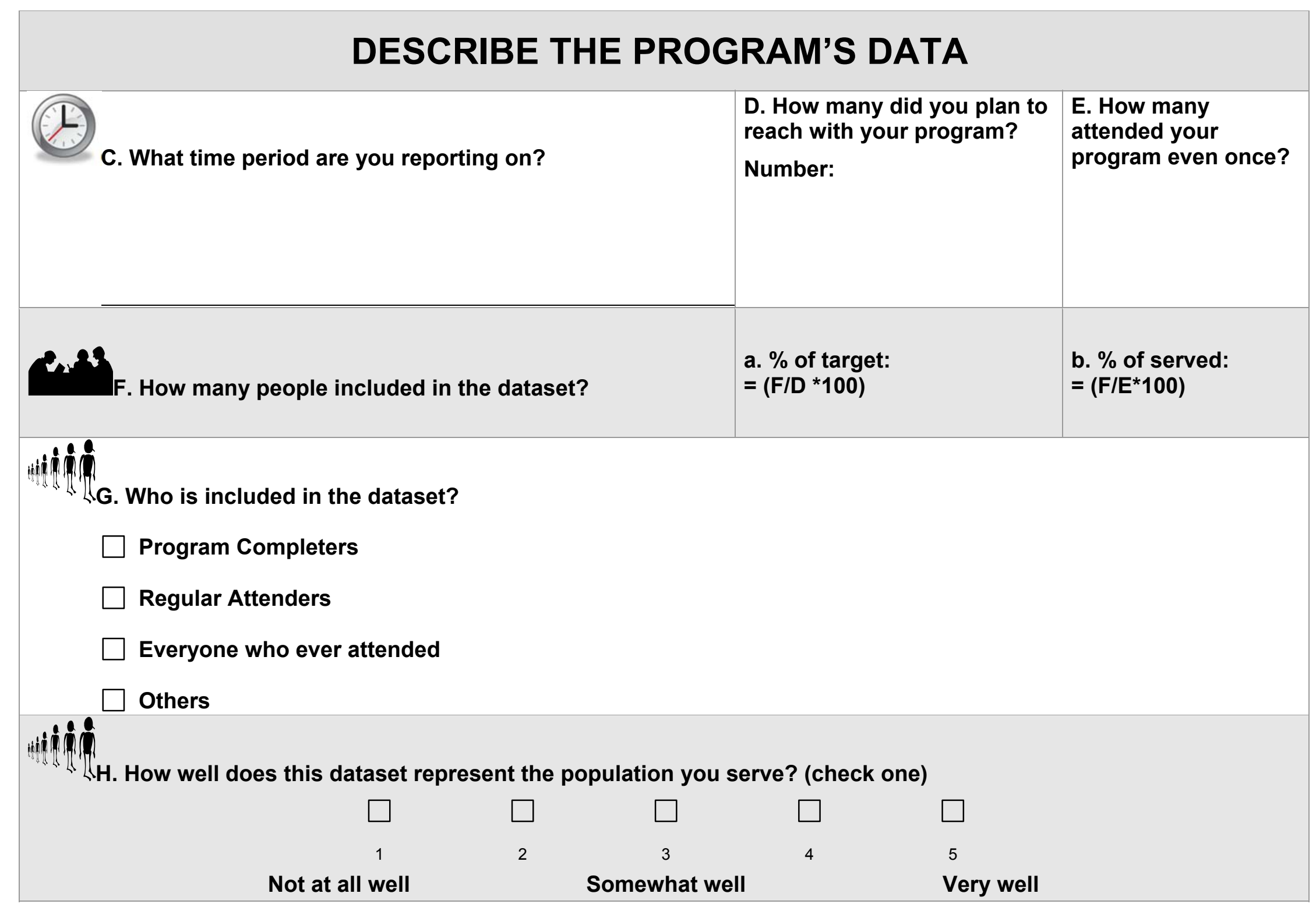




\section{PROGRAM OUTCOMES}

0

I. My Program Outcome Objective \#1: (see page 1)

\begin{tabular}{|c|c|c|c|c|c|}
\hline \multirow[t]{3}{*}{$\begin{array}{l}\text { Measure(s) } \\
\text { What are you measuring to } \\
\text { figure out whether you are } \\
\text { meeting the program } \\
\text { outcome objectives? }\end{array}$} & $\begin{array}{c}\text { Pre } \\
\text { The value before } \\
\text { the program }\end{array}$ & $\begin{array}{l}\text { Post } \\
\text { The value after the } \\
\text { program }\end{array}$ & $\begin{array}{l}\text { Difference/Change } \\
\text { The difference between the } \\
\text { pre and post value }\end{array}$ & $\begin{array}{l}\text { Met Objective? } \\
\text { Is the difference/change the same as } \\
\text { (met), less than (missed), or more than } \\
\text { (exceeded) the objective? }\end{array}$ & $\begin{array}{l}\text { Action Needed? } \\
\text { Based on this information, does } \\
\text { something in the program need } \\
\text { to change? }\end{array}$ \\
\hline & & & & $\begin{array}{l}\square \text { Met } \square \text { Missed } \square \text { Exceeded } \\
\text { What is the trend from prior periods? } \\
\square \text { Better } \square \text { Same } \square \text { Worse }\end{array}$ & $\square$ Yes $\square$ No \\
\hline & & & & $\begin{array}{l}\square \text { Met } \square \text { Missed } \square \text { Exceeded } \\
\text { What is the trend from prior periods? } \\
\square \text { Better } \square \text { Same } \square \text { Worse }\end{array}$ & $\square$ Yes $\square$ No \\
\hline \multirow[t]{3}{*}{ Measure(s) } & Pre & Post & Difference/Change & Met Objective? & Action Needed? \\
\hline & & & & $\begin{array}{l}\square \text { Met } \square \text { Missed } \square \text { Exceeded } \\
\text { What is the trend from prior periods? } \\
\square \text { Better } \square \text { Same } \square \text { Worse }\end{array}$ & $\square$ Yes $\square$ No \\
\hline & & & & $\begin{array}{l}\square \text { Met } \square \text { Missed } \square \text { Exceeded } \\
\text { What is the trend from prior periods? } \\
\square \text { Better } \square \text { Same } \square \text { Worse }\end{array}$ & $\square$ Yes $\square$ No \\
\hline \multirow[t]{3}{*}{ Measure(s) } & Pre & Post & Difference/Change & Met Objective? & Action Needed? \\
\hline & & & & $\begin{array}{l}\square \text { Met } \square \text { Missed } \square \text { Exceeded } \\
\text { What is the trend from prior periods? } \\
\square \text { Better } \square \text { Same } \square \text { Worse }\end{array}$ & $\square$ Yes $\square$ No \\
\hline & & & & $\begin{array}{l}\square \text { Met } \square \text { Missed } \square \text { Exceeded } \\
\text { What is the trend from prior periods? } \\
\square \text { Better } \square \text { Same } \square \text { Worse }\end{array}$ & $\square$ Yes $\square$ No \\
\hline
\end{tabular}




\section{WORKSHEET 3: COMPONENT WORKSHEET (CW)}

Program Name:

Date

1

The purpose of this worksheet is to document strengths and weaknesses of the different program phases (i.e., referrals, intake, service delivery and outcomes).

A. Referrals

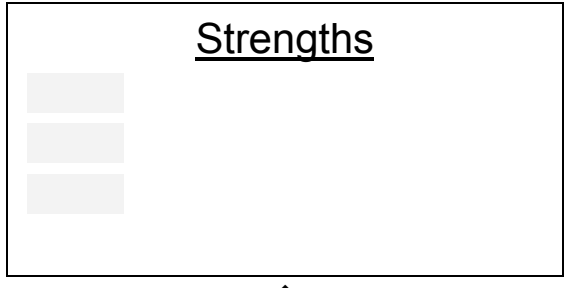

A. Referrals

- Marketing materials/efforts used?

- Funding fit?

- Reaching intended population?

- Program perceived valuable?

- Process user- friendly?

- Personal relationships?

- Coordination with related programs?

- Other?
B. Intake to Program Strengths

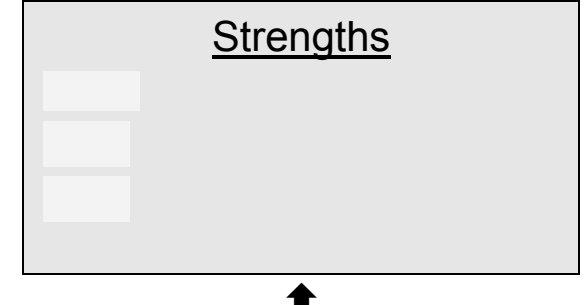

\section{B. Intake to Program}

- Schedule meets clients' needs?

- Adequate numbers/waiting list?

- Resources?

- Follow up with referral/client?

- Assessment process?

- Coordination/cross referral?

- Evaluation of intake process?

- Other?
7

Weaknesses
Weaknesses
C. Service Delivery

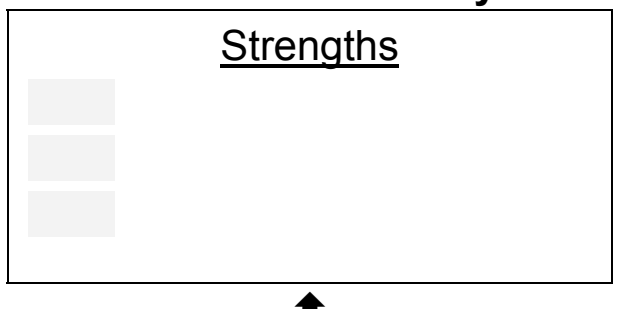

\section{Service Delivery}

- Evidence-based?

- Quality and consistency?

- Attendance/completion/retention?

- Adequate/quality materials?

- Client satisfaction /experience?

- Serving intended population?

- Resources (staff training, curriculum)?

- Follow-up?

- Other?
D. Outcomes

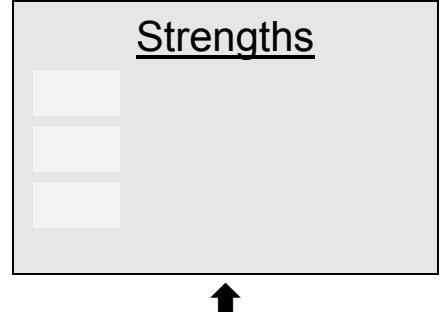

\section{Outcomes}

- Objectives $\mathrm{met} / \mathrm{missed} / \mathrm{exceeded}$ ?

- Grant objectives realistic?

- Evaluation challenges?

- Resources?

- Other?

$\underline{\text { Weaknesses }}$

Weaknesses

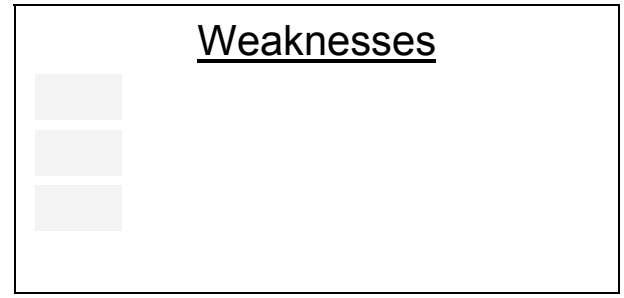


WORKSHEET 4: CQI ACTION IDENTIFICATION WORKSHEET (CQI-AIW)

\section{Program Name:}

Date:

11

The purpose of this worksheet is to help you assess your program, prioritize it and identify what to focus on for CQI.

\begin{tabular}{|c|c|c|c|c|}
\hline 1. Program Issues & 2. My Program's Performance & 3. Known challenges & $\begin{array}{l}\text { 4. Setting } \\
\text { Priorities }\end{array}$ & 5. Level Rationale \\
\hline & $\begin{array}{l}\text { Compared to prior, what's the trend? } \\
\square \text { Better } \square \text { Same } \square \text { Worse } \\
\text { Compared to national standards or program } \\
\text { benchmarks: } \\
\square \text { Better } \square \text { Same } \square \text { Worse } \\
\text { My program objectives were: } \\
\square \text { Met } \quad \square \text { Missed } \square \text { Exceeded }\end{array}$ & & $\begin{array}{c}\text { Is this a priority area? } \\
\square \text { High } \\
\square \text { Medium } \\
\square \text { Low }\end{array}$ & \\
\hline & $\begin{array}{l}\text { Compared to prior, what's the trend? } \\
\square \text { Better } \square \text { Same } \square \text { Worse } \\
\text { Compared to national standards or program } \\
\text { benchmarks: } \\
\square \text { Better } \square \text { Same } \square \text { Worse } \\
\text { My program objectives were: } \\
\square \text { Met } \quad \square \text { Missed } \square \text { Exceeded }\end{array}$ & & $\begin{array}{c}\text { Is this a priority area? } \\
\square \text { High } \\
\square \text { Medium } \\
\square \text { Low }\end{array}$ & \\
\hline & $\begin{array}{l}\text { Compared to prior, what's the trend? } \\
\square \text { Better } \square \text { Same } \square \text { Worse } \\
\text { Compared to national standards or program } \\
\text { benchmarks: } \\
\square \text { Better } \square \text { Same } \square \text { Worse } \\
\text { My program objectives were: } \\
\square \text { Met } \quad \square \text { Missed } \square \text { Exceeded }\end{array}$ & & $\begin{array}{c}\text { Is this a priority area? } \\
\square \text { High } \\
\square \text { Medium } \\
\square \text { Low }\end{array}$ & \\
\hline
\end{tabular}


5a. DESCRIBE YOUR CQI ACTION (SELECT ONE HIGH RANKING PRIORITY AREA FOR CQI AND DEVELOP THE ACTION.

l.e., What is the Action? How will it be undertaken? Who will be responsible and what is the timeline for doing it? ):

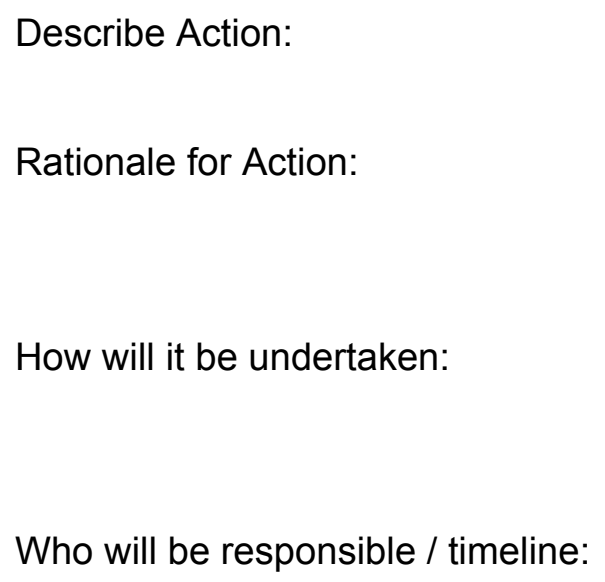


WORKSHEET 5: LAUNCHING CQI

Program Name:

Date: 1

The purpose of this worksheet is to document your plans for launching and implementing your CQI Action.

Specify CQI Action:

\begin{tabular}{|l|l|l|l|l|}
\hline $\begin{array}{c}\text { A. Define tasks to } \\
\text { carry out your CQI } \\
\text { Action }\end{array}$ & \multicolumn{2}{|c|}{$\begin{array}{c}\text { B. Designate the lead for the task, other staff } \\
\text { involved, and key task responsibilities. }\end{array}$} & $\begin{array}{l}\text { C. Identify the tools and } \\
\text { resources for the task. }\end{array}$ & $\begin{array}{c}\text { D. Identify the } \\
\text { timeline for task }\end{array}$ \\
\hline \hline Task \#1 & Lead: & Responsibilities: & & Start date: \\
\hline Task \#2 & Other Staff: & & & Start date: \\
& Other Staff: & & & End date: \\
\hline Task \#3 & Lead: & & & Start date: \\
& & & & \\
\end{tabular}




\section{WORKSHEET 6: STUDYING CQI WORKSHEET}

Program Name:

Date:

The purpose of this worksheet is to document how you will study the impact of your CQI Action.

Specify CQI Action:

Part 1. How will you study the CQI Action tasks? (e.g., How will you know that the task happened? How will you know the outcome of the tasks?)

\begin{tabular}{|l|c|c|c|}
\hline $\begin{array}{c}\text { Tasks: } \\
\text { Activities that will be needed to } \\
\text { accomplish your CQI Action }\end{array}$ & $\begin{array}{c}\text { Measure: } \\
\text { A measure that would show } \\
\text { you that the task was } \\
\text { accomplished }\end{array}$ & $\begin{array}{c}\text { Data Sources: } \\
\text { Where you will get the } \\
\text { measure that is the } \\
\text { evidence that you have } \\
\text { accomplished your task }\end{array}$ & $\begin{array}{c}\text { Monitoring Schedule: } \\
\text { How frequently you plan to examine the } \\
\text { measure }\end{array}$ \\
\hline Task \#1 & & & \\
\hline Task \#2 & & & \\
& & & \\
\hline Task \#3 & & & \\
& & & \\
& & & \\
& & & \\
& & & \\
& & & \\
\end{tabular}




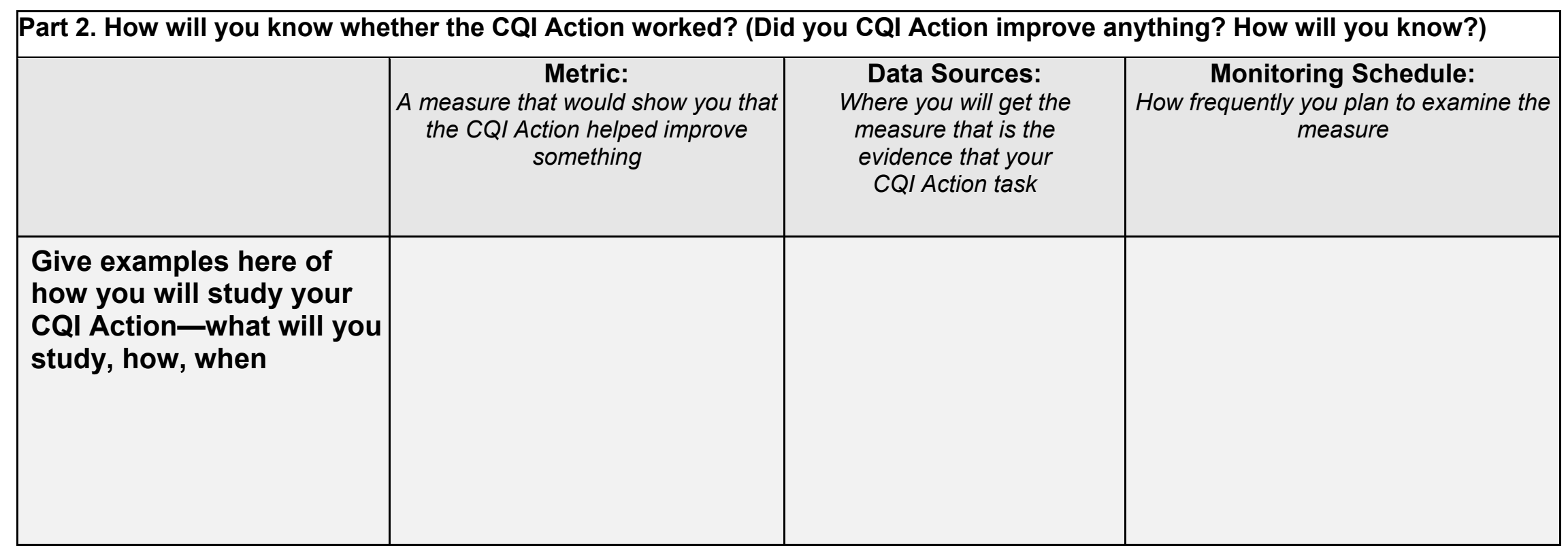




\section{WORKSHEET 7: CQI NEXT STEPS WORKSHEET}

Program Name:

Date:

$1 /$

The purpose of this worksheet is to help you determine whether to adopt, modify, or discontinue your CQI Action.

Specify CQI Action:

1) How did you study the impact of your CQI Action? (e.g., did you use surveys, look at databases, gather/make observations?)

2) What did you learn from the data, observations, or other feedback? (e.g., Did the CQI Action work as planned/not work as planned? Was the CQI Action effective/not effective?)

3) What accounts for this? Anything else? (e.g., Did your CQI Action make a difference or did you end up learning something else about your program or organization?)

4) Were you able to tell whether your CQI Action made a difference? (Check one)

$\square$ YES

5a) Given these results, what is your next step? Will you ...

$\square$ NO

(Check one).

$\square$ Adopt CQI Action—It worked! Plan to make CQI Action permanent.

Modify CQI Action-It may work, but didn't yet. Go back to

"Worksheet 5: Launching CQI" and make the necessary changes

to redo the CQI Action.

$\square$ Discontinue CQI Action-It did not work. Go back to the CW and develop a new CQI Action.

5b) Did you ask the right questions/ capture the right information?

$\square$ YES

$\downarrow$

5c) Was your data accurate and credible?

$\square$ YES

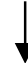

$5 d)$ Is there any other reason for your findings?

$\square$ NO $\rightarrow$ Revisit metrics, data sources, and monitoring

NO $\rightarrow$ Examine data for reporting errors/rethink data sources 


\title{
Appendix C. How to Set Up a CQI Workshop
}

\begin{abstract}
A CQI workshop can be an effective vehicle for launching CQI within an organization. A CQI Workshop is an event where members of the organization gather to develop and implement a CQI Action. In our experience, the workshops can be held on an annual or semi-annual basis. At the CQI Workshop, participants receive training and practice CQI. The workshop launches an effort with team-building and support from and accountability to the organization's management. The success depends on significant planning effort by champions of CQI and representatives of programs or departments expected to participate. In preparation for a CQI Workshop, we recommend setting up a CQI planning committee. In the following sections, we describe the planning committee's roles and responsibilities and the CQI Workshop format. In this section, we will outline some recommendations on how to undertake such efforts in your organization to undertake CQI and give examples from our experience in planning such events.
\end{abstract}

\section{Appendix C.1. Steps in Planning a Workshop}

a) Establish a CQI planning committee. This committee should consist of adequate representation across the organization so that planning of CQI workshop takes into account the diverse perspectives and needs of the participants.

b) Schedule regular planning meetings to develop the workshop agenda, invitation, workshop activities, and materials.

c) Elect a chairperson for the planning committee who is responsible for:

- $\quad$ finding a venue for the meetings

- scheduling the meetings at a time that accommodates the planning committee's schedules

- developing meeting agendas and sending them to committee in advance to meeting

- taking/circulating minutes from the meetings.

The chairperson may be able to delegate some of these tasks, but should have ultimate responsibility for them. It is helpful to establish a chairperson prior to or at the first meeting.

d) Develop and support Workshop preparation by participants: Because the focus of the workshop will be on developing a CQI Action and the steps associated with launching and studying it, it is important that staff have already systematically assessed the strengths and weaknesses of their program and are ready to prioritize and develop a CQI Action. We do not recommend developing a CQI Action without completing the planning worksheets (DW (Delivery Worksheet), OW (Outcomes Worksheet), and $\mathrm{CW}$ (Components Worksheet). Since the DW, OW, and $\mathrm{CW}$ may require culling information from several places over time to complete, it is useful to ask staff to complete these at least a few weeks in advance to the workshop. We recommend providing opportunities to discuss the planning worksheets (DW, OW, and $\mathrm{CW}$ ) with the potential participants so that they feel supported and there is a chance to address concerns and questions about how to fill them in advance to the workshop. In preparation for the workshop, the planning committee should collect completed DW, OW, and CW from each program that plans to participate in the CQI Workshop. To facilitate their use in the workshop, the planning committee should arrange to have copies of the completed worksheets for staff to review at the workshop.

e) Prepare a CQI Workshop promotion campaign. In order to inform potential participants in the CQI workshop, the planning committee can develop and send invitations. 


\section{EXAMPLE: SETTING UP A CQI WORKSHOP}

Establish a CQI planning committee: We invited the managers of all the programs that would be invited to participate in the CQI Workshop and other staff that expressed interest in being involved. The key to size is adequate representation without excessive difficulty in scheduling meetings to get everyone's participation on a regular basis.

Schedule meetings: In our previous work, we found it helpful to have 4-6 of these meetings prior to the workshop, starting at least three months in advance to the actual workshop date. This allowed adequate time to make iterations on the agenda, invitation, workshop activities, and materials. By scheduling the meetings at regular intervals (e.g., first and third Friday of the month at $10 \mathrm{am}$ ), members are more likely to attend. Email reminders with an agenda for the meeting were sent out in advance of each meeting to help promote attendance.

Agendas: Here is an example of a planning committee meeting agenda:

- Review action items from last meeting.

- Review of the agenda for the Quality Improvement Annual Workshop.

- Review of the data collection tools in preparation for the Workshop (the CW, DW, and OW).

- Plan for Workshop announcement at next weekly staff meeting.

Develop and support Workshop preparation by participants: Participating program staff were required to submit completed planning worksheets (i.e., the DW, OW, and CW) a week in advance to the CQI Workshop. Program-specific binders were made that had a copy of each of the completed worksheets. At the CQI Workshop, program staff were given a programspecific binder that included the workshop materials (i.e., PowerPoint slides of the presentations, completed copies of the DW, OW, and CW, and blank copies of the worksheets to be completed at the workshop (CQI-Action Worksheet, Launching CQI and Studying CQI). 
Here is a sample invitation. The CQI planning committee should work with its organization's leadership to identify programs/units/departments within the organization that will be asked to participate in the workshop. In our previous work, we invited 2-3 staff from up to 10 programs to participate in the workshop

Appendix Figure C.1. Sample Invitation to CQI workshop

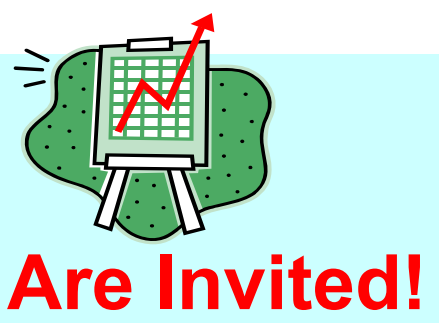

\section{Join your colleagues for the [insert organization name here]'s first annual GTO Quality Improvement Workshop}

$\checkmark$ Harness the power of program data to maximize results!

$\checkmark$ Explore your ideas for change!

$\checkmark$ Develop Actions to improve program performance!

$\checkmark$ Make a bigger difference to your population!

When? Xxxx (XAM-XPM) $\quad$ Where? XXX

RSVP to XXX at XXX@XXX.xxx

Free parking and continental breakfast and lunch included! 
f) Prepare a CQI Workshop Agenda. A CQI Workshop agenda is a schedule that outlines the activities at the workshop. Things to consider including in the workshop are:

1) Give a workshop welcome/introduction by the CSO leader. In this introduction, the CSO leader should emphasize the importance of CQI to the organization. For example presentation materials, see pages 100-106.

2) Provide GTO and CQI descriptions. It would be helpful to define for all participants the GTO planning tool and what CQI is to help orient participants to the framework of the Workshop. Materials to assist with this can be found on pages 107-126.

3) Inform participants CQl's role in the organization. At the workshop, it is helpful for the CSO leader and CSO champion to clarify how CQI will be incorporated into staff meetings or other venues to maintain its presence within the organization.

4) Allow participants to reflect and engage. Borrowing from effective strategies to engage adult learners (Conner, 2004), incorporate an activity that has participants reflect on the value on incorporating CQI within their organization. Materials to stimulate a discussion about quality improvement are provided on pages 127-130 (handout, presenter notes, FAQ page).

\section{EXAMPLE: RUNNING THE CQI WORKSHOP}

In our work, we formed three breakout groups, composed of members from different programs or departments so that staff had a chance to interact with others in the organization that they may not typically work with. Next, we passed out a list of questions for the members of the groups to think about in terms of how CQI could be used in their organization. We had members of the planning committee and external consultants on each of the three breakout groups so that the groups would have a person to call upon if they didn't understand the question or needed additional follow-up. Here are examples of the questions that groups were given to discuss:

1) Why do you think it's important to do quality improvement?

2) How do you think CQI can help you?

3) What is it going to take to do CQI?

4) How do you think CQI can be integrated into your work? (Can it be integrated? Why/why not? What are the barriers?)

5) How do you know whether you are doing CQI well?

6) How will you assess its benefit?

7) What are the possible benefits to CQI for our programs?

8) What are the possible costs of CQI for our programs?

5) Review of completed DW, OW, and CW by participants to help identify strengths and weaknesses of the program under study. Note that the workshop should be devoted to completing the CQI-Action Worksheet and Launching and Studying CQI worksheets. Participants will not have time to complete these worksheets in addition to the DW, OW, and $\mathrm{CW}$ in one day. We highly recommend that participants complete the DW, OW, and CW worksheets in advance to the workshop.

6) Give instructions on how to complete the Worksheets. Staff should be given an overview of what the worksheet is designed to do. Tackle one worksheet at a time, starting with the CQI Action Identification Worksheet, followed by the Launching CQI Worksheet and the Studying CQI Worksheet. It is best to try to complete these worksheets in 
the workshop so that the CQI Action can be launched soon following the workshop and the necessary plans and resources have been considered before doing so.

7) Allot time for staff to complete the Worksheets. We recommend giving participants 45 minutes to complete each worksheet. This should be done under supervision, and if people get distracted or "stuck," efforts should be made to intervene and move on. In the first breakout session, we had members of the planning committee and external consultants circulate among the programs to answer questions and help interpret the worksheets. Some participants may need only 20-30 minutes, so the workshop schedule should be flexible for allow for changes based on participant needs.

8) Allot time to report out on the results from the Worksheet. Efforts should be made to share the results from each worksheet with other members of the organization, including the CSO leader, to get feedback on any issues that arose when completing it and whether the plans that have been developed on the worksheet are feasible. Reporting out on the CQI plans that have been laid out on the worksheets may form the first step of accountability to doing CQI in the organization.

9) Schedule follow-up meetings to discuss progress on the CQI Actions that are developed in the workshop. It is helpful to institutionalize formal check-ins on the status of the CQI Actions among participants to further enhance accountability for following through on the CQI Actions. A schedule to follow-up with programs could be developed and announced here so that participants have a sense of the expectations leaving the workshop on what will be happening in the upcoming months. Participants should leave feeling like they have set out with a plan to be implemented. That means that the workshop should be perceived as the beginning of CQI.

10) Evaluate the workshop. As with any event that may be recurring, it is helpful to get feedback from participants about what they liked and disliked, what could have been done better, etc., to assist planners of the next workshop (see Appendix C-5). 


\section{Example Workshop Agenda}

To further illustrate these points, we have included a sample agenda from a CSO's first annual CQI Workshop. It outlines the time allotted for each activity in the Workshop. The "Moderator" column has recommendations for the speaker/moderator for each activity.

\begin{tabular}{|c|c|c|}
\hline Time & Activity & Moderator \\
\hline $8: 30$ & Continental Breakfast & \\
\hline 9:00 & Introductions \& Overview of the Day & CEO/Leader of Organization \\
\hline 9:05 & Welcome and Charge to the Group & $\begin{array}{l}\text { CQI Champion/Workshop Planning Committee } \\
\text { Chair }\end{array}$ \\
\hline $9: 15$ & 10 Steps to Getting to Outcomes & $\begin{array}{l}\text { CQI Champion/Workshop Planning Committee } \\
\text { Chair OR Member External Consultant }\end{array}$ \\
\hline $9: 25$ & Introduction to CQI & $\begin{array}{l}\text { CQI Champion/Workshop Planning Committee } \\
\text { Chair OR Member OR External Consultant }\end{array}$ \\
\hline $9: 35$ & $\begin{array}{l}\text { How does CQI apply to us? } \\
\text { Breakout groups: Discuss Value of CQI }\end{array}$ & $\begin{array}{l}\text { CQI Champion/Workshop Planning Committee } \\
\text { Chair or Member }\end{array}$ \\
\hline $9: 50$ & Break & \\
\hline $10: 00$ & $\begin{array}{l}\text { Summary Reports (from Breakout Groups)(5-10 } \\
\text { minutes each) \& Discussion }\end{array}$ & $\begin{array}{l}\text { CQI Champion/Workshop Planning Committee } \\
\text { Chair or Member }\end{array}$ \\
\hline $10: 15$ & $\begin{array}{l}\text { Individual Program Breakout groups: Data and } \\
\text { Component Review and CQI-Action Worksheet }\end{array}$ & $\begin{array}{l}\text { CQI Champion/Workshop Planning Committee } \\
\text { Chair OR Member OR External Consultant }\end{array}$ \\
\hline $11: 30$ & Break and Lunch & \\
\hline $12: 30$ & $\begin{array}{l}\text { Individual Program Break-out Groups: } \\
\text { Launching CQI Worksheet }\end{array}$ & $\begin{array}{l}\text { CQI Champion/Workshop Planning Committee } \\
\text { Chair OR Member OR External Consultant }\end{array}$ \\
\hline $1: 15$ & BREAK & \\
\hline $1: 30$ & $\begin{array}{l}\text { Individual Program Break-out Groups: } \\
\text { Studying CQI Worksheet }\end{array}$ & $\begin{array}{l}\text { CQI Champion/Workshop Planning Committee } \\
\text { Chair OR Member OR External Consultant }\end{array}$ \\
\hline $2: 15$ & Group Reports & $\begin{array}{l}\text { CQI Champion/Workshop Planning Committee } \\
\text { Chair OR Member OR External Consultant }\end{array}$ \\
\hline 3:00 & Next Steps \& Feedback & $\begin{array}{l}\text { CEO/Leader of Organization OR CQI } \\
\text { Champion/Workshop Planning Committee } \\
\text { Chair OR Member OR External Consultant }\end{array}$ \\
\hline
\end{tabular}




\section{Appendix C.2. Example Presentation Materials for Workshop Welcome/ Introduction by the CSO Leader}




\section{[Insert your organization name/logo here]}

\section{BUILDING ON SUCCESS}

\section{GTO Continuous Quality Improvement Workshop}

[Insert date here] 


\section{This organization is achieving its goals}

- [Insert one or two positive goal-achieving event/award/press that your organization has recently received] 


\section{But, we cannot afford to stand still}

- [Insert public health problem that your organization addresses here]

- [Insert examples from your community here]

- Demand for our programs is strong

- Funding is more competitive than ever

- only effective programs will survive adopt Continuous Quality Improvement (CQI) strategies as part of our mission. 


\section{What can others teach us about quality improvement?}

- Education in Japan, Finland, and Canada integrate CQI practices, e.g.

- "jugyokenkyu" is a group of practices that Japanese teachers use to hone their skills, including observing each other, discussing lesson afterward, and studying curriculum with colleagues

- Use of systematic approaches with an emphasis on preparation and need for constant feedback is common in these educational systems 


\section{What can others teach us about quality improvement?}

- A focus on incremental gains has led to large advances in sports, chess, and musical performance

- Innate ability matters, but now paired with science and technology to produce exceptional performance

- Half the shots taken in 50-60s games would now be booed by today's fans

- The number of "elite" chess players and classical music players at record high 


\section{Today, we focus on improving our performance}

- At the height of our success, we are critically examining what we are doing

- Using the tools of GTO, we are going to put into place a Continuous Quality Improvement (CQI) system. CQI will:

- Be ongoing

- Build on our past data collection efforts

- Result in better programs, thus better outcomes

- Be part of your job! 


\section{Appendix C.3. Example Presentation Materials for the GTO and CQI Descriptions}

Here are samples of two presentations that can be given to introduce participants to CQI and GTO

1. Introduction to CQI (modified) slides

2. Preparing for QI using GTO (modified) slides 


\section{Introduction to Continuous Quality Improvement (CQI)}

[Insert your organization name here]

First Annual

GTO CQI Workshop

[Insert date here] 


\section{A Brief History of CQI}

- From assembly lines to assembly rooms

- It's not about changing the world; but assumes that improvement is possible

- Other assumptions:

- It's ongoing

- Everyone has a role-it's part of our job

- The organization is behind it 


\section{Why Should We Do CQI?}

-We all recognize room for improvement

- Competition is growing for funding and only the most effective will survive

- Our clients deserve the best 


\section{What Is Involved in Doing CQI?}

- Brief 4 step cycles that

- examine what we're doing

- plan needed changes

- carry out changes

- check what differences it makes

- incorporate changes into routine or start over 


\section{Let's Look at a Cycle in More Detail}

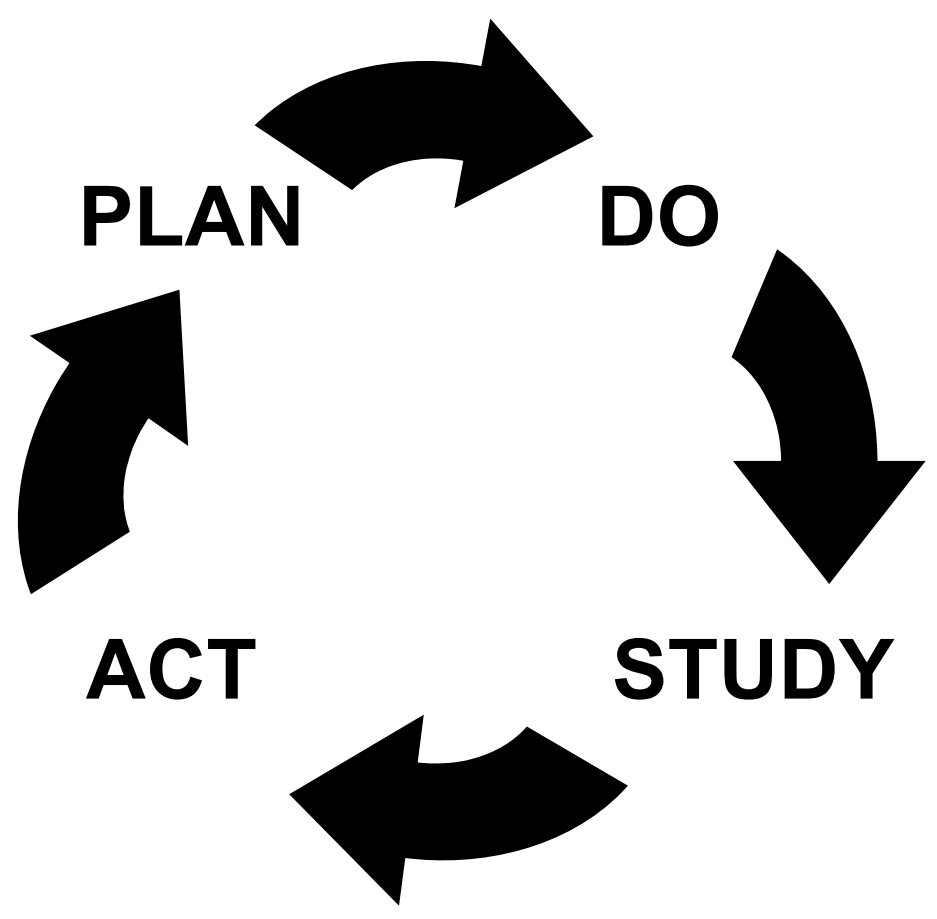




\section{Plan}

- Analysis of program strengths and weaknesses and outcomes data

- Determine a target and objective

- Decide who, what, where, when, and how

- Revisit and finalize plan 


\section{Do}

- Carry out your plan

- Document problems and unexpected observations

- Collect your measures of progress/impact 


\section{Study}

- Analyze your data and your experience

- Compare results with your plans, predictions

- Summarize what you've learned 


\section{Act}

- Will you routinize the new practice, change it, or give it up?

- Move on to next cycle of planning, doing, checking, acting 


\section{Lessons Others Have Learned}

- Improvements can be significant even from small actions

- Be realistic

- There is no perfect program

- Don't expect to be "finished," do expect to follow through

- CQI requires good management, training, teamwork, measurement of performance, time, and faith

- Routinize new practices quickly and move on 


\section{Preparing for Quality Improvement using GTO}

Putting Information to Work in [Insert your organization name here] 


\section{Overview of the Presentation}

- Your organization is striving to be "data driven".... what is the next step?

- The quality improvement implementation process

- A brief history

- Developing an implementation strategy and CQI Action

- Evaluating this experience 


\section{GTO's 10 steps: A refresher}

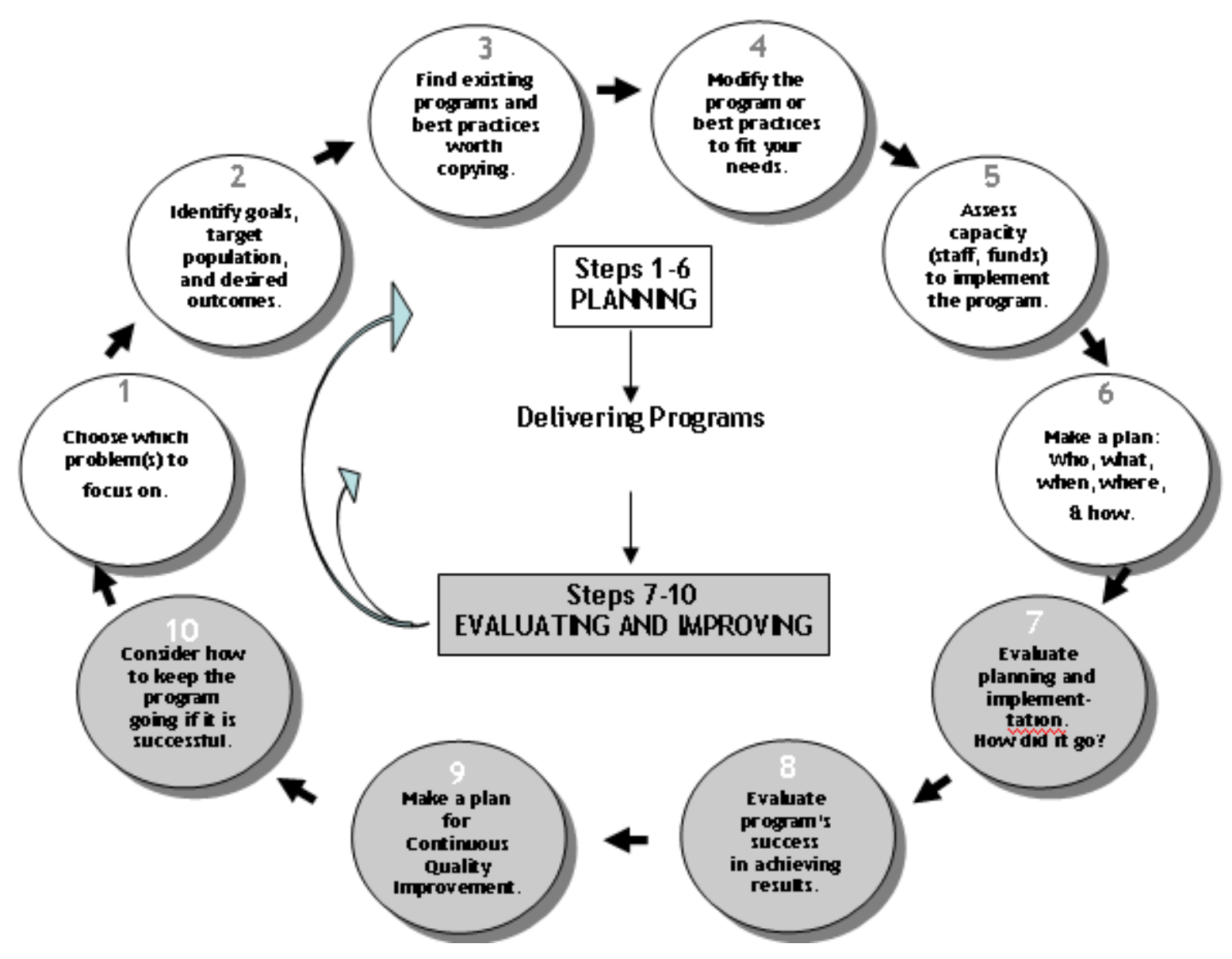




\section{Developing Your CQI Action}

Steps to establish actions:

- Understand and agree on linkages between the areas of the Components Worksheet and program elements

- Assess current practices using goals established by funded grants; norms for the field

- Set priorities for actions to change practices

- Develop a focused, realistic CQI Action 


\section{Executing and Adapting the CQI Action}

- Do: Begin to introduce planned changes

- Studly: Do small-scale tests of new practices or procedures

- Act: Apply test results to make larger changes 


\section{Developing an Implementation Strategy and CQI Action}




\section{Support Materials to Help You}

- Your program's Worksheets

- Written step-by-step planning process with worksheets for preparing an action plan

- PowerPoint slide formats to brief your CQI Action

- Example of a strategy and action plan for improving program elements

- Discussion sessions for teams to interact 


\section{Four-Step Process for CQI Action Development}

- Analyze data and assess performance of program elements

- Identify barriers to successful implementation

- Develop an overall quality improvement strategy and specific actions

- Establish measures and a process to monitor progress 


\section{Getting Started}

- Develop consensus on CQI Action by program leadership and others

- Involve staff in the implementation process

- Confirm measures to monitor progress

- Finalize CQI Action and submit to CQI Planning Committee

- Begin carrying out the CQI tasks and collecting data for monitoring 


\section{Appendix C.4. Example Presentation Materials and Handouts for Group Discussion}




\section{Quality Improvement Journey}

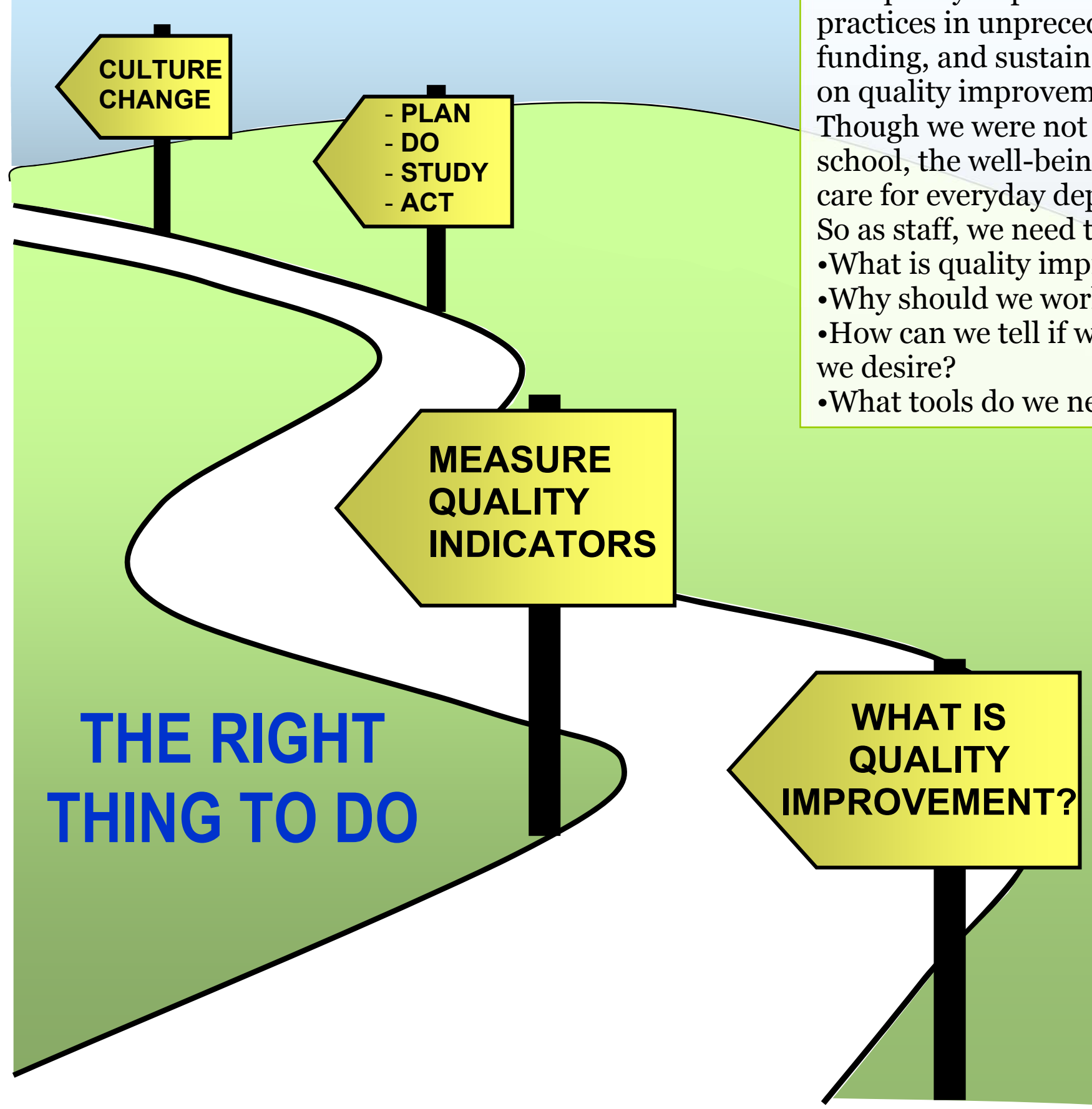

The quality improvement movement is affecting our practices in unprecedented ways. Our reputation, funding, and sustainability are beginning to depend on quality improvement.

Though we were not taught quality improvement in school, the well-being and the lives of the youth we care for everyday depends on it.

So as staff, we need to explore:

-What is quality improvement?

-Why should we work for quality improvement?

-How can we tell if we've achieved the improvements we desire?

What tools do we need to improve our services?
Adapted from Jain, M. Road Map for Quality Improvement: A Guide for Doctors. Retrieved from: http://www.mjain.net/medicine/ roadmap_for_quality_improvement.pdf 


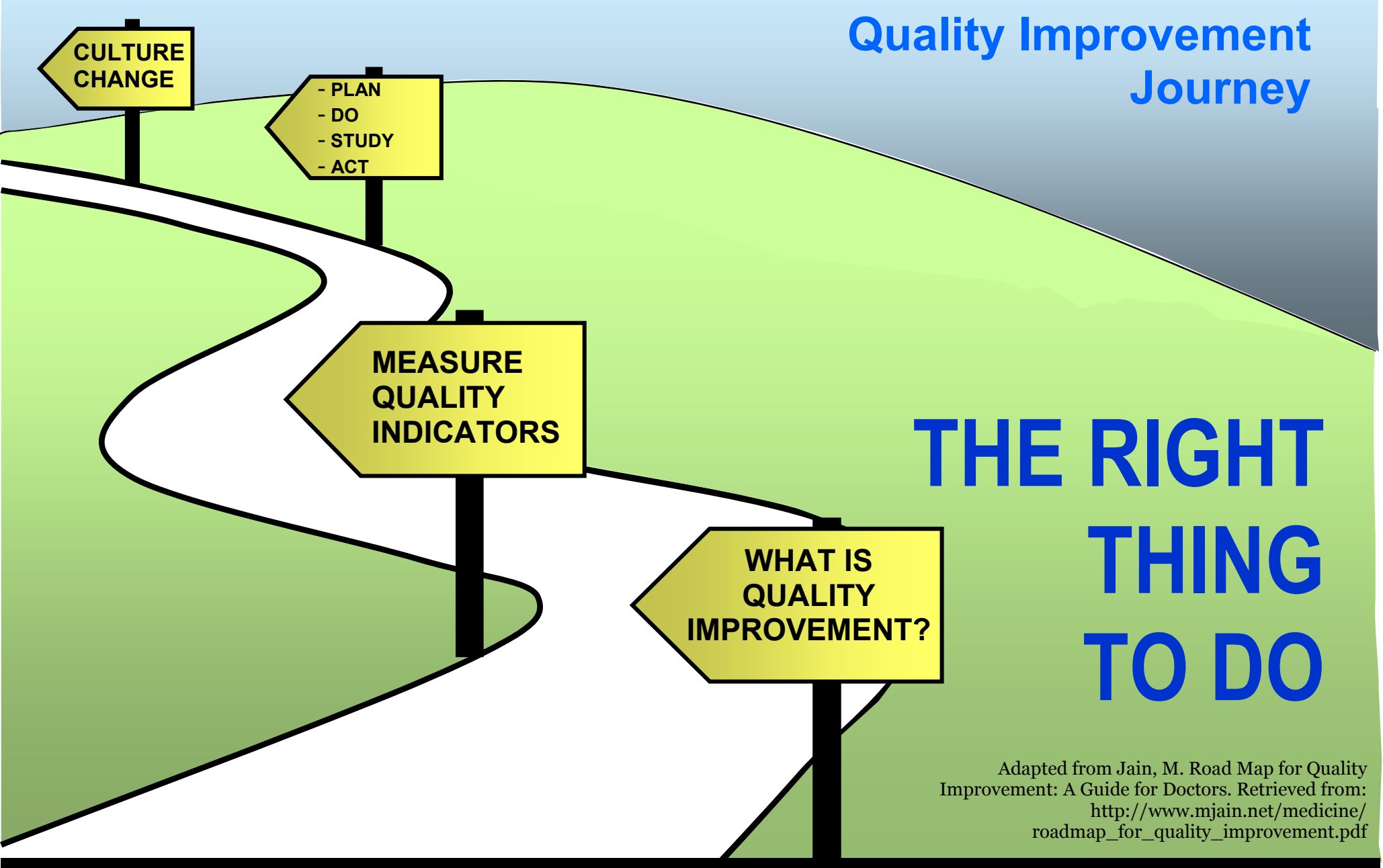

The quality improvement movement is affecting our practices in unprecedented ways. Our reputation, funding, and sustainability are beginning to depend on quality improvement. Though we were not taught quality improvement in school, the well-being and the lives of the youth we care for everyday depends on it. So as staff, we need to explore:

-What is quality improvement?

$>$ Quality is providing the right service for every client or student, every time.

$>$ Quality Improvement is the body of knowledge, attitudes, and skills needed to continuously improve a program.

-Why should we work for quality improvement?

$>$ Improving the quality of programs is the right thing to do.

$>$ Our reputation, credentialing, and funding depends on quality.

$>$ Our kids deserve it.

-How can we tell if we've achieved the improvements we desire?

We must measure quality to improve it. Should measure:

$>$ Process indicators-about the program (e.g. fidelity of curriculum, number of sessions), and

$>$ Outcome indicators-addresses changes in the participants (e.g. drug use).

-What tools do we need to improve our services?

Often many cycles are needed to improve programs.

$>$ Plan is setting aims, selecting the change to make, and establishing measures (e.g. who, what, where, when how).

$>\underline{\text { Do }}$ is implementing the changes.

$>$ Study is evaluating the change to see if it had impacts.

$>$ Act is to adopt, reject, or modify the change.

- How is this a culture change?

$>$ It routinizes quality improvement in the work we do. 


\title{
Appendix C.5. Example Event Feedback Form
}

Next we present a sample event feedback form that can be used to collect information about participants' reactions to the CQI Workshop. This form was adapted from one used by the Centers for the Application of Prevention Technologies Project (Center of Substance Abuse Prevention, 2007).

\section{GTO CQI Event Feedback Form-(INSERT DATE) Workshop}

The purpose of this form is to obtain your feedback on this event. The form is completely anonymous.

Please do NOT put your name anywhere on this form.

It is important to obtain information from all participants to maintain quality of service; however, your participation is voluntary.

1. Please rate your satisfaction with each of the following aspects of the workshop. (check one box on each line)

\begin{tabular}{|c|c|c|c|c|}
\hline & $\begin{array}{c}\text { Very } \\
\text { Dissatisfied }\end{array}$ & $\begin{array}{l}\text { Somewhat } \\
\text { Dissatisfied }\end{array}$ & $\begin{array}{c}\text { Somewhat } \\
\text { Satisfied }\end{array}$ & $\begin{array}{c}\text { Very } \\
\text { Satisfied }\end{array}$ \\
\hline Quality of the information you received & 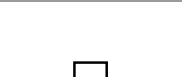 & 7 & 7 & 7 \\
\hline
\end{tabular}

\section{Relevance of the information to your work Comments:}

\section{Organization of the workshop}

Comments:

\section{Sensitivity of the presenters to the participants Comments:}

\section{Opportunity for questions/discussion}

\author{
Comments:
}

\section{Handouts or materials \\ Comments:}

\section{Time allocated to tasks}

Comments:

\section{What were the most helpful features of the workshop?}

\section{What were the least helpful features of the workshop?}


4. In what ways could this workshop be improved? (check all that apply)

$\begin{array}{llll}\square \text { More time to prepare } & \square \text { More discussion among } & \square \text { More discussion within my } & \square \text { More information about GTO } \\ \text { programs } & & \\ \text { More information about } & \square \text { More help with analyzing my } & \square \text { More help with action } & \square \text { Other, please specify } \\ \text { quality improvement } & \text { program's data } & \text { planning }\end{array}$

5. Did you have the opportunity to develop any new ideas about your program at this workshop? (check one)

$\square$ No New Information/Ideas $\square$ A Little New Information/Ideas $\square$ Some New Information/Ideas $\square$ A Lot of New Information/Ideas

6. How likely are you to use the plans that you developed at this workshop? (check one)

$\square$ Not at All Likely $\square$ Not Very Likely $\square$ Somewhat Likely $\square$ Very Likely

7. Overall, how satisfied are you with the workshop? (check one)

$\square$ Very Dissatisfied $\quad \square$ Somewhat Dissatisfied $\quad \square$ Somewhat Satisfied $\quad \square$ Very Satisfied

8. Would you like to participate in a workshop like this again? (check one)

$\square$ Yes $\quad \square$ No $\quad \square$ Not Sure

9. This workshop focused on Quality Improvement. Is there any other GTO step that you would like additional training on? (check all that apply)

$\begin{array}{lll}\square \text { Needs/Resources (1) } & \square \text { Goals (2) } & \square \text { Best Practice (3) } \\ \square \text { Fit (4) } & \square \text { Capacities (5) } & \square \text { Plan (6) } \\ \square \text { Process Evaluation (7) } & \square \text { Outcomes Evaluation (8) } & \square \text { Sustain (10) }\end{array}$

10. Please write in any additional comments or suggestions that you may have that would help prepare for this workshop next year.

11. Did you attend a prior CQI Workshop in [insert date here]?

$\square$ Yes $\quad \square$ No 


\title{
Appendix C.6. Post-Workshop CQI Activities
}

\author{
Planning Committee \\ After the CQI Workshop, the role of the CQI planning committee does not stop! At the end of the CQI \\ Workshop, it will be helpful to collect the completed worksheets and make copies to share with staff \\ following the workshop. The planning committee and/or CQI champion may want to maintain a copy of \\ the completed forms to assist in feedback sessions and follow-up after the workshop with individual \\ programs. The CEO may also want to keep copies to ascertain program performance related to CQI. In \\ addition, the planning committee might want to plan a meeting in a few weeks to share the results from \\ the event feedback form and plan a strategy to communicate to the CEO on its impact.
}

\section{Regular Updates}

It is recommended that the programs be prompted on a monthly basis following the workshop on CQI Action status, e.g., has the CQI Action been launched? How is it doing? What changes have occurred as the result of the CQI Action? What challenges have been encountered by undertaking the CQI Action? The CQI champion and/or the planning committee's role may be to help individual programs troubleshoot following the Workshop. The CEO should also be informed on a monthly or quarterly basis on CQI progress within the organization. For example, programs may report on whether they were able to successfully launch their CQI Action and/or whether it's been modified. Within the next 3-6 months, we recommend that programs be introduced to the Next Steps in CQI Worksheet to help document the results from the Study phase of their CQI Action and assist them with determining what to do next ("Act"). Again, similar to the other worksheets, making it organizational policy to complete the worksheet will help assist in accountability to implementing CQI.

\section{Future events}

Given that many organizations experience turnover and CQI Actions will evolve over time and eventually be either adopted, modified, or rejected, it is important to think about how your organization will continue $\mathrm{CQI}$, either through semi-annual or annual events such as this workshop to help programs develop and launch a CQI Action. In turn, in 3-6 months, it's important for the programs to come to some closure on their CQI Action, through completion of the Next Steps in CQI Worksheet or some other communication on the CQl's Action to the leadership so that new CQI efforts can be considered. 